\title{
Changes in body mass index and short-term healthcare expenditures in a Medicare population
}

\author{
Tricia Lee Wilkins \\ West Virginia University
}

Follow this and additional works at: https://researchrepository.wvu.edu/etd

\section{Recommended Citation}

Wilkins, Tricia Lee, "Changes in body mass index and short-term healthcare expenditures in a Medicare population" (2010). Graduate Theses, Dissertations, and Problem Reports. 3004.

https://researchrepository.wvu.edu/etd/3004

This Thesis is protected by copyright and/or related rights. It has been brought to you by the The Research Repository @ WVU with permission from the rights-holder(s). You are free to use this Thesis in any way that is permitted by the copyright and related rights legislation that applies to your use. For other uses you must obtain permission from the rights-holder(s) directly, unless additional rights are indicated by a Creative Commons license in the record and/ or on the work itself. This Thesis has been accepted for inclusion in WVU Graduate Theses, Dissertations, and Problem Reports collection by an authorized administrator of The Research Repository @ WVU. For more information, please contact researchrepository@mail.wvu.edu. 
Changes in Body Mass Index and Short-term Healthcare Expenditures in a Medicare Population

Tricia Lee Wilkins, Pharm. D.

\author{
Thesis submitted to the \\ School of Pharmacy \\ at West Virginia University \\ in partial fulfillment of the requirements \\ for the degree of
}

\author{
Master of Science \\ in \\ Pharmaceutical Sciences
}

\author{
Usha Sambamoorthi, Ph.D., Chair \\ Joel Halverson, Ph.D. \\ Michael Hendryx, Ph.D. \\ Department of Pharmaceutical Systems and Policy \\ Morgantown, West Virginia \\ 2010
}

Keywords: Obesity, Changing Body Mass Index, Expenditures, Medicare Beneficiaries

Copyright 2010 Tricia Lee Wilkins 


\section{ABSTRACT \\ Changes in Body Mass Index and Short-term Healthcare Expenditures \\ in a Medicare Population}

Tricia Lee Wilkins, Pharm. D.

\section{PURPOSE}

The main objective of the study was to estimate the short-term changes in healthcare expenditures that result from weight gain or loss in a population of Medicare patients using longitudinal data. Changes in total healthcare expenditures and its components (inpatient, outpatient, prescription, dental and other) by changes in body mass index (BMI) categories were analyzed.

\section{METHODS}

Design: The study design was longitudinal and retrospective.

Data: The Medicare Current Beneficiary Survey, a nationally representative survey of Medicare beneficiaries for the years 2000 through 2005 was used. Four panels of Medicare beneficiaries were followed for three years each.

Sample: Analytical sample included individuals: a) who were community dwelling, b) age 65 and older; c) with full-year enrollment in Medicare parts A and B; and d) with no missing BMI values for the years BMI changes were measured. After exclusions, the analytical sample consisted of 10,698 Medicare beneficiaries, with a similar distribution across panels: 2000-02 $(n=2,757) ; 2001-03(n=2,745) ; 2002-04(n=2,562)$; and 2003-05 $(n=2,634)$.

Measures - Changes in BMI categories: Changes in BMI were measured between Year 1 and Year 2 and individuals were classified into 6 categories: 1) Stayed normal (BMI 18.5-24.9 $\mathrm{kg} / \mathrm{m}^{2}$ ); 2) BMI loss (decrease in BMI in individuals with baseline BMI greater than or equal to $25 \mathrm{~kg} / \mathrm{m}^{2}$, where the resulting BMI belongs to a category lower than that of baseline); 3) Stayed overweight (BMI between 25 and $29.9 \mathrm{~kg} / \mathrm{m}^{2}$ in baseline and follow-up years); 4) Stayed obese (BMI greater than or equal to $30 \mathrm{~kg} / \mathrm{m}^{2}$ in baseline and follow-up years); 5) BMI gain (increase in BMI category in individuals with baseline BMI $>18.5 \mathrm{~kg} / \mathrm{m}^{2}$, where the resulting BMI belongs to a category higher than that of baseline) and 6) Stayed Underweight/Other (BMI < $18.5 \mathrm{~kg} / \mathrm{m}^{2}$ in baseline and follow-up years/weight changes not defined by previous categories). The group "BMI loss" included individuals who moved to a lower category of BMI between Year 1 and Year 2. For example, an individual moving from obese to overweight or from obese to normal BMI would have experienced BMI loss. Similarly, "BMI gain” included individuals who moved to a higher BMI category. For example, an individual moving from normal weight to overweight or overweight to obese would be classified as having BMI gain. 
To examine the relationship between BMI changes and expenditures, three specifications of expenditures were used. The primary measure of expenditures was relative changes in expenditures transformed into log-ratio. Under the log-ratio approach positive values indicate increased expenditures, and negative values indicate decreased expenditures. Other measures included logged expenditures (Year 3) derived after BMI changes were measured and relative changes in healthcare expenditures (i.e. percent change in expenditures) grouped into 1) no change; 2 ) greater than $10 \%$ decline; 3 ) greater than $10 \%$ increase and 4 ) minimal variations.

Bivariate: The Chi-square tests of independence were used to determine significance between BMI change categories and subject characteristics. F-tests were used to test significant differences in average expenditures and BMI changes.

Mutivariate: Multinomial Logistic Regression was used to analyze the relationships between BMI change categories and independent variables. Ordinary Least Squares (OLS) regressions were used to model logged expenditures and log-ratio of expenditures by changes in BMI, while controlling for other independent variables (age, gender, race/ethnicity, marital status, education, poverty level, metro status, supplemental insurance, general health, functional limitations, smoking and physical and mental illness). Multinomial logistic regressions were used to analyze the relationship between relative changes in healthcare expenditures by groups and BMI changes, after controlling for other independent variables measured in the study.

\section{RESULTS}

Only a small fraction of the elderly experienced weight loss as measured by changes in BMI: Of 10,698 individuals, 9\% experienced BMI loss ( $\mathrm{N}=982)$ and 8.2\% experienced BMI gain $(\mathrm{N}=867)$. Subgroup differences in $\mathrm{BMI}$ changes were noted: females were less likely than males to experience BMI loss or BMI gain [AOR 0.81, 95\% CI 0.68-0.97; AOR 0.73 95\% CI $\mathbf{0 . 6 0 - 0 . 9 0 ]}$. Increased age ( $80+$ years) decreased the likelihood of BMI loss or BMI gain as compared to individuals 65-69 years[AOR 0.57, 95\% CI 0.45-0.73; AOR 0.40 95\%CI 0.310.52] ; individuals older than 80 years were the only age group with increased risk of staying underweight/other.

After controlling for all the independent variables measured in this study, results from OLS regression for short-term logged expenditures revealed that compared to persons who stayed in normal BMI group, individuals with BMI loss had outpatient expenditures that were $23 \%$ higher. Compared to individuals who belonged to stayed normal BMI group, individuals with BMI gain had total expenditures that were $11 \%$ higher, outpatient expenditures that were $25 \%$ higher, and other expenditures that were $20 \%$ higher $(\mathrm{p}<0.05)$.

OLS regressions on log-ratio of expenditures suggested that when compared to individuals who stayed in normal BMI group, individuals who experienced BMI loss had significantly lower inpatient expenditures ( $\beta=-0.54$ ). When compared to individuals who stayed in normal BMI group, individuals with BMI gain significantly higher outpatient expenditures $(\beta=0.172)$.

Comorbid mental illness did not substantially alter the magnitude or direction of association between BMI and changes in expenditures in the population studied. 


\section{CONCLUSIONS/IMPLICATIONS}

Obesity has become an epidemic affecting all ages including the elderly, and is associated with increased morbidity, mortality and healthcare expenditures. Previous studies have focused primarily on the effects of weight loss on healthcare expenditures an d have several limitations: . The current study explored how changes in BMI affect a variety of healthcare expenditures within a Medicare population and additionally how comorbid mental illness impacts this relationship.

The current findings highlight the importance of maintaining normal weight and avoiding weight fluctuations. In light of the increased expenditures due to overweight and obesity, and the positive association between increasing BMI values and healthcare expenditures in the elderly, having a stable BMI is necessary to reduce healthcare costs. Collectively, findings from the current study emphasize the need for preventing overweight and obesity rather than treating these conditions and their negative effects. In this context, weight management and wellness programs that include nutrition and physical activity need to be an integral part of health promotion efforts for all individuals including the elderly.

Future research needs to distinguish between intentional versus unintentional weight loss and its effect on healthcare expenditures to understand the dynamics of weight change. Patterns of service utilization among persons with BMI changes also deserve closer examination. The link between obesity and mental illness remains unclear. Research in this area is ongoing, and a better understanding of the causal pathways of the relationship between obesity, mental illness and healthcare expenditures is needed. 


\section{ACKNOWLEDGEMENTS}

The author of this manuscript would like to thank Dr. Usha Sambamoorthi, committee chair and advisor for her untiring help and support during the completion of this thesis. Special thanks to Dr. Joel Halverson and Dr. Michael Hendryx for their time and participation as members on my committee.

The author also recognizes Drs. George Rust and Patricia Findley for access to the Medicare Current Beneficiary Survey for the years 2000-2005. 


\section{TABLE OF CONTENTS}

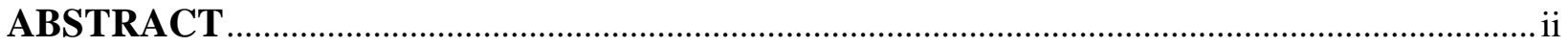

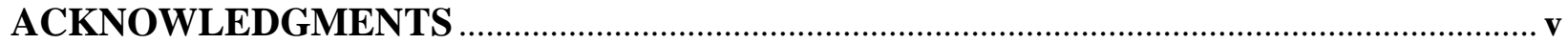

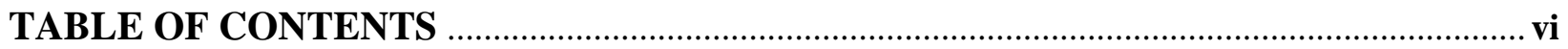

LIST OF TABLES ..................................................................................................... ix

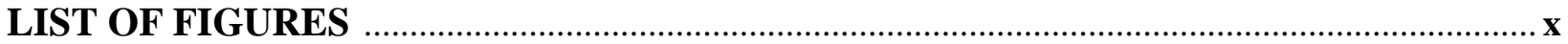

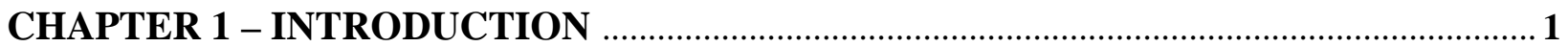

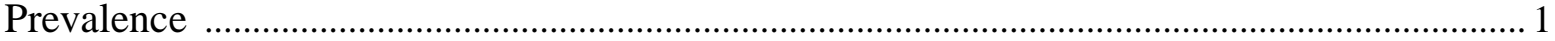

Health Impact of Obesity ...................................................................................................... 1

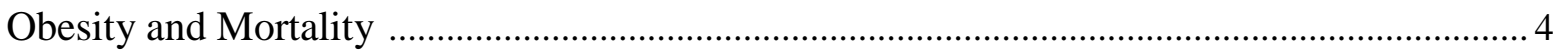

Obesity Prevention for the Elderly …………………….................................................... 5

Body Mass Index Categories and Healthcare Expenditures............................................................. 6

Problem Statement ............................................................................................................... 10

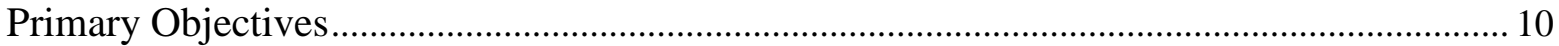

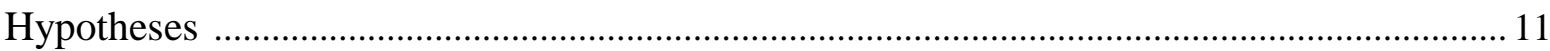

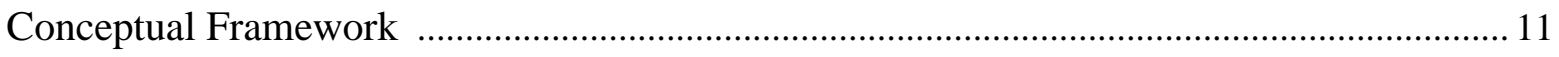

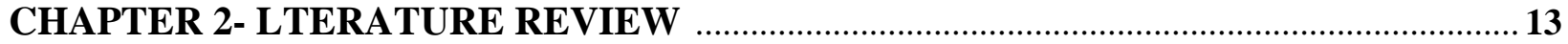

Association Between Weight Loss or Changing Body Mass Index and Healthcare Expenditures ............................................................................................... 13

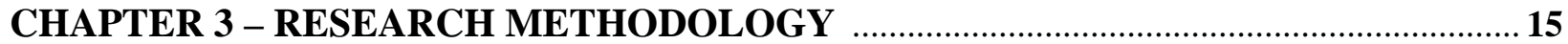

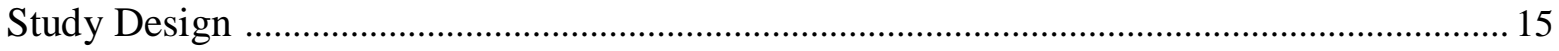

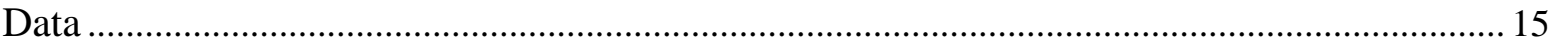

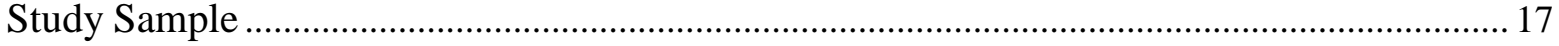

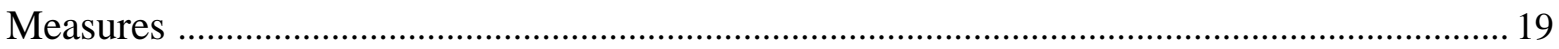

Statistical Methods.......................................................................................................... 24

CHAPTER 4 -RESULTS AND DISCUSSION ………......................................................... 27

Sample Descriptives ………………………………………………………………….... 27

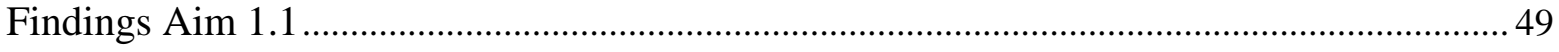

Total Expenditures …………………………………………………………… 49 


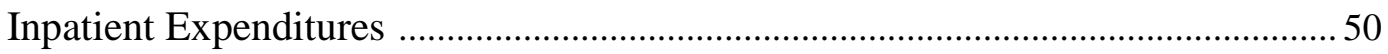

Outpatient Expenditures ……………………………………………………….... 51

Prescription Expenditures .......................................................................................... 52

Dental Expenditures ………………………………………………………………. 53

Other Expenditures .............................................................................................. 54

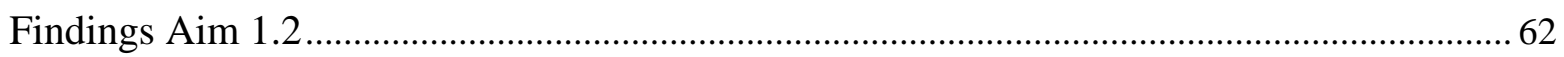

Total Expenditures ……………………………………………………………… 63

Inpatient Expenditures ............................................................................................ 63

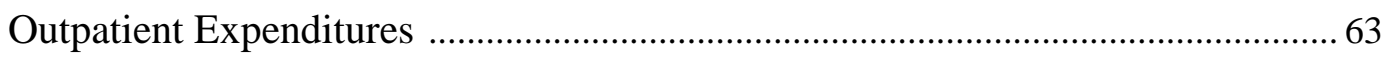

Prescription Expenditures ........................................................................................ 64

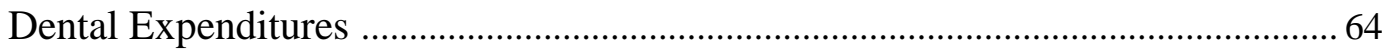

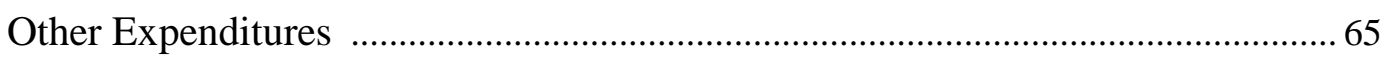

Alternate Specifications of Changes in Healthcare Expenditures............................................................6 65

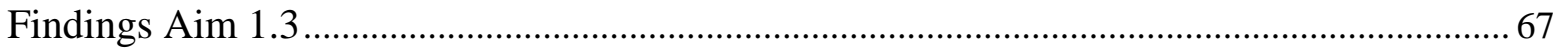

Discussion Overview …………………………………………………………………………... 67

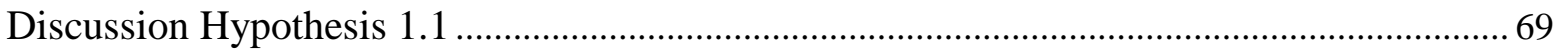

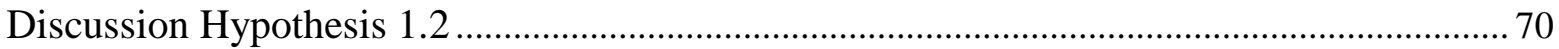

Discussion Hypothesis 1.3 ............................................................................................... 72

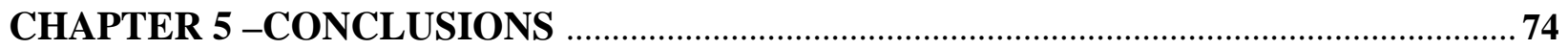

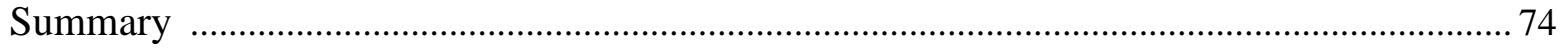

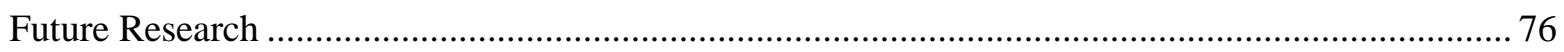

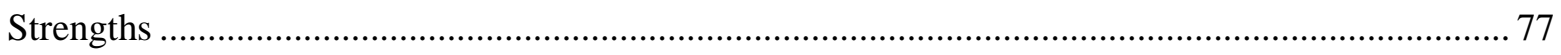

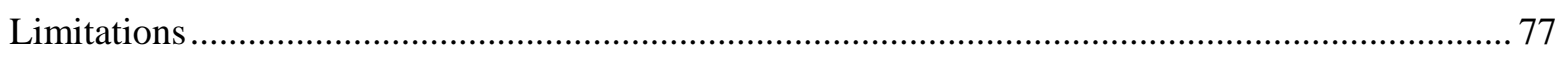

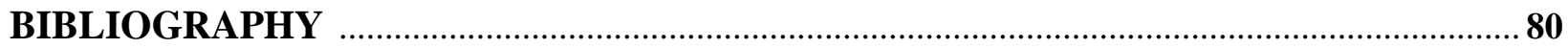

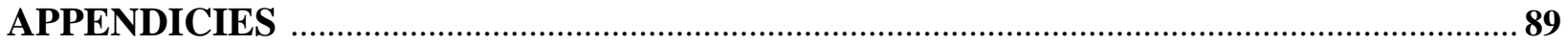

Appendix A: Sample Sizes by Round and Observation Year of Survey

Medicare Current Beneficiary Survey 2000-2005

Appendix B: Secondary Analyses of Change in Body Mass Index Categories and

Expenditures Alternative Specifications of the Dependent Variable (Expenditures)

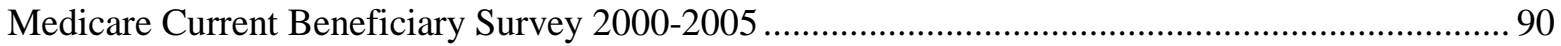

Appendix C:Mental Illness and Change in Body Mass Index Categories and Short-

Term Expenditures Ordinary Least Squares Regression on Logged Expenditures 
(Constant \$ 2005). 


\section{LIST OF TABLES}

Table 1. Description of Characteristics Medicare Current Beneficiary Survey 2000-2005

Table 2. Sample Characteristics by BMI Change Categories Medicare Current Beneficiary Survey 2000-2005

Table 3. Adjusted Odds Ratios and 95\% Confidence Intervals from Multinomial Logistic Regression on Body Mass Index Change Categories Medicare Current Beneficiary Survey 2000-2005

Table 4. 3-Year Trend in Expenditures (Constant \$ 2005) and Change in Body Mass Index Categories Mean and Standard Errors Medicare Current Beneficiary Survey 2000-2005

Table 5. Mean and Standard Error of Short-term Expenditures by Expenditure

Type and Change in Body Index Categories (Constant Dollars -2005) Medicare Current Beneficiary Survey 2000-2005

Table 6. OLS Models on Log Ratio of Expenditures by Type Changes in Body Mass Index Categories Medicare Current Beneficiaries Survey 2000-2005 Beneficiary Survey 2000-2005

Table 7.A Ordinary Least Squares Regression on Logged Expenditures (Constant 2005 \$) by Type Change in Body Mass Index Categories Medicare Current Beneficiary Survey 2000-2005

Table 7.B Ordinary Least Squares Regression on Logged Expenditures (Constant 2005 \$) by Type Change in Body Mass Index Categories Adjusted for Baseline Expenditures, Medicare Current Beneficiary Survey 2000-2005 


\section{LIST OF FIGURES}

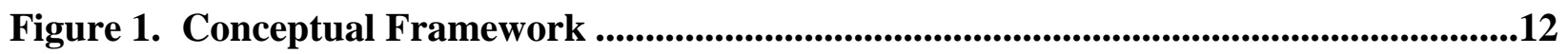

Figure 2. Transition of the Rotating Panel Design Medicare Current Beneficiary

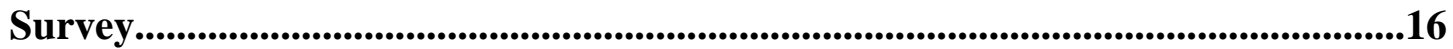

Figure 3. Study Attrition Medicare Current Beneficiary Survey 2000-2005 ........................18

Figure 4. Mean Annual Total and Component Healthcare Expenditures (Constant \$ 2005) at Baseline and Follow-up Years, Medicare Current Beneficiary Survey 2000-2005.........................................................................46 


\section{CHAPTIER ONE}

\section{INTRODUCTION}

\section{Prevalence}

Nearly one-third (33.8\%) of adults in the United States are reported to be obese, with the combined overall prevalence of both overweight and obesity being 68\% (Flegal et al.,2010). According to the Centers for Disease Control, between 1988 and 2006, the prevalence of obesity among US adults has risen from 23\% to 34\% (CDC, 2009).

\section{Obesity among the Elderly}

In a report from the American Geriatric Society, Arterburn and colleagues estimated the prevalence of obesity among US adults age 60 and above will increase to 37.4\% by 2010, up from 32\% in the year 2000. The prevalence of normal weight in this age group would decrease to 26.7\% by 2010, down from 30.6\% in 2000 (Arterburn et al., 2004). The US Census Bureau has projected the elder population of US adults to be 88.5 million by the year 2050. Current projections from the Agency on Aging (AOA), estimate the population of adults 65 and older to be near 40 million (AOA, 2009). If the current projections hold true, the prevalence of obesity will continue to rise among older Americans.

\section{Health Impact of Obesity}

\section{Causal link between obesity and chronic diseases}

Cardiovascular Diseases: The risk for cardiovascular diseases has been shown to increase in the presence of obesity. One cross-sectional study from the Vitamins and Lifestyle study of 
Washington state, included 73,003 adults aged 50-76, showing the risk of congestive heart failure to be $50 \%$ higher for overweight individuals as compared to those of normal weight. Being obese more than doubled the odds of heart failure as compared to normal weight individuals [Adjusted Odds Ratio (AOR) = 2.5, p <0.001] (Patterson et al., 2004). Similarly, the relative risk for coronary artery disease was shown to be 36 among individuals with body mass index (BMI) greater than or equal to $29 \mathrm{~kg} / \mathrm{m}^{2}$ as compared to those of normal weight (Willett et al., 1999). The relative risk of first venous thromboembolism was shown to be 27 among individuals with a BMI $\geq 40 \mathrm{~kg} / \mathrm{m}^{2}$, and the relative risk of stroke 22 among individuals with BMI $\geq 32 \mathrm{~kg} / \mathrm{m}^{2}$ (Tsai et al., 2002; Rexrode et al., 1997). The association of obesity with hypertension is established (Bechtold et al, 2006; Janssen et al., 2002; Nguyen et al., 2008). Using the well known Framingham study, Wilson et al., estimated that obesity may account for up to $26 \%$ of cases of hypertension ( Wilson et al., 2002).

Metabolic Disorders: Overweight and obesity have also been associated with an increased risk of type 2 diabetes (Green V., 2005; Hibbert-Jones et al., 2004;Haslam D., 2008; and LechleitnerM, 2008). Compared to persons of normal weight, the risk of diabetes is $60 \%$ higher[ AOR=1.6, $\mathbf{p}<\mathbf{0 . 0 0 1}$. The risk nearly quadruples among the obese [AOR 3.8, $\mathbf{p}<\mathbf{0 . 0 0 1}$ ] (Patterson et al., 2004). Additionally, the prevalence of obstructive sleep apnea is expected to rise with increasing rates of obesity (Lawati et al., 2009).

Respiratory Diseases: Compared to those of normal weight the risk of asthma increases within classes of obesity. The risk of asthma is reportedly $40 \%$ higher among those with class II/III obesity( BMI 35-39.9kg/m $\mathrm{m}^{2}$ and BMI $\geq 40 \mathrm{~kg} / \mathrm{m}^{2}$ ) [AOR=1.4, $\mathbf{p}<\mathbf{0 . 0 5}$ ], and the risk of 
obstructive sleep apnea has been reported to be between 2-4 fold greater among individuals with obesity (Patterson et al., 2004;Gami et al., 2003).

Osteoarthritis: Compared to individuals of normal weight, Patterson et al., showed the risk of osteoarthritis to be $20 \%$ greater among the overweight, and $60 \%$ higher in the obese [AOR 1.6 and 1.6, respectively, $\mathbf{p}<\mathbf{0 . 0 0 1 ]}$ (Patterson et al., 2004). One cross-sectional study of 1,003 women from the UK reported the odds of osteoarthritis to be 6.17 [95\% CI (3.26-11.71)] among women with BMI $>26.4 \mathrm{~kg} / \mathrm{m}^{2}$ ( Hart and Spector, 1993).

Depression and Mental Illness: Reports on the association of overweight and obesity with depression have also been studied. Compared to individuals of normal weight, the risk of taking an antidepressant was reported to be $20 \%$ higher among obese individuals (Patterson et al., 2004). A recent meta-analysis on 15 longitudinal studies, totaling 58, 745 subjects, showed obesity at baseline resulted in an increased risk of depression at follow-up [AOR 1.55, $\mathbf{p}<\mathbf{0 . 0 0 1}$ ] (Luppino et al., 2010).

\section{Obesity and Functional Impairment}

Obesity has been shown to worsen age-related functional decline and disability. Hubbard et al., measured phenotypic frailty among 3,055 community-dwelling adults ages 65 and older. Phenotypic frailty was defined by grip strength, duration and intensity of physical activity and gait speed. Phenotypic frailty was increased among those with $\mathrm{BMI}<20 \mathrm{~kg} / \mathrm{m}^{2}$ and BMI $>30 \mathrm{~kg} / \mathrm{m}^{2}$. Within each BMI category individuals with a large waist circumference $(\geq 88$ $\mathrm{cm}$ for women and $\geq 102 \mathrm{~cm}$ for men) were frailer than individuals without a large waist circumference (Hubbard et al., 2010). Ferraro et al., analyzed longitudinal data on 6,833 adults 25-70 years old followed over a period of 20 years. An upper-body disability index was used to 
measure domains of dressing, grooming, eating, reaching and gripping. A lower-body index measured domains for toileting, arising, walking and running errands. At 10 and 20-year followup, persons with BMI $\geq 30 \mathrm{~kg} / \mathrm{m}^{2}$ had higher levels of both upper and lower-body disability (Ferraro et al., 2004).

\section{Obesity and Quality of Life}

Health complaints such as frequent headaches, stress, fatigue, lack of energy, indigestion, heartburn and impotence are all significantly increased among individuals who are overweight or obese as compared to individuals of normal weight ( Patterson et al., 2004). With such complaints, a relationship between obesity and quality of life (QOL) measures is expected. One study on 18,584 Europeans aged 50 and older showed obese men and both overweight and obese women were significantly less likely to report being in "very good” or "good” health (Peytremann-Bridevaux I and Santos-Eggimann B, 2008). In another cross-sectional study of 250 menopausal women, ages 50-64 years, obesity did not significantly affect global Health Related Quality of Life (HR-QOL), it did however, affect sexual and “psychical” domains (Llaneza et al., 2007).

\section{$\underline{\text { Obesity and Mortality }}$}

Paradoxically, obesity as been shown to be associated with decreased mortality among older adults. These findings have been observed for elder patients with heart failure, for which increased adiposity has been shown to improve patient survival. (Habbu et al, 2006; McAuley et al., 2007;Oreopoulos et al., 2009). Although, the potential for longevity may exist, 
multimorbidity is common among older individuals, and obesity has been shown to negatively affect a number of diseases of varying organ systems, which can result in premature mortality.

Addressing the obesity epidemic among the elderly is necessary due to the associated risks of increased morbidity and mortality. Obesity prevention and treatment serves as a means whereby negative health effects of obesity can be relieved, if not avoided all together. Obesity prevention is common among health conscious adults, but should not be neglected among older populations.

\section{Obesity Prevention for the Elderly}

Overweight and Obesity have deleterious effects on health and wellbeing for all persons including the elderly. According to the National Heart Lung Blood Institutes (NHLBI, 2000), age should not preclude treatment of obesity in persons age 65 and over. Moreover,

"A clinical decision to forgo obesity treatment in an older adult should be guided by an evaluation of the potential benefits of weight reduction for day-to-day functioning and reduction of the risk of future cardiovascular events, as well as the patient's motivation for weight reduction.” (NHLBI, 2000)

Once initiated, weight loss regimens should be individually tailored and require counseling on proper nutrition and physical activity. The US Department of Health and Human Services (DHHS) and the Centers for Disease Control (CDC) currently recommend the following for older adults: 150 minutes of moderate-intensity aerobic activity per week or 75 minutes of vigorous intensity aerobic activity per week. Individuals are also advised to engage in muscle strengthening activities at least twice per week (DHHS, 2008; CDC, 2010). Aerobic activities include bicycling, golf (without a cart), swimming, walking, jogging and some yard work such as pushing a lawn mower. Muscle strengthening activities include carrying groceries, exercises 
using exercise bands, weight machines or dumbbells, some types of yoga and washing windows or floors (Elsawy and Higgins, 2010).

\section{Body Mass Index Categories and Healthcare Expenditures}

Many studies have reported increased healthcare expenditures due to obesity. One study that utilized longitudinal data from the Medical Expenditure Survey, showed increased expenditures for individuals with diabetes, dyslipidemia and hypertension. Medical expenses for each condition were significantly higher when comorbid obesity was considered (Sullivan et al., 2008). Wee et al., analyzed data for 11,212 adults from the 1998 MEPS. Results showed mean per person annual healthcare expenditures were significantly higher for overweight and obese person 65 and older as compared to those of normal weight (Wee et al., 2005). Yang and Hall, analyzed longitudinal data from the Medicare Current Beneficiaries Survey. For the years 19992001, elderly men who were overweight or obese had life-time expenditures that were 6-13\% higher than men of normal weight. Women who were overweight or obese had lifetime expenditures that were 11-17\% higher than women of normal weight (Yang and Hall, 2008).

Another cross-sectional study attributed increasing national healthcare expenditures to obesity. Data on 34,215 individuals from the 2003 Medical Expenditure Panel Survey revealed an increased prevalence of treatment for common chronic diseases among obese individuals as compared to those of normal weight: mental disorders (22\% v.17\%), diabetes (14\% v. 3\%), hyperlipidemia (34\% v.7\%), hypertension (30\% v. 12\%) and arthritis (19\% v. 10\%) (Thorpe KE, 2006). Although this may be a result of the increased risk of chronic conditions due to obesity, the increased prevalence of treatment suggests increased service utilization and hence increased expenditures and well. 
Finkelstein et al., estimated total medical spending attributable to overweight and obesity to be as high as $\$ 78$ billion in 1998 ( Finkelstein et al., 2003) and a later estimate in 2008 dollars places it at $\$ 147$ billion per year (Finkelstein, Trogdon, et al., 2009). Several reports have been published that show increased medical expenditures for person who are overweight or obese (Bell et al., 2010; Wee et al., 2005; Trasande and Chatterjee, 2009). In 2000, one cross-sectional study of 16,262 US adults showed compared to normal weight individuals, the odds of incurring any healthcare expenditure was $23 \%$ higher for overweight individuals. The odds of incurring any healthcare expenditure were also increased within categories of obesity. Compared to individuals of normal weight, those with class I (BMI 30-34.9 kg/m²), class II (BMI 35-39.9 $\mathrm{kg} / \mathrm{m}^{2}$ ) and class III (BMI $>40 \mathrm{~kg} / \mathrm{m}^{2}$ ) obesity were $58 \%, 45 \%$ and $100 \%$ more likely to incur any healthcare expenditure (Arterburn, et al., 2005). Additionally, total healthcare expenditures for the year 2000 were estimated to be $\$ 17.2$ billion for overweight, and $\$ 16.5$ billion, $\$ 11.2$ billion and \$11.1 billion for class I-III obese categories.

Another cross-sectional study of 25,038 adults and 2,440 adolescents who participated in the 2000-2001 Canadian Community Health Survey found mean annual physician costs varied by BMI category and age. Compared to those of normal BMI, obese individuals had higher mean physician costs. For individuals 60 years and older, the finding were significantly different. Obese individuals 60 years and older had mean costs that were $28.3 \%$ higher than their normal weight counterparts (\$1029 v. \$802)(Jansen et al., 2009).

The Australian Diabetes, Obesity and Lifestyle study followed 6,140 individuals ages 25 and older for 5 years to compare annual total healthcare costs between persons of varying BMI and waist circumference. Annual total direct healthcare costs were \$2,788 (95\% CI, \$2,542$\$ 3,035$ ) for obese individuals, whereas persons of normal weight had annual costs of $\$ 1,472$ 
(95\% CI, \$1,204-\$1,740). The authors reported that overweight and obesity accounted for an excess in total costs of $\$ 10.7$ billion for the year 2005(Colagiuri et al., 2010).

Yang and Hall used longitudinal data from the Medicare Current Beneficiary Survey (MCBS) for 1999-2001 to simulate the life-time healthcare expenditures for underweight, normal weight, overweight and obese individuals. Men who were overweight or obese at age 65, had higher inpatient, outpatient and prescription expenditures over their life-time than men who were normal weight. Average total healthcare expenditures were $6 \%$ and $12.5 \%$ higher for overweight and obese men when compared to normal weight men. Women who were overweight or obese at age 65, had higher inpatient, outpatient, prescription and nursing home expenditures over their life-time than women who were normal weight. Average total healthcare expenditures were $10.7 \%$ and $16.8 \%$ higher for overweight and obese women when compared to normal weight women (Yang and Hall, 2008).

Using data from 2003 MCBS, it has been reported that prescription drug spending for 2003 was significantly higher at \$2,374 for obese class I and at \$2,976 for obese class III compared to $\$ 1,764$ for normal weight beneficiaries (Stuart et al., 2008). Obese individuals also had higher utilization rates for selected medications used to treat diabetes, hypertension, ischemic heart disease, heart failure, hyperlipidemia, and osteoarthritis.

Most studies analyzing the relationship between obesity and health expenditures have utilized cross-sectional designs and have evaluated the association between various BMI categories and expenditures. From these studies, it can be concluded that obesity is associated with increased life-time and disease specific health expenditures. However, it is not known as to whether changing BMI categories (ie. weight loss or weight gain) is related to short-term 
changes in healthcare expenditures. This study contributes to the current body of literature by exploring how changes in weight affect short-term changes in healthcare expenditures within a Medicare population. 


\section{Problem Statement}

Due to well established associations of overweight and obesity with increased morbidity and healthcare expenditures, these conditions have become prime targets of public health initiatives and campaigns, such as the "Let’s Move“ campaign, championed by Michelle Obama. The epidemic has also caught the attention of employers as well as health plans which are instituting disincentives for unhealthy weight gain (Gabel et al., 2009). Alabama state employees with BMI greater than $35 \mathrm{~kg} / \mathrm{m}^{2}$ have been given one year to lose weight. Beginning on January 1, 2011, those who have not met this goal will be required to pay $\$ 25$ per month towards their health insurance (Associated Press, 2008). Currently, Clarian Health of Indiana deducts up to $\$ 10$ per pay check for employees not meeting goals which include a BMI less than $30 \mathrm{~kg} / \mathrm{m}^{2}$ (Associated Press, 2009). With the annual costs of overweight and obesity estimated to be as high as $\$ 147$ billion (Finkelstein, Trogdon et al., 2009), this study seeks to determine the short-term changes in healthcare expenditures that result from weight gain or loss within a Medicare population

\section{Primary Objectives}

1. Using longitudinal data, estimate healthcare expenditures (total, inpatient, outpatient, prescription, dental and other) associated with changes in BMI categories with sub analysis for those with mental illnesses.

1.1. How do the changes in BMI categories affect the total and specific components (inpatient, outpatient, prescription, dental and other) of expenditures? 
1.2. What is the association between changes in BMI and healthcare expenditures, after controlling for individuals’ demographic, socioeconomic status, physical illness and mental illness?

1.3. How does the relationship between weight gain or loss and healthcare expenditures change in the presence of mental illness (depression)?

\section{Hypotheses}

1.1. Decreases in BMI will result in reductions in short-term total and/or component health expenditures.

1.2. Increases in BMI will result in increases in total and/or component healthcare expenditures.

1.3. The effect of BMI on health expenditures will be magnified in the presence of comorbid mental illness.

\section{Conceptual Framework}

The conceptual framework for analyzing changes in BMI categories and health expenditures is an adaptation and mixture of sociological theories (Anderson R., 1995) and competing demands (Piette et al., 2004; Nutting et al., 2000; Klinkman, 1997; Jaen et al., 1994). Competing demands literature explores the process by which patients and physicians prioritize and treat medical conditions. It is proposed that some problems are addressed readily, while others are not, due to an implicit agenda of the patient and/or physician. A clear example is when treatment of a physical disease takes priority over comorbid mental illness (Rost et al., 2000). To draw a parallel, obesity treatment may be neglected because patients with obesity present with many health conditions and challenges which may take priority. 
In the context of obesity, the "competing demands" model views the association between BMI categories and healthcare utilization/expenditures as an active choice influenced by threesets of interrelated “domains” representing the clinician, the patient, and the practice (i.e. healthcare delivery) system. In its operational form, the patient domain includes predisposing, enabling, need, life-style and the external environment. Clinician and practice factors include type of visit, alternative demands, knowledge/expertise, practice location, availability of consultants, and practice structure. The current study addresses the relationship between BMI change and healthcare expenditures by observing factors of the patient domain. Future studies should evaluate the effects of clinician and practice domains on the relationship between BMI change and healthcare expenditures. Operational elements of the “competing demands” model with variables available from the administrative and survey data of MCBS are illustrated in Figure 1 and defined in Measures section.

Figure 1. Conceptual Framework

\section{PATIENT FACTORS}

Predisposing: gender, age, race/ethnicity and marital status

Enabling(Socioeconomic/Access to Care): education, income, supplemental insurance, usual source of care

Need/Competing demands: mental illness, chronic illness; health status and functional limitation.

Lifestyle: smoking

External Environment: metro/ non-metro

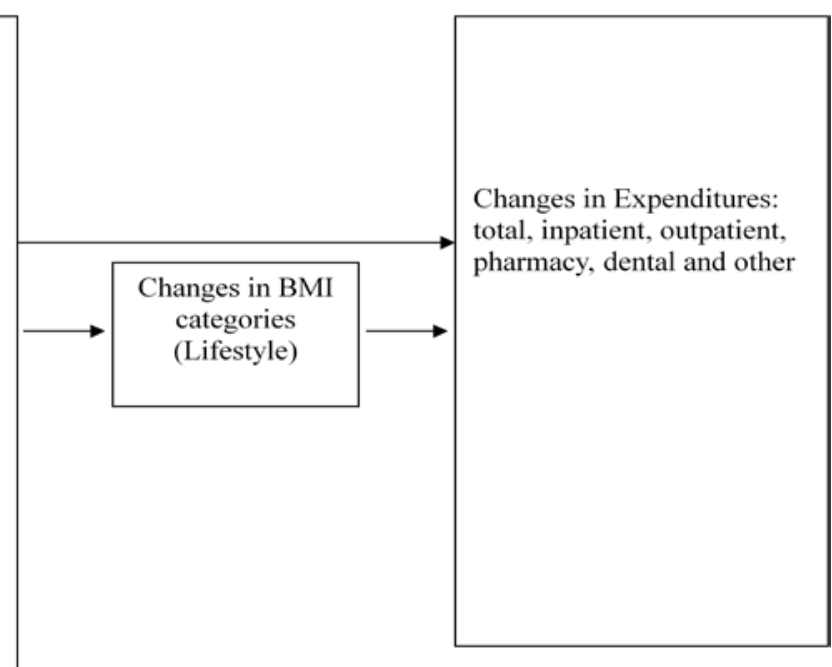




\section{CHAPTER 2}

\section{REVIEW OF LITERATURE}

\section{Association between Weight Loss or Changing Body Mass Index and Healthcare Expenditures}

Most studies that have analyzed the effects of weight changes on healthcare expenditures have focused specifically on weight loss. In one prospective study, 965 obese Swedish subjects were followed for 6 years post intervention (surgical or conventional weight loss). At the end of the 6 year period, annual costs for diabetes and cardiovascular medications had increased for individuals losing less than $15 \%$ baseline body weight. The largest increase in annual medication costs, $96 \%$, was seen for those who lost less than $5 \%$ baseline body weight. Individuals losing greater than $15 \%$ baseline body weight saw medication costs decrease by $8 \%$ (Argen et al., 2002a). Another retrospective study of 64 obese patients, with mean follow-up of 16 months, showed reductions in medication costs post-gastric bypass. Preoperative medication costs were \$317 per person compared to \$135 postoperatively, resulting in estimated yearly savings of \$2,184 per person (Monk et al., 2004). Collins and Anderson evaluated the economic impact of weight loss among 40 obese individualsages $40-70$ years. At 12 week follow-up, subjects had lost an average of 15lbs, and monthly prescription costs for hypertension and diabetes medications were $\$ 20$, down from $\$ 63.30$ at baseline. By one-year follow-up, subjects had lost an average of 20 lbs and average monthly prescription costs were $\$ 32.40$ (Collins and Anderson, 1995).

Dynamic modeling of a sustained 10\% weight loss decreased lifetime healthcare expenditures due to hypertension, hypercholesterolemia, type-2 diabetes, coronary heart disease and stroke by as much as $\$ 2,200-\$ 5,300$ (Oster et al, 1999). Another simulation study aimed to predict the return on investment for workplace obesity interventions. Annual savings due to 
medical costs and absenteeism were estimated to be $\$ 90$ per worker for those achieving at least 5\% weight loss (Trogdon et al., 2009). In a follow up study, Finkelstein et al., merged medical claims and absenteeism data for employees from 17 North Carolina based colleges. Overweight and obese participants with at least $5 \%$ weight loss did not have lower medical expenditures or absenteeism at 12 or 24 months (Finkelstein et al., 2009).

All these studies have made important contributions by reporting that obesity is associated with increased healthcare expenditures due to its impact on comorbid conditions such as hypertension and diabetes; bariatric surgery decreases prescriptions costs following surgical weight loss interventions; weight loss is not associated with lower expenditures over a short (1-2 year) time frame in a working population. However, these studies have limitations. Some have examined only weight loss although subjects were followed over a longer time frame; others have analyzed only changes in prescription expenditures; other studies included only certain conditions such as diabetes.

The current study will advance current knowledge by modeling both weight loss and weight gain using longitudinal data. Additionally, this study has evaluated the effects of changing BMI on a variety of health expenditures, including total, inpatient, outpatient, dental and prescription. The current study will explore how changes in BMI categories may affect healthcare expenditures using data over a 3 year period among elderly. As suggested in the introduction and obesity prevention guidelines among the elderly, it is important to study this population. Given the public health and economic implications of increasing rates of overweight and obesity among the elderly, the question that must be addressed is what monetary difference may payers of healthcare expect as a result of changes in weight categories? 


\section{CHAPTER 3}

\section{RESEARCH METHODOLOGY}

\section{Study Design}

The study design is longitudinal and retrospective with three panels of individuals followed over a period of three years.

\section{Data}

The data for the current study is derived from the Medicare Current Beneficiary Survey (MCBS). The MCBS uses both survey and claims data to compile a continuous, multipurpose survey of a nationally representative sample of aged, disabled, and institutionalized Medicare beneficiaries. MCBS, which is sponsored by the Centers for Medicare \& Medicaid Services (CMS), is the only comprehensive source of information on Medicare beneficiaries. The survey is designed to focus on cost and use of medical services. Sources of information on expenditures and utilization for healthcare services include in-person interviews conducted every four months as well as Medicare claims. The MCBS data consists of two annually released public use files: "access to care" and "cost and use". The "access to care" files contain information relating to respondents' access to medical providers and their satisfaction with healthcare, and include beneficiaries who were enrolled in Medicare for the entire year. The "cost and use" files, in contrast, contain information on personal healthcare expenditures and payment sources for all beneficiaries who were eligible for Medicare at any time throughout the calendar year. The two data files can be used separately or (for those enrolled for the full year) in combination. The current project utilized the cost and use files. 


\section{MCBS Cost and Use Files:}

Data collection for MCBS began in 1991 and continues today. The most recent files for analysis are the 2006 cost and use files, and the 2008 access to care files. MCBS utilizes a rotating panel design of four overlapping panels of Medicare beneficiaries surveyed each year. Each panel contains a nationally representative sample of beneficiaries who will be interviewed 12 times to collect 3 complete years of utilization data. All four panels are included in the Access to Care files, while only three panels are used in the Cost and Use files. Cost and use file cover only three of four years since the panel that is being retired during a calendar year is not asked about medical utilization for that year. Individuals may be tracked across years by combining a unique person identifier with the round number that indicates survey entry. Figure 2 below presents a visual depiction of the rotating panel design (http://www.cms.gov/MCBS/Downloads/HHC_2000_appendixA.pdf, Accessed June 1, 2010). For example, individuals who enter the survey in the year 2000, have entered in panel 25. They will be interviewed over the next four years, as other beneficiaries enter the sample (i.e. rounds $28,31,34 \ldots)$.

Figure 2. Transition of the Rotating Panel Design Medicare Survey Current Beneficiary

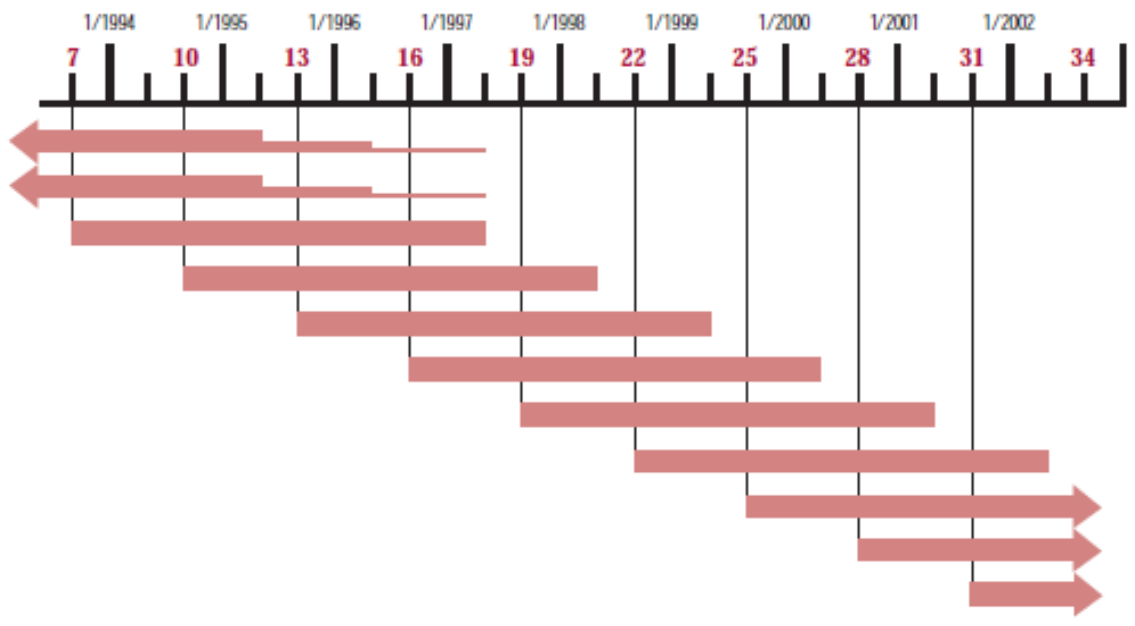




\section{Study Sample}

This study analyzed merged data from multiple years of the Medicare Current Beneficiaries Survey (MCBS). The study sample was derived from MCBS datasets from the following years: 2000, 2001, 2002, 2003, 2004 and 2005. From these files, four longitudinal panels were created: 1) 2000-2002, 2) 2001-2003 3)2002-2004 and 4) 2003-2005. These years were chosen for recency of availability. Additionally, variables chosen for analysis were coded consistently across all years. Table A.1 (Appendix A), tracks each of the four panels across survey years, in which each box shows the number of individuals for each year with respective round information. For example, the 2000-2002 panel consists of individuals who entered the survey in round 25, and continued through all three years. In Table A.1, 4,547 individuals started in round 25 for year 2000, 4,042 continued through the second year, and by 2002, 3,663 individuals had been continuously followed.

Newly enrolled beneficiaries are included in interviews even if they became Medicare eligible after the start date for a new round. These individuals are termed "ghosts" and have missing or incomplete survey information. These individuals are easily identified by the letter "G” at the end of their unique person identifier. In Table A.1, numbers in red represent "ghost” participants in each year.

\section{Analytic Sample: Inclusion/exclusion criteria}

The study sample was composed of four panels spanning three years each 1) 2000-2002, 2) 2001-2003, 3)2002-2004 and 4) 2003-2005). Individuals who met the following criteria were eligible for inclusion:

- Community dwelling, age 65 and older 
- $\quad$ Alive for all three years

- $\quad$ BMI information for all three years

- Full-year enrollment in Medicare parts A and B

The resulting sample size was 10,698, with an even division across panels: 2000-02 (n= 2,757); 2001-03 ( $=2,745) ; 2002-04(n=2,562)$; and 2003-05 $(n=2,634)$. Please see Figure 3 for a visual description of the sample selection process (Figure 3, Author 2010).

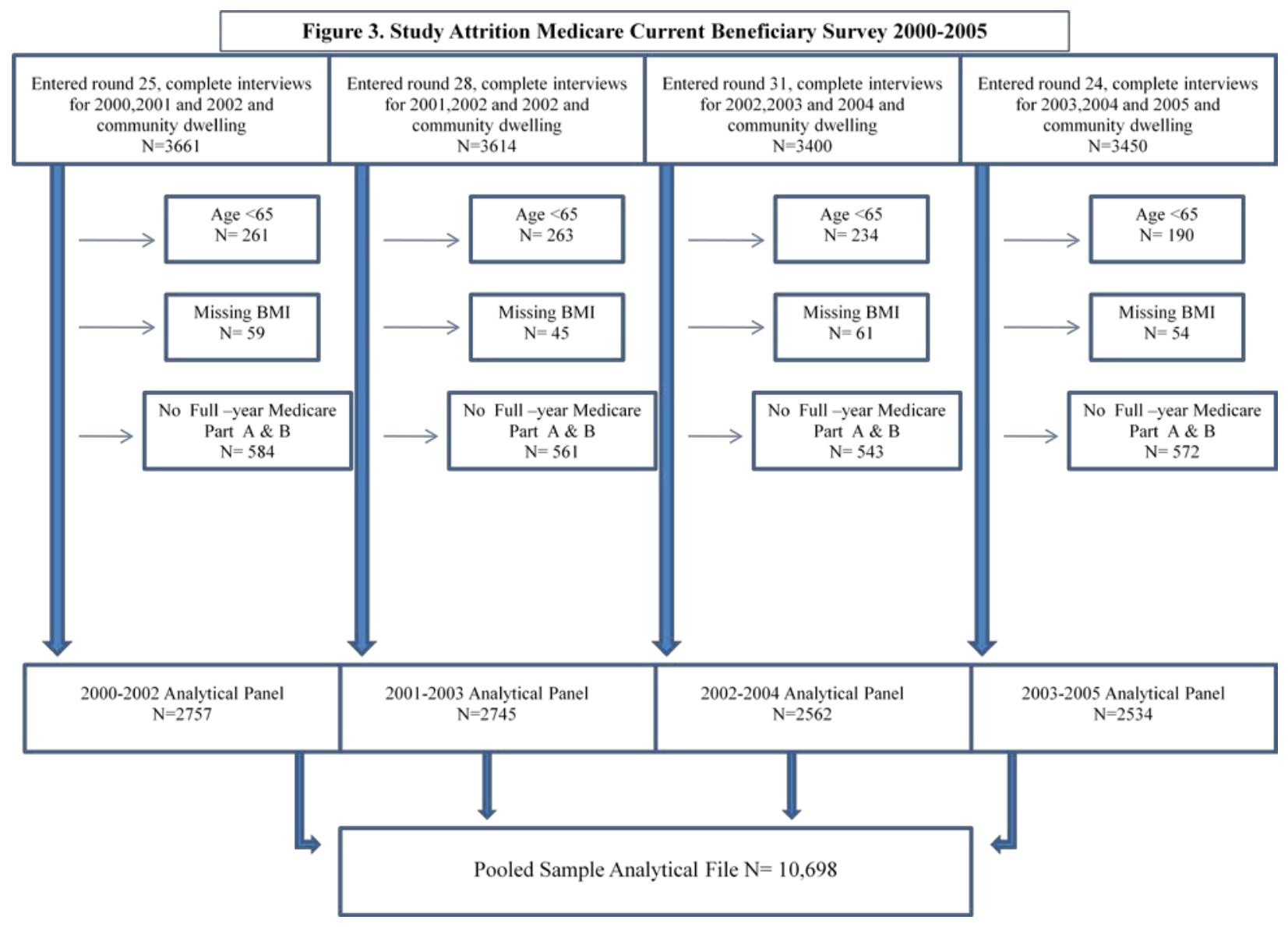




\section{Measures}

\section{Dependent Variable:}

Expenditures: Information on expenditures was obtained from Medicare claims data and personal interviews conducted at four-month intervals. Expenditure data consists of payments made by the third-party payers including Medicare, Medicaid, Medicare-Health Maintenance Organization, Veterans Affairs Health Insurance, private HMO, individually purchased insurance, employer-sponsored insurance, out-of-pocket and other payer. Expenditure types include total, inpatient, outpatient, pharmaceutical, dental and other. Other expenditures covers payments made for facility, home health, institutional, medical providers and laboratory. For the purpose of this study, the medical provider component was not separated from the other expenditures because medical provider expenditures also contained “other” expenditures that could not be identified.

Expenditures obtained from the cost and use files represent those obtained from both the survey and administrative bills. To receive an accurate picture of amounts paid, the files have undergone a careful reconciliation process that identifies payments recorded on the survey only, the bill only or on both.

\section{Short-term Expenditures}

Short-term expenditures refer to the expenditures that occurred after the measurement of BMI changes (ie. during the $3^{\text {rd }}$ year of follow up).

\section{Changes in Expenditures}

Unless otherwise specified, changes in expenditures refer to differences between followup years 2 and 3 for each panel. 


\section{Relative Changes in Expenditures: Log-ratio}

Absolute differences in expenditures between two time points are not satisfactory because not all individuals have the same baseline expenditures. As such, an increase of $\$ 200$ from 0 to $\$ 200$ is inappropriately interpreted the same way as an increase of $\$ 200$ from $\$ 10,000$ to $\$ 10,200$. Relative change in expenditures is an alternative method. However, under this approach, an increase from $\$ 100$ to $\$ 200$ would produce a change of $100 \%$ relative to the baseline value, whereas the same absolute change in the opposite direction (i.e., a decrease from $\$ 200$ to $\$ 100$ ) would produce a change of 50\%. This study used a method known as "logchange ratio” (Lorenzez G., 1989; Helmer et al, 2007), by which the ratio of Year 3 expenditures to Year 2 expenditures was computed, and then the log of this ratio calculated. Because zeros in baseline expenditures (division by zero) or follow-up expenditures will produce undefined values a minimal constant (\$1) was added to all zero expenditures to ensure defined values for the logchange ratio without compromising the magnitude of the ratio(log of zero is undefined). For the present study, the log-ratio served as the dependent variable for primary analysis.

\section{Relative Changes in Expenditures: Percent Change Categories}

Levels of expenditure change were 1) no expenditures at year 2 or at Year 3; 2)greater than $10 \%$ decrease in expenditures from Year 2 to Year 3; 3)greater than $10 \%$ increase in expenditures from Year 2 to Year3; and 4)minimal variation, that represents changes in expenditures in either direction that are less than $10 \%$. Ten percent was chosen as an arbitrary threshold for variation. However, different levels of percent change were analyzed (data not presented). For the sensitivity analysis a multinomial logistic regression on levels of expenditure change by BMI change groups was performed. For the analyses, minimal variation served as the reference group. 


\section{Comparing Expenditures across Different Years: Conversion to Constant Dollars}

Comparisons of monetary values cannot be made across years due to inflation. Monetary values may be adjusted to account for inflation and changes in purchasing power over time. In all analyses expenditures were transformed to constant dollars and represented in 2005 dollars using the annual consumer price index (CPI) for medical care services available from the Bureau of Labor Statistics (http://data.bls.gov/cgi-bin/surveymost, Accessed June 01, 2010). The Medical CPI accounts for inflation across the following sectors: professional services, hospital and related services, health insurance, medicinal drugs, and medical equipment/ supplies (BLS, 2010).

\section{Key Independent Variable}

\section{Body Mass Index Categories:}

The MCBS collects information on respondents’ weight ( in pounds) and height (in inches). Body Mass Index (BMI) was calculated from these measures using the commonly used formula (CDC, 2009): BMI (kg/m²) = weight $(\mathbf{k g}) /$ height $\left(\mathbf{m}^{2}\right)$.

Following the Center for Disease Control's criterion (CDC, 2009) BMI was categorized into the following groups:

1. underweight $\left(\mathrm{BMI}<18.5 \mathrm{~kg} / \mathrm{m}^{2}\right)$

2. normal weight (18.5 to $24.9 \mathrm{~kg} / \mathrm{m}^{2}$ )

3. overweight $\left(25-29.9 \mathrm{~kg} / \mathrm{m}^{2}\right)$

4. obese (BMI 30-34.9 kg/m²) and

5. morbidly obese (BMI $\left.>35 \mathrm{~kg} / \mathrm{m}^{2}\right)$ 


\section{Changes in Body Mass Index Categories:}

Changes in body mass index were measured between Year 1 and Year 2. They were then grouped into the following categories and used to predict expenditures in follow-up years.

1) Stayed normal (BMI $\left.18.5-24.9 \mathrm{~kg} / \mathrm{m}^{2}\right)$.

2) BMI loss (decrease in BMI in individuals with baseline BMI greater than or equal to 25 $\mathrm{kg} / \mathrm{m}^{2}$, where the resulting BMI belongs to a category lower than that of baseline).

3) Stayed overweight (BMI between 25 and $29.9 \mathrm{~kg} / \mathrm{m}^{2}$ in baseline and follow-up years).

4) Stayed obese (BMI greater than or equal to $30 \mathrm{~kg} / \mathrm{m}^{2}$ in baseline and follow-up years)

5) BMI gain (increase in BMI category in individuals with baseline BMI $>18.5 \mathrm{~kg} / \mathrm{m}^{2}$, where the resulting BMI belongs to a category higher than that of baseline)

6) Stayed Underweight/Other (BMI $<18.5 \mathrm{~kg} / \mathrm{m}^{2}$ in baseline and follow-up years/weight changes not defined by previous categories)

The group "BMI loss" included individuals whose moved to a lower category of BMI between Year 1 and Year 2. For example, an individual moving from obese to overweight or from obese to normal BMI would have experienced BMI loss. Similarly, "BMI gain” included individuals who moved to a higher BMI category. For example, an individual moving from normal weight to overweight or overweight to obese would have experienced BMI gain.

\section{Other Independent Variables}

\section{Predisposing:}

- gender (women, men)

- race/ethnicity (white, African American, Latina, other)

- age, and marital status (married, widowed, divorced/separated, never married) 


\section{External Environment:}

- metropolitan status (metro versus non-metro)

\section{Enabling:}

- education (less than high school, high school, greater than high school)

- $\quad$ poverty status (as a percentage of the Federal Poverty Level (FPL), less than 200\% FPL, greater than $200 \%$ FPL)

- $\quad$ having supplemental private insurance (yes/no)

- dually enrolled in Medicaid (yes/no)

\section{Life style /Risk factors:}

- $\quad$ smoking status (current, past, never)

\section{Need Variables/Competing Demand:}

History of depression and medical illnesses were derived from both self-report and Medicare claims data.

- $\quad$ Self-reported general health (excellent/very good, good, fair/poor)

- Activities of Daily Living (ADL) Limitations (Functional status is a scale reflecting health related difficulty with six activities. The number of reported limitations was recorded.)

- $\quad$ Instrumental Activities of Daily Living (IADL)

- Limitations (Functional status is a scale reflecting health related difficulty with six activities. The number of reported limitations was recorded.)

- history of medical illness

- history of depression 
- history of mental illness

Note: ADL ranged from basic self-care tasks such as bathing, dressing, eating, getting to the toilet; IADLs consisted of physically demanding tasks such as heavy housework and managing money. Dummy variables for history of medical illness, indicated the presence or absence of physical health conditions. These were derived from a list of conditions (eg. arthritis, cancer, diabetes, heart disease, hypertension, stroke, respiratory disease, osteoporosis, and any mental illness). Depression was defined by both self-report and Medicare fee-for-service claims with ICD9 codes for depression. These diseases/conditions were chosen for their prevalence in elder populations, and for their association with overweight/obesity (See Introduction). In addition, these conditions have been shown to increase healthcare expenditures (Charlson et al., 2007; Vogeli et al., 2007).

\section{Statistical Methods}

Statistical analyses included both bivariate and multivariate analyses and are described below.

\section{Bivariate:}

The Chi-square test of independence was used to determine significance between BMI change categories and subject characteristics.

F-tests were used to test significant differences in average expenditures by changes in BMI categories and relative changes in expenditures by changes in BMI categories.

\section{Mutivariate:}

Multinomial Logistic Regression_was used to analyze the relationships between BMI change categories and independent variables. 


\title{
Ordinary Least Squares (OLS) Reqressions
}

OLS regressions were used in which expenditures were modeled by changes in BMI, while controlling for other independent variables. Expenditures were transformed on a natural logarithmic scale to minimize errors due to non-normality. The models for analyses had the following functional forms:

\author{
${ }^{*}$ Log-ratio EXP $=f\left(\mathrm{BMI}_{\text {changei }}+\mathrm{X} \mathbf{1}_{\mathbf{i}} \ldots \mathrm{Xn_{i }}\right)+\mathbf{\epsilon}_{\mathbf{i}}$

$$
\operatorname{EXP}=f\left(\mathrm{BMI}_{\text {changei }}\right)+\boldsymbol{\epsilon}_{\mathrm{i}}
$$

$\ln \mathbf{E X P}=f\left(\mathrm{BMI}_{\text {changei }}+\mathrm{X} 1_{\mathrm{i}} \ldots . \mathrm{Xn_{ \textrm {i } }}\right)+\mathbf{c}_{\mathrm{i}}$

where, EXP = expenditures, X1 . .Xn are all independent variables, and “*” = primary analysis

\section{Sensitivity Analysis:}

Due to the longitudinal nature of the MCBS, the number of observations per person varied from a minimum of one to a maximum of three, producing an unbalanced design. While the study’s primary analyses used "balanced panel” requiring Medicare beneficiaries to be observed for all 12 rounds of interviews (i.e 3 years), this approach did not utilize all the information available and excluded individuals with only two years of observations. Therefore, to minimize the loss of information sensitivity analyses were also conducted. These analyses utilized repeated measures with an unbalanced design. Under this approach, the unit of observation was the person year and repeated observations (2 or 3) of expenditures, BMI and other independent variables were used. This analytical technique has been used in prior studies on trends in diagnosed depression (Sambamoorthi et al., 2005; Crystal et al., 2003) and end-oflife expenditures among the elderly (Hoover et al., 2002). Both studies have used the MCBS and 
pooled multiple years of observations. For the sensitivity analysis a multinomial logistic regression on levels of expenditure change by BMI change groups was performed.

All analyses controlled for the complex sample design of MCBS and were conducted using Statistical Analysis System (SAS version 9.2 Cary, North Carolina) using survey procedures. 


\section{CHAPTER 4}

\section{RESULTS AND DISCUSSION}

\section{Sample Descriptives}

A description of baseline characteristics of the analytical sample can be found in Table 1. At baseline, the analytical sample $(n=10,698)$ was mostly female $(58 \%)$, Caucasian $(81 \%)$, and of the age group 65-69 years (31\%). Most individuals were married (57\%) and lived within a metro community (77\%). More individuals had only a high school education (37\%), and there was an even split between individuals living below 200\% federal poverty (49\%) and those above (51\%). A small proportion of the sample was enrolled in Medicaid (10\%), and those with private insurance or an HMO represented $67 \%$ and 28\% respectively. A third of the sample, reported having excellent physical health (33\%). Accordingly, the majority of individuals reported no functional limitations. Those with no limitations by ADL or IADLs comprised $76 \%$ of the sample. History of chronic disease/illness formed the following distribution; arthritis (59\%), cancer (68\%), heart disease (35\%) hypertension (58\%), stroke (10\%), respiratory diseases (13\%), osteoporosis (18\%), any mental illness (10\%) and baseline depression (13\%). Also, at baseline, 2.1\% were underweight, $36.8 \%$ normal weight, $39.7 \%$ overweight, $19.7 \%$ obese, and $1.7 \%$ morbidly obese. Finally, 11\% of the study sample were current smokers. 


\begin{tabular}{|c|c|c|}
\hline \multicolumn{3}{|c|}{$\begin{array}{c}\text { Table 1 } \\
\text { Description of Sample Characteristics } \\
\text { Medicare Current Beneficiary Survey } \\
2000-2005 \\
\end{array}$} \\
\hline & $\mathbf{N}$ & $\%$ \\
\hline ALL & 10,698 & 100.0 \\
\hline \multicolumn{3}{|l|}{ Body Mass Index-Base } \\
\hline Underweight & 247 & 2.1 \\
\hline Normal & 4,070 & 36.8 \\
\hline Over weight & 4,208 & 39.7 \\
\hline Obese & 2,002 & 19.7 \\
\hline Morbidly obese & 171 & 1.7 \\
\hline \multicolumn{3}{|c|}{ Body Mass Index-Follow-up } \\
\hline Underweight & 281 & 2.4 \\
\hline Normal & 4,116 & 37.0 \\
\hline Over weight & 4,171 & 39.6 \\
\hline Obese & 1,971 & 19.5 \\
\hline Morbidly obese & 159 & 1.6 \\
\hline \multicolumn{3}{|l|}{ Panel } \\
\hline $2000-2002$ & 2,757 & 25.1 \\
\hline $2001-2003$ & 2,745 & 25.6 \\
\hline $2002-2004$ & 2,562 & 23.8 \\
\hline $2003-2005$ & 2,634 & 25.5 \\
\hline \multicolumn{3}{|l|}{ Gender } \\
\hline Women & 6,108 & 57.7 \\
\hline Men & 4,590 & 42.3 \\
\hline \multicolumn{3}{|l|}{ Race/Ethnicity } \\
\hline White & 8,660 & 81.1 \\
\hline African American & 875 & 7.9 \\
\hline Latina & 750 & 7.1 \\
\hline Other & 399 & 4.0 \\
\hline \multicolumn{3}{|l|}{ Age } \\
\hline $65-69$ & 2,550 & 30.6 \\
\hline $70-74$ & 2,326 & 23.0 \\
\hline $75-79$ & 2,328 & 22.5 \\
\hline $85+$ & 3,494 & 23.9 \\
\hline \multicolumn{3}{|l|}{ Marital Status } \\
\hline Married & 5,829 & 56.8 \\
\hline Widowed & 3,769 & 32.1 \\
\hline Div/Separated & 790 & 8.1 \\
\hline Never Married & 309 & 3.0 \\
\hline
\end{tabular}




\begin{tabular}{|c|c|c|}
\hline \multicolumn{3}{|c|}{$\begin{array}{c}\text { Table 1 } \\
\text { Description of Sample Characteristics } \\
\text { Medicare Current Beneficiary Survey } \\
2000-2005 \\
\end{array}$} \\
\hline & $\mathbf{N}$ & $\%$ \\
\hline \multicolumn{3}{|l|}{ Metro Status } \\
\hline Metro & 7,792 & 76.5 \\
\hline Non-metro & 2,905 & 23.5 \\
\hline \multicolumn{3}{|l|}{ Education } \\
\hline LT HS & 3,348 & 29.2 \\
\hline HS & 3,871 & 36.7 \\
\hline Some College & 1,509 & 14.8 \\
\hline College & 1,940 & 19.3 \\
\hline \multicolumn{3}{|l|}{ Poverty Status } \\
\hline LT 200\% FPL & 5,480 & 49.1 \\
\hline GE 200\% FPL & 5,218 & 50.9 \\
\hline \multicolumn{3}{|l|}{ Usual Source of Care } \\
\hline Yes & 10,139 & 96.4 \\
\hline No & 370 & 3.6 \\
\hline \multicolumn{3}{|l|}{ Medicaid } \\
\hline Yes & 1,172 & 10.3 \\
\hline No & 9,526 & 89.7 \\
\hline \multicolumn{3}{|l|}{ Private Insurance } \\
\hline Yes & 7,126 & 66.7 \\
\hline No & 3,572 & 33.3 \\
\hline \multicolumn{3}{|l|}{ HMO } \\
\hline Yes & 2,796 & 27.7 \\
\hline No & 7,902 & 72.3 \\
\hline \multicolumn{3}{|l|}{ General Health } \\
\hline Excellent & 1,825 & 17.7 \\
\hline Very Good & 3,120 & 30.2 \\
\hline Good & 3,542 & 32.9 \\
\hline Fair & 1,710 & 15.1 \\
\hline Poor & 459 & 4.1 \\
\hline \multicolumn{3}{|c|}{ Functional Status (ADL) } \\
\hline Not limited & 7,866 & 76.2 \\
\hline $1-2$ & 1,999 & 17.1 \\
\hline 3 and above & 821 & 6.7 \\
\hline \multicolumn{3}{|c|}{ Functional Status (IADL) } \\
\hline Not limited & 7,878 & 76.0 \\
\hline $1-2$ & 2,172 & 18.9 \\
\hline 3 and above & 636 & 5.1 \\
\hline Continued... & & \\
\hline
\end{tabular}




\begin{tabular}{|c|c|c|}
\hline \multicolumn{3}{|c|}{$\begin{array}{c}\text { Table 1 } \\
\text { Description of Sample Characteristics } \\
\text { Medicare Current Beneficiary Survey } \\
2000-2005 \\
\end{array}$} \\
\hline & $\mathbf{N}$ & $\%$ \\
\hline \multicolumn{3}{|l|}{ Smoking } \\
\hline Current Smoker & 1,071 & 10.7 \\
\hline Past smoker & 5,140 & 48.2 \\
\hline Never Smoked & 4,470 & 41.1 \\
\hline \multicolumn{3}{|l|}{ Arthritis } \\
\hline Yes & 6,436 & 59.0 \\
\hline No & 4,262 & 41.0 \\
\hline \multicolumn{3}{|l|}{ Cancer } \\
\hline Yes & 3,567 & 32.1 \\
\hline No & 7,131 & 67.9 \\
\hline \multicolumn{3}{|l|}{ Diabetes } \\
\hline Yes & 1,965 & 18.3 \\
\hline No & 8,733 & 81.7 \\
\hline \multicolumn{3}{|l|}{ Heart Disease } \\
\hline Yes & 3,960 & 35.1 \\
\hline No & 6,738 & 64.9 \\
\hline \multicolumn{3}{|l|}{ Hypertension } \\
\hline Yes & 6,275 & 57.7 \\
\hline No & 4,423 & 42.3 \\
\hline \multicolumn{3}{|l|}{ Stroke } \\
\hline Yes & 1,158 & 9.9 \\
\hline No & 9,540 & 90.1 \\
\hline \multicolumn{3}{|l|}{ Respiratory Diseases } \\
\hline Yes & 1,420 & 13.1 \\
\hline No & 9,278 & 86.9 \\
\hline \multicolumn{3}{|l|}{ Osteoporosis } \\
\hline Yes & 2,047 & 18.4 \\
\hline No & 8,651 & 81.6 \\
\hline \multicolumn{3}{|l|}{ Any Mental Illness } \\
\hline Yes & 1,096 & 10.2 \\
\hline No & 9,602 & 89.8 \\
\hline \multicolumn{3}{|l|}{ Depression Year 1} \\
\hline Yes & 1,374 & 13 \\
\hline No & 9,324 & 88 \\
\hline \multicolumn{3}{|l|}{ Depression Year 2} \\
\hline Yes & 1,719 & 16 \\
\hline No & 8,979 & 84 \\
\hline Continued... & & \\
\hline
\end{tabular}




\begin{tabular}{ccc}
\hline \multicolumn{3}{c}{ Table 1 } \\
\multicolumn{2}{c}{$\begin{array}{c}\text { Description of Sample Characteristics } \\
\text { Medicare Current Beneficiary Survey } \\
\text { 2000 - 2005 }\end{array}$} & \\
\hline & N & $\%$ \\
\hline Depression Year 3 & & \\
& & \\
Yes & 1,789 & 16 \\
No & 8,909 & 84 \\
\hline
\end{tabular}

Note: Based on community-dwelling Medicare beneficiaries over age 65, followed for three years and had no missing body mass index values and were first included in the survey between 2000 and 2003.

Body Mass Index categories were defined as follows: underweight (BMI $<18.5 \mathrm{~kg} / \mathrm{m}^{2}$ ), normal weight (BMI 18.5 to

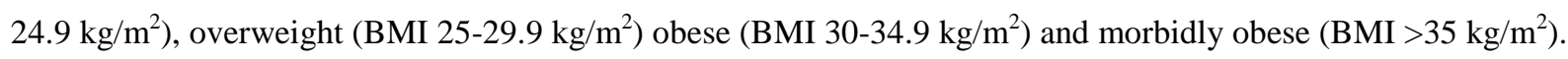
Poverty categories indicate greater than (GT) or less than (LT) 200\% of the Federal Poverty Line (FPL) in base year. 
Table 2

Sample Characteristics by BMI Change Categories

Medicare Current Beneficiary Survey 2000-2005

\begin{tabular}{|c|c|c|c|c|c|c|c|c|c|c|c|c|c|c|c|c|}
\hline & & \multicolumn{2}{|c|}{ Stayed Normal } & \multicolumn{2}{|c|}{ BMI Loss } & \multicolumn{2}{|c|}{ Stayed Overweight } & \multicolumn{2}{|c|}{ Stayed Obese } & \multicolumn{2}{|c|}{ BMI Gain } & \multicolumn{2}{|c|}{ Stayed Underweight/Other } & \multirow[b]{3}{*}{ Chi-sq } & \multirow[b]{3}{*}{ P-val } & \multirow[b]{3}{*}{ Sig } \\
\hline & & $\mathbf{N}$ & $\%$ & $\mathbf{N}$ & $\%$ & $\mathbf{N}$ & $\%$ & $\mathbf{N}$ & $\%$ & $\mathbf{N}$ & $\%$ & $\mathbf{N}$ & $\%$ & & & \\
\hline & & 3,465 & 31.3 & 982 & 9.0 & 3,330 & 31.6 & 1,696 & 16.8 & 867 & 8.2 & 358 & 3.0 & & & \\
\hline \multirow[t]{5}{*}{ Panel } & & & & & & & & & & & & & & 14.099 & 0.518 & \\
\hline & $2000-2002$ & 909 & 25.4 & 257 & 25.6 & 860 & 25.3 & 409 & 23.7 & 222 & 24.5 & 100 & 26.7 & & & \\
\hline & 2001-2003 & 914 & 26.6 & 244 & 24.1 & 862 & 26.1 & 414 & 24.1 & 218 & 25.1 & 93 & 25.7 & & & \\
\hline & 2002-2004 & 796 & 22.6 & 232 & 23.8 & 781 & 23.3 & 452 & 26.9 & 225 & 24.9 & 76 & 21.9 & & & \\
\hline & 2003-2005 & 846 & 25.4 & 249 & 26.5 & 827 & 25.4 & 421 & 25.3 & 202 & 25.5 & 89 & 25.7 & & & \\
\hline \multirow[t]{3}{*}{ Gender } & & & & & & & & & & & & & & 198.411 & 0.000 & $* * *$ \\
\hline & Women & 2,148 & 62.9 & 586 & 59.8 & 1,578 & 48.0 & 1,023 & 61.8 & 500 & 57.7 & 273 & 75.9 & & & \\
\hline & Men & 1,317 & 37.1 & 396 & 40.2 & 1,752 & 52.0 & 673 & 38.2 & 367 & 42.3 & 85 & 24.1 & & & \\
\hline \multicolumn{2}{|c|}{ Race/Ethnicity } & & & & & & & & & & & & & 80.370 & 0.000 & $* * *$ \\
\hline & $\begin{array}{l}\text { White } \\
\text { African }\end{array}$ & 2,836 & 81.5 & 767 & 78.7 & 2,751 & 82.9 & 1,346 & 79.7 & 673 & 78.1 & 287 & 80.3 & & & \\
\hline & Latina & 241 & 7.1 & 84 & 8.4 & 226 & 6.9 & 108 & 6.6 & 68 & 8.2 & 23 & 5.8 & & & \\
\hline & Other & 170 & 5.5 & 32 & 3.2 & 100 & 3.0 & 44 & 2.7 & 38 & 4.7 & 15 & 5.7 & & & \\
\hline \multirow[t]{5}{*}{ Age } & & & & & & & & & & & & & & 330.086 & 0.000 & $* * *$ \\
\hline & $65-69$ & 649 & 25.0 & 224 & 29.2 & 870 & 33.1 & 536 & 38.3 & 225 & 32.1 & 46 & 19.2 & & & \\
\hline & $70-74$ & 640 & 20.4 & 196 & 21.8 & 765 & 23.7 & 488 & 28.2 & 190 & 23.5 & 47 & 16.3 & & & \\
\hline & $75-79$ & 766 & 23.8 & 215 & 22.7 & 743 & 22.7 & 349 & 20.1 & 196 & 22.8 & 59 & 19.0 & & & \\
\hline & $85+$ & 1,410 & 30.8 & 347 & 26.3 & 952 & 20.6 & 323 & 13.4 & 256 & 21.5 & 206 & 45.6 & & & \\
\hline \multicolumn{2}{|c|}{ Marital Status } & & & & & & & & & & & & & 109.011 & 0.000 & $* * *$ \\
\hline \multicolumn{2}{|c|}{ Married } & 1,761 & 53.3 & 508 & 54.2 & 2,029 & 63.0 & 957 & 57.5 & 449 & 54.1 & 125 & 39.2 & & & \\
\hline \multicolumn{2}{|c|}{ Widowed } & 1,339 & 35.1 & 372 & 34.0 & 999 & 27.5 & 553 & 31.1 & 315 & 33.3 & 191 & 47.9 & & & \\
\hline \multicolumn{2}{|c|}{ Div/Separated } & 256 & 8.3 & 82 & 9.7 & 224 & 7.2 & 131 & 8.2 & 72 & 8.8 & 25 & 7.6 & & & \\
\hline \multicolumn{2}{|c|}{ Never Married } & 109 & 3.4 & 20 & 2.1 & 77 & 2.3 & 55 & 3.2 & 31 & 3.9 & 17 & 5.3 & & & \\
\hline
\end{tabular}


Table 2

Sample Characteristics by BMI Change Categories

Medicare Current Beneficiary Survey 2000-2005

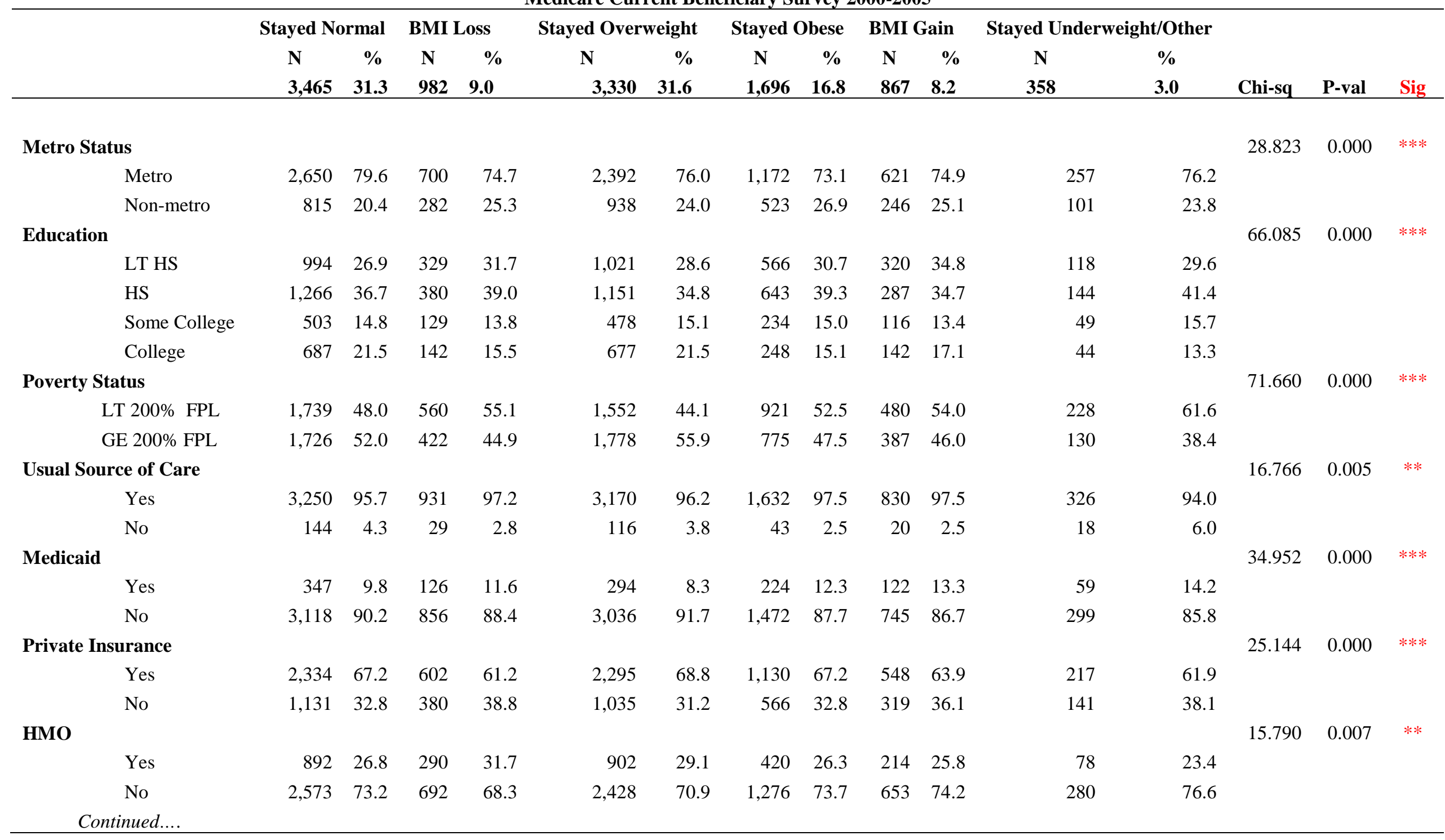


Table 2

Sample Characteristics by BMI Change Categories

Medicare Current Beneficiary Survey 2000-2005

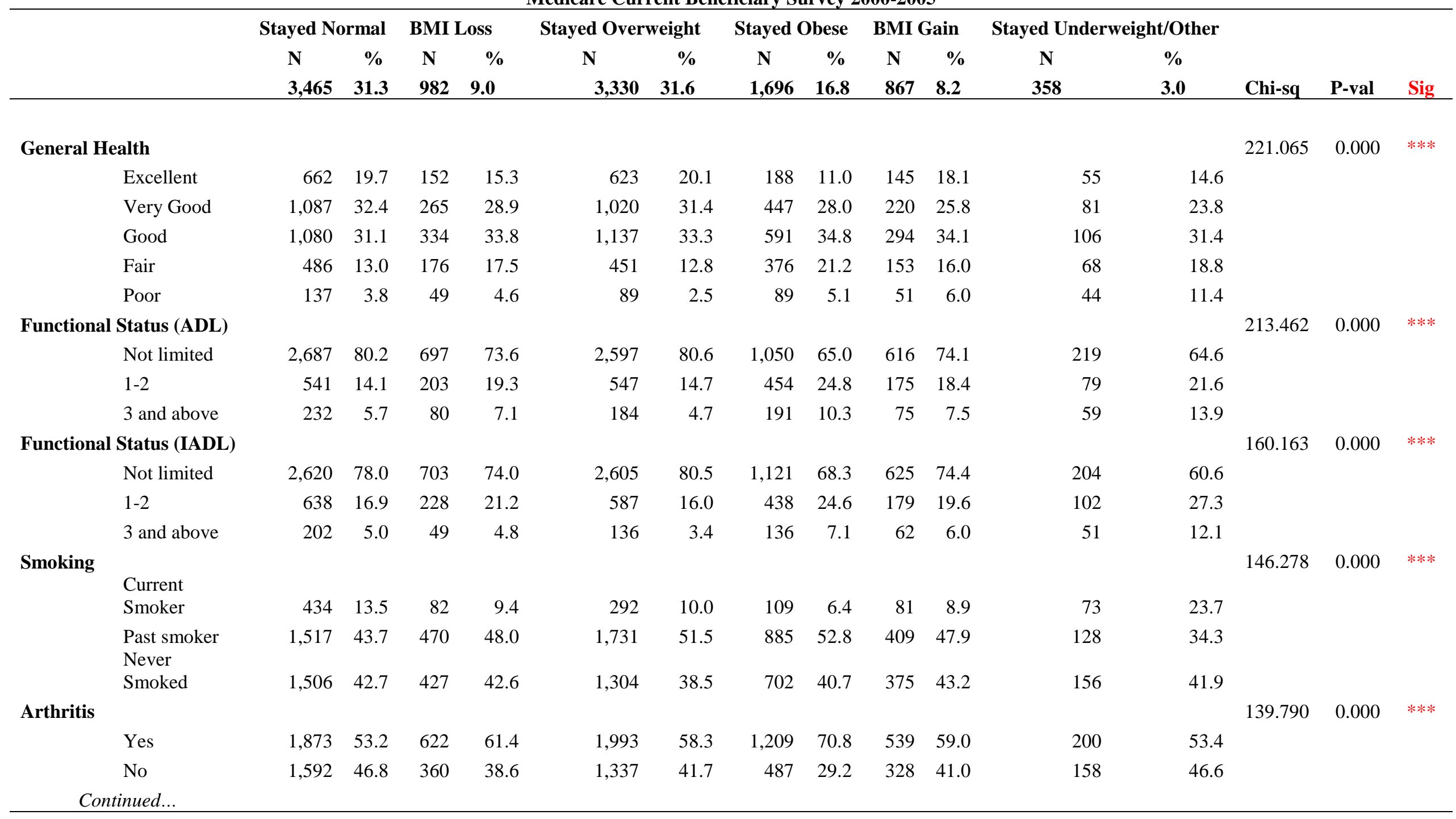


Table 2

Sample Characteristics by BMI Change Categories

Medicare Current Beneficiary Survey 2000-2005

\begin{tabular}{|c|c|c|c|c|c|c|c|c|c|c|c|c|c|c|c|c|}
\hline & & \multicolumn{2}{|c|}{ Stayed Normal } & \multicolumn{2}{|c|}{ BMI Loss } & \multicolumn{2}{|c|}{ Stayed Overweight } & \multicolumn{2}{|c|}{ Stayed Obese } & \multicolumn{2}{|c|}{ BMI Gain } & \multicolumn{2}{|c|}{ Stayed Underweight/Other } & \multirow[b]{3}{*}{ Chi-sq } & \multirow[b]{3}{*}{ P-val } & \multirow[b]{3}{*}{ Sig } \\
\hline & & $\mathbf{N}$ & $\%$ & $\mathbf{N}$ & $\%$ & $\mathbf{N}$ & $\%$ & $\mathbf{N}$ & $\%$ & $\mathbf{N}$ & $\%$ & $\mathbf{N}$ & $\%$ & & & \\
\hline & & 3,465 & 31.3 & 982 & 9.0 & 3,330 & 31.6 & 1,696 & 16.8 & 867 & 8.2 & 358 & 3.0 & & & \\
\hline \multirow[t]{3}{*}{ Cancer } & & & & & & & & & & & & & & 5.423 & 0.367 & \\
\hline & Yes & 1,154 & 32.3 & 315 & 30.3 & 1,162 & 33.4 & 542 & 30.5 & 275 & 31.1 & 119 & 34.0 & & & \\
\hline & No & 2,311 & 67.7 & 667 & 69.7 & 2,168 & 66.6 & 1,154 & 69.5 & 592 & 68.9 & 239 & 66.0 & & & \\
\hline \multirow[t]{3}{*}{ Diabetes } & & & & & & & & & & & & & & 428.515 & 0.000 & $* * *$ \\
\hline & Yes & 383 & 10.8 & 225 & 22.2 & 579 & 16.7 & 584 & 34.5 & 179 & 20.3 & 15 & 4.5 & & & \\
\hline & No & 3,082 & 89.2 & 757 & 77.8 & 2,751 & 83.3 & 1,112 & 65.5 & 688 & 79.7 & 343 & 95.5 & & & \\
\hline \multicolumn{2}{|c|}{ Heart Disease } & & & & & & & & & & & & & 13.187 & 0.022 & $*$ \\
\hline & Yes & 1,204 & 32.8 & 369 & 35.7 & 1,248 & 35.6 & 665 & 37.6 & 344 & 36.6 & 130 & 34.5 & & & \\
\hline & No & 2,261 & 67.2 & 613 & 64.3 & 2,082 & 64.4 & 1,031 & 62.4 & 523 & 63.4 & 228 & 65.5 & & & \\
\hline \multicolumn{2}{|c|}{ Hypertension } & & & & & & & & & & & & & 272.208 & 0.000 & $* * *$ \\
\hline & Yes & 1,745 & 49.0 & 641 & 64.7 & 1,939 & 56.8 & 1,221 & 71.1 & 561 & 64.0 & 168 & 45.6 & & & \\
\hline & No & 1,720 & 51.0 & 341 & 35.3 & 1,391 & 43.2 & 475 & 28.9 & 306 & 36.0 & 190 & 54.4 & & & \\
\hline \multirow[t]{3}{*}{ Stroke } & & & & & & & & & & & & & & 11.505 & 0.042 & $*$ \\
\hline & Yes & 395 & 10.6 & 123 & 11.7 & 326 & 9.0 & 166 & 8.7 & 101 & 10.6 & 47 & 11.7 & & & \\
\hline & No & 3,070 & 89.4 & 859 & 88.3 & 3,004 & 91.0 & 1,530 & 91.3 & 766 & 89.4 & 311 & 88.3 & & & \\
\hline \multicolumn{3}{|c|}{ Respiratory Diseases } & & & & & & & & & & & & 42.533 & 0.000 & $* * *$ \\
\hline & Yes & 416 & 12.1 & 113 & 11.8 & 409 & 11.9 & 272 & 15.8 & 130 & 14.2 & 80 & 22.9 & & & \\
\hline & No & 3,049 & 87.9 & 869 & 88.2 & 2,921 & 88.1 & 1,424 & 84.2 & 737 & 85.8 & 278 & 77.1 & & & \\
\hline \multicolumn{2}{|c|}{ Osteoporosis } & & & & & & & & & & & & & 151.547 & 0.000 & $* * *$ \\
\hline & Yes & 813 & 22.9 & 169 & 16.2 & 491 & 14.3 & 289 & 16.7 & 152 & 16.0 & 133 & 37.0 & & & \\
\hline & No & 2,652 & 77.1 & 813 & 83.8 & 2,839 & 85.7 & 1,407 & 83.3 & 715 & 84.0 & 225 & 63.0 & & & \\
\hline \multicolumn{2}{|c|}{ Any Mental Illness } & & & & & & & & & & & & & 26.051 & 0.000 & $* * *$ \\
\hline & Yes & 336 & 9.5 & 101 & 10.0 & 290 & 8.9 & 223 & 12.9 & 103 & 12.3 & 43 & 12.9 & & & \\
\hline & No & 3,129 & 90.5 & 881 & 90.0 & 3,040 & 91.1 & 1,473 & 87.1 & 764 & 87.7 & 315 & 87.1 & & & \\
\hline
\end{tabular}




\begin{tabular}{|c|c|c|c|c|c|c|c|c|c|c|c|c|c|c|c|}
\hline \multicolumn{16}{|c|}{$\begin{array}{c}\text { Table } 2 \\
\text { Sample Characteristics by BMI Change Categories } \\
\text { Medicare Current Beneficiary Survey 2000-2005 }\end{array}$} \\
\hline & \multicolumn{2}{|c|}{ Stayed Normal } & \multicolumn{2}{|c|}{ BMI Loss } & \multicolumn{2}{|c|}{ Stayed Overweight } & \multicolumn{2}{|c|}{ Stayed Obese } & \multicolumn{2}{|c|}{ BMI Gain } & \multicolumn{2}{|c|}{ Stayed Underweight/Other } & \multirow[b]{3}{*}{ Chi-sq } & \multirow[b]{3}{*}{ P-val } & \multirow[b]{3}{*}{ Sig } \\
\hline & $\mathbf{N}$ & $\%$ & $\mathbf{N}$ & $\%$ & $\mathbf{N}$ & $\%$ & $\mathbf{N}$ & $\%$ & $\mathbf{N}$ & $\%$ & $\mathbf{N}$ & $\%$ & & & \\
\hline & 3,465 & 31.3 & 982 & 9.0 & 3,330 & 31.6 & 1,696 & 16.8 & 867 & 8.2 & 358 & 3.0 & & & \\
\hline Yes & 430 & 12.1 & 129 & 12.6 & 359 & 10.4 & 247 & 14.1 & 144 & 16.8 & 65 & 18.5 & & & \\
\hline No & 3,035 & 87.9 & 853 & 87.4 & 2,971 & 89.6 & 1,449 & 85.9 & 723 & 83.2 & 293 & 81.5 & & & \\
\hline Depression Year 2 & & & & & & & & & & & & & 37.490 & 0.000 & $* * *$ \\
\hline Yes & 523 & 14.7 & 192 & 18.7 & 451 & 13.2 & 313 & 18.1 & 155 & 17.1 & 85 & 22.6 & & & \\
\hline No & 2,942 & 85.3 & 790 & 81.3 & 2,879 & 86.8 & 1,383 & 81.9 & 712 & 82.9 & 273 & 77.4 & & & \\
\hline Depression Year 3 & & & & & & & & & & & & & 29.552 & 0.000 & $* * *$ \\
\hline No & 2,898 & 84.1 & 799 & 81.8 & 2,851 & 86.3 & 1,383 & 82.3 & 702 & 82.2 & 276 & 77.4 & & & \\
\hline
\end{tabular}

Note: Based on community-dwelling Medicare beneficiaries over age 65, followed for three years and had no missing body mass index values and were first included in the survey between 2000 and 2003.

Body mass index change categories were defined as follows: Stayed Normal- individuals with a normal BMI (18.5-24.9 kg/m²) at baseline and follow-up; BMI gain- individuals with normal BMI ( $18.5-24.9 \mathrm{~kg} / \mathrm{m}^{2}$ ) or overweight BMI (25-29.9 kg/m²) at baseline who moved to a higher BMI category at follow up ( i.e. overweight, obese, morbidly obese); BMI loss- individuals with overweight BMI (25-29.9 kg/m²) or obese BMI (>30 kg/m²) at baseline who moved to a lower BMI category at follow up ( i.e. overweight or normal); Stayed Overweight- Individuals with overweight BMI ( $25-29.9$ kg/m²) at baseline and follow-up; Stayed Obese- Individuals with obese BMI ( $>30 \mathrm{~kg} / \mathrm{m}^{2}$ ) at baseline and follow-up; and Stayed Underweight/Other- includes individuals with underweight BMI $\left(<18.5 \mathrm{~kg} / \mathrm{m}^{2}\right)$ at base line and follow-up as well as those with weight changes not defined by the categories above.

Chisq $=$ Chi square test for independence; $* * *=\mathrm{p}<0.001 ; * * 0.001 \leq \mathrm{p} \leq 0.01 ; * 0.01 \leq \mathrm{p} \leq 0.05$ 


\section{Subgroup differences in BMI change categories: Bivariate Analysis}

The bivariate analysis between groups of BMI change categories showed significant differences between groups for all independent variables tested with the exception of cancer history. Individuals with or without a history of cancer were no more likely to belong to any BMI change category. Results showed that 31\% of the study sample maintained a normal BMI from baseline through follow up, 9\% experienced BMI loss, 31.6 \% stayed overweight, $16.8 \%$ stayed obese, $8.2 \%$ experienced BMI gain, and the remaining 3\% either stayed under weight or had some other weight change undefined by the previous categories (Table 2).

\section{Subgroup differences in BMI change Categories: Multinomial Logistic Regression}

Table 3 presents the multinomial logistic regression on BMI change categories and selected independent variables with stayed normal as the BMI reference category for the dependent variable.

Predisposing - Compared to males, females were significantly less likely to belong to all BMI categories, with the exception of stayed underweight/other, for which females were $71 \%$ more likely to have stayed underweight/other [AOR 1.71, 95\% CI 1.20-2.42]. Compared to their white counterparts, individuals of African American race were more likely to experience BMI loss or to have stayed obese [AOR 1.47, 95\% CI 1.10-1.95; AOR 1.67 95\% CI 1.33-2.11]. Compared to their white counterparts, individuals of other race, were less likely to belong to BMI loss, stayed overweight and stayed obese categories [AOR 0.53, 95\% CI 0.35-0.81; AOR 0.50 95\% CI 0.38-0.67; AOR 0.42 95\% CI 0.29-0.62]. Compared to individuals ages 65 -69 years, those ages 70-74 were less likely to stay overweight or obese [AOR $\mathbf{0 . 8 2}, \mathbf{9 5 \%}$ CI 0.700.95; AOR 0.78 95\% CI 0.66-0.91]. In addition to stayed overweight and obese, individuals ages 75-79 were also less likely to belong to BMI loss or BMI gain [AOR 0.72, 95\% CI 0.55- 
0.93; AOR 0.63 95\% CI 0.48-0.83]. Finally, compared to individuals ages 65-69, those 80 and older were less likely to belong to all BMI categories, except for stayed underweight/other, for which the risk was nearly 90\% higher [AOR 1.89, 95\% CI 1.33-2.67]. Individuals who were never married were less likely to stay overweight and twice as likely to stay underweight/other as compared to those were married [AOR 0.63, 95\% CI 0.47-0.85; AOR 2.01 95\% CI 1.093.71]. Individuals living in non-metro areas were more likely to belong to BMI loss, stayed overweight, stayed obese and BMI gain [AOR 1.30, 95\% CI 1.05-1.60; AOR 1.17 95\% CI 1.03-1.34; AOR 1.32 95\% CI 1.14-1.51; AOR 1.25 95\% CI 1.00-1.57].

Enabling Variables- Education had significant effects on the odds of belonging to most BMI categories. Compared to those with a college education, individuals with less than high school education were more likely to belong to all BMI categories except for stayed underweight. Individuals with a high school education were 38\% more likely to experience BMI loss and 53\% more likely to stay obese than those with a college education [AOR 1.38 95\% CI 1.07-1.79; AOR 1.53 95\% CI 1.22-1.94]. Compared to those with a college education, those with some college education were $46 \%$ more likely to have stayed obese [AOR 1.46, 95\% CI 1.11-1.91]. No significant results were found when comparing poverty categories less than 200\% FPL and greater than 200\% FPL. Although, Medicaid status also revealed non-significant findings, individuals without private health insurance, were more likely to experience BMI loss [AOR 1.21, 95\% CI 1.01-1.44].

Lifestyle/Risk Variables- Compared to those reporting excellent health, those reporting very good health were 55\% more likely to stay obese [AOR 1.55, 95\% CI 1.24-1.92]. Individuals reporting good health were 33\% and 83\% more likely to have BMI loss or stay obese [AOR 1.33, 95\% CI 1.06-1.66; AOR 1.83, 95\% CI 1.47-2.28]. Individuals reporting poor 
health were less likely to stay overweight, and were the only health group to be three times more likely to stay underweight/other [AOR 0.61, 95\% CI 0.44-0.85; AOR 2.97, 95\% CI 1.81-4.88]. Compared to those who never smoked, current smokers were less likely to belong to all BMI categories with the exception of stayed underweight, for which current smokers were more than twice as likely to stay underweight [AOR 2.46, 95\% CI 1.73-3.51].

Need/Competing Demand- Results for history of chronic disease were not reported since the literature has extensively shown the association of these conditions with overweight and obesity. However, results for functional status are presented. Compared to those reporting no functional limitations, those reporting 1-2 ADL limitations were more likely to experience BMI loss, stay overweight, stay obese, or experience BMI gain [AOR 1.47, 95\% CI 1.22-1.78; AOR 1.29 95\% CI 1.09-1.53; AOR 2.58 95\% CI 2.11-3.15; AOR 1.53 95\%CI 1.23-1.90]. As expected, individuals reporting 3-6 functional limitations were more likely t o stay obese, experience BMI gain or stay overweight/other. Compared to those with no limitations, individuals reporting 3-6 limitations were nearly 3 times as likely to stay obese, have a $44 \%$ increased risk of BMI gain, and have a 62\% increased risk of staying underweight/other [AOR 2.87, 95\% CI 2.23-3.69; AOR 1.44 95\% CI 1.04-1.99; AOR 1.62 95\% CI 1.11-2.36]. 


\begin{tabular}{|c|c|c|c|c|c|c|c|c|c|c|c|c|c|c|c|}
\hline \multicolumn{16}{|c|}{$\begin{array}{c}\text { Table } 3 \\
\text { Adjusted Odds Ratios and 95\% Confidence Intervals from } \\
\text { Multinomial Logistic Regression on Body Mass Index Change Categories } \\
\text { Medicare Current Beneficiary Survey 2000-2005 } \\
\text { Reference Group for Body Mass Index Change Categories: Stayed Normal }\end{array}$} \\
\hline & \multirow[b]{2}{*}{ AOR } & \multirow{2}{*}{$\begin{array}{l}\text { BMI } \\
\text { Loss } \\
95 \% \text { CI } \\
\end{array}$} & \multirow[b]{2}{*}{ Sig } & \multicolumn{3}{|c|}{$\begin{array}{c}\text { Stayed } \\
\text { Overweight }\end{array}$} & \multicolumn{3}{|c|}{$\begin{array}{l}\text { Stayed } \\
\text { Obese }\end{array}$} & \multicolumn{3}{|c|}{$\begin{array}{l}\text { BMI } \\
\text { Gain }\end{array}$} & \multicolumn{3}{|c|}{$\begin{array}{c}\text { Stayed Underweight/ } \\
\text { Other }\end{array}$} \\
\hline & & & & AOR & $95 \%$ CI & Sig & AOR & $95 \%$ CI & Sig & AOR & $95 \%$ CI & Sig & AOR & $95 \%$ CI & Sig \\
\hline \multicolumn{16}{|l|}{ Panel } \\
\hline 2001-03 & 0.90 & {$[0.73,1.11]$} & & 0.98 & {$[0.84,1.14]$} & & 0.94 & {$[0.77,1.15]$} & & 0.97 & {$[0.76,1.22]$} & & 0.92 & {$[0.68,1.25]$} & \\
\hline 2002-04 & 1.07 & {$[0.86,1.34]$} & & 1.05 & {$[0.90,1.22]$} & & 1.31 & {$[1.06,1.62]$} & * & 1.15 & {$[0.91,1.47]$} & & 0.95 & {$[0.67,1.35]$} & \\
\hline 2003-05 & 1.05 & {$[0.84,1.32]$} & & 1.00 & {$[0.86,1.17]$} & & 1.08 & {$[0.88,1.32]$} & & 1.03 & {$[0.82,1.29]$} & & 0.94 & {$[0.67,1.32]$} & \\
\hline \multicolumn{16}{|l|}{ Gender } \\
\hline Female & 0.81 & {$[0.68,0.97]$} & $*$ & 0.55 & {$[0.48,0.62]$} & $* * *$ & 0.85 & {$[0.72,1.00]$} & & 0.73 & {$[0.60,0.90]$} & $* *$ & 1.71 & {$[1.20,2.42]$} & $* *$ \\
\hline \multicolumn{16}{|c|}{ Race/Ethnicity } \\
\hline AA & 1.47 & {$[1.10,1.95]$} & ** & 1.25 & {$[0.99,1.58]$} & & 1.67 & {$[1.33,2.11]$} & $* * *$ & 1.32 & {$[0.94,1.85]$} & & 1.18 & {$[0.74,1.87]$} & \\
\hline Latino & 1.00 & {$[0.74,1.35]$} & & 0.93 & {$[0.73,1.19]$} & & 0.79 & {$[0.58,1.10]$} & & 0.98 & {$[0.72,1.32]$} & & 0.76 & {$[0.49,1.19]$} & \\
\hline Other race & 0.53 & {$[0.35,0.81]$} & $* *$ & 0.50 & {$[0.38,0.67]$} & $* * *$ & 0.42 & {$[0.29,0.62]$} & $* * *$ & 0.76 & {$[0.52,1.12]$} & & 1.10 & {$[0.60,2.02]$} & \\
\hline \multicolumn{16}{|c|}{ Age Groups } \\
\hline $70-74$ & 0.86 & {$[0.67,1.10]$} & & 0.82 & {$[0.70,0.95]$} & $* *$ & 0.78 & {$[0.66,0.91]$} & $* *$ & 0.83 & {$[0.65,1.06]$} & & 1.13 & {$[0.72,1.79]$} & \\
\hline $75-79$ & 0.72 & {$[0.55,0.93]$} & $*$ & 0.65 & {$[0.55,0.76]$} & $* * *$ & 0.40 & {$[0.33,0.48]$} & $* * *$ & 0.63 & {$[0.48,0.83]$} & $* * *$ & 1.12 & {$[0.73,1.72]$} & \\
\hline $80+$ & 0.57 & {$[0.45,0.73]$} & $* * *$ & 0.44 & {$[0.37,0.51]$} & $* * *$ & 0.16 & {$[0.13,0.20]$} & $* * *$ & 0.40 & {$[0.31,0.52]$} & $* * *$ & 1.89 & {$[1.33,2.67]$} & $* * *$ \\
\hline \multicolumn{16}{|c|}{ Marital Status } \\
\hline Widowed & 1.02 & {$[0.84,1.23]$} & & 0.98 & {$[0.85,1.12]$} & & 1.04 & {$[0.89,1.22]$} & & 1.11 & {$[0.90,1.37]$} & & 1.17 & {$[0.85,1.62]$} & \\
\hline Div/Sep & 1.06 & {$[0.78,1.44]$} & & 0.80 & {$[0.63,1.02]$} & & 0.81 & {$[0.61,1.08]$} & & 1.01 & {$[0.73,1.38]$} & & 1.04 & {$[0.61,1.76]$} & \\
\hline Other & 0.61 & {$[0.35,1.05]$} & & 0.63 & {$[0.47,0.85]$} & $* *$ & 0.97 & {$[0.67,1.39]$} & & 1.20 & {$[0.71,2.03]$} & & 2.01 & {$[1.09,3.71]$} & $*$ \\
\hline \multicolumn{16}{|c|}{ Metro Status } \\
\hline Not Metro & 1.30 & {$[1.05,1.60]$} & $*$ & 1.17 & {$[1.03,1.34]$} & $*$ & 1.32 & {$[1.14,1.51]$} & $* * *$ & 1.25 & {$[1.00,1.57]$} & $*$ & 1.22 & {$[0.96,1.55]$} & \\
\hline Continue & & & & & & & & & & & & & & & \\
\hline
\end{tabular}




\begin{tabular}{|c|c|c|c|c|c|c|c|c|c|c|c|c|c|c|c|}
\hline \multicolumn{16}{|c|}{$\begin{array}{c}\text { Table } 3 \\
\text { Adjusted Odds Ratios and 95\% Confidence Intervals from } \\
\text { Multinomial Logistic Regression on Body Mass Index Change Categories } \\
\text { Medicare Current Beneficiary Survey 2000-2005 } \\
\text { Reference Group for Body Mass Index Change Categories: Stayed Normal }\end{array}$} \\
\hline & \multirow[b]{2}{*}{ AOR } & \multirow{2}{*}{$\begin{array}{l}\text { BMI } \\
\text { Loss } \\
95 \% \text { CI } \\
\end{array}$} & \multirow[b]{2}{*}{ Sig } & \multicolumn{3}{|c|}{$\begin{array}{c}\text { Stayed } \\
\text { Overweight }\end{array}$} & \multicolumn{3}{|c|}{$\begin{array}{c}\text { Stayed } \\
\text { Obese }\end{array}$} & \multicolumn{3}{|c|}{$\begin{array}{l}\text { BMI } \\
\text { Gain }\end{array}$} & \multicolumn{3}{|c|}{$\begin{array}{l}\text { Stayed Underweight/ } \\
\text { Other }\end{array}$} \\
\hline & & & & AOR & $95 \%$ CI & Sig & AOR & $95 \%$ CI & Sig & AOR & $95 \%$ CI & Sig & AOR & $95 \%$ CI & Sig \\
\hline \multicolumn{16}{|l|}{ Education } \\
\hline LT HS & 1.36 & {$[1.02,1.81]$} & $*$ & 1.31 & {$[1.09,1.57]$} & $* *$ & 1.55 & {$[1.20,2.02]$} & $* * *$ & 1.50 & [1.14,1.99] & $* *$ & 1.02 & {$[0.63,1.66]$} & \\
\hline HS & 1.38 & {$[1.07,1.79]$} & $*$ & 1.11 & {$[0.96,1.29]$} & & 1.53 & {$[1.22,1.94]$} & $* * *$ & 1.18 & {$[0.91,1.55]$} & & 1.30 & {$[0.84,2.02]$} & \\
\hline $\begin{array}{l}\text { some } \\
\text { college }\end{array}$ & 1.22 & {$[0.89,1.67]$} & & 1.10 & {$[0.92,1.32]$} & & 1.46 & {$[1.11,1.91]$} & $* *$ & 1.12 & {$[0.84,1.50]$} & & 1.52 & {$[0.90,2.55]$} & \\
\hline \multicolumn{16}{|l|}{ Poverty } \\
\hline LT 200\% & 1.17 & {$[0.96,1.43]$} & & 0.96 & {$[0.85,1.10]$} & & 1.13 & {$[0.96,1.33]$} & & 1.14 & {$[0.94,1.38]$} & & 1.28 & {$[0.97,1.68]$} & \\
\hline \multicolumn{16}{|l|}{ Medicaid } \\
\hline Medicare & 0.90 & {$[0.67,1.21]$} & & 1.01 & {$[0.82,1.24]$} & & 1.06 & {$[0.82,1.38]$} & & 1.10 & {$[0.80,1.51]$} & & 0.95 & {$[0.63,1.44]$} & \\
\hline \multicolumn{16}{|c|}{ Private Insurance } \\
\hline No Pvt.Ins & 1.21 & {$[1.01,1.44]$} & * & 0.94 & {$[0.83,1.06]$} & & 0.87 & {$[0.75,1.02]$} & & 0.99 & {$[0.82,1.19]$} & & 1.11 & {$[0.85,1.46]$} & \\
\hline \multicolumn{16}{|c|}{ Health Status } \\
\hline Very good & 1.15 & {$[0.91,1.46]$} & & 0.99 & {$[0.85,1.14]$} & & 1.55 & {$[1.24,1.92]$} & $* * *$ & 0.89 & {$[0.70,1.14]$} & & 0.96 & {$[0.65,1.40]$} & \\
\hline Good & 1.33 & {$[1.06,1.66]$} & $*$ & 1.10 & {$[0.94,1.28]$} & & 1.83 & {$[1.47,2.28]$} & $* * *$ & 1.16 & {$[0.91,1.48]$} & & 1.19 & {$[0.83,1.70]$} & \\
\hline Fair & 1.49 & {$[1.09,2.02]$} & * & 1.01 & {$[0.82,1.24]$} & & 2.19 & {$[1.66,2.88]$} & $* * *$ & 1.16 & {$[0.88,1.52]$} & & 1.49 & {$[1.00,2.23]$} & \\
\hline Poor & 1.20 & {$[0.74,1.93]$} & & 0.61 & {$[0.44,0.85]$} & $* *$ & 1.38 & {$[0.92,2.09]$} & & 1.32 & {$[0.84,2.06]$} & & 2.97 & {$[1.81,4.88]$} & $* * *$ \\
\hline \multicolumn{16}{|c|}{ Functional Status } \\
\hline 1-2 ADL & 1.47 & {$[1.22,1.78]$} & $* * *$ & 1.29 & {$[1.09,1.53]$} & $* *$ & 2.58 & {$[2.11,3.15]$} & $* * *$ & 1.53 & {$[1.23,1.90]$} & $* * *$ & 1.30 & {$[0.96,1.77]$} & \\
\hline 3-6 ADL & 1.34 & {$[0.96,1.85]$} & & 1.18 & {$[0.93,1.50]$} & & 2.87 & {$[2.23,3.69]$} & $* * *$ & 1.44 & {$[1.04,1.99]$} & $*$ & 1.62 & {$[1.11,2.36]$} & $*$ \\
\hline \multicolumn{16}{|l|}{ Smoking } \\
\hline Current & 0.54 & {$[0.39,0.74]$} & $* * *$ & 0.56 & {$[0.45,0.68]$} & $* * *$ & 0.32 & {$[0.25,0.41]$} & $* * *$ & 0.46 & {$[0.35,0.62]$} & $* * *$ & 2.46 & {$[1.73,3.51]$} & $* * *$ \\
\hline Past & 1.02 & {$[0.86,1.22]$} & & 1.01 & {$[0.90,1.14]$} & & 1.13 & {$[0.97,1.31]$} & & 0.97 & {$[0.81,1.16]$} & & 1.03 & {$[0.79,1.36]$} & \\
\hline
\end{tabular}


Note: Based on community-dwelling Medicare beneficiaries over age 65, followed for three years and had no missing body mass index values and were first included in the survey between 2000 and 2003.

Body mass index change categories were defined as follows: Stayed Normal- individuals with a normal BMI (18.5-24. 9 kg/m²) at baseline and follow-up; BMI gain- individuals with normal BMI ( $18.5-24.9 \mathrm{~kg} / \mathrm{m}^{2}$ ) or overweight BMI (25-29.9 kg/m²) at baseline who moved to a higher BMI category at follow up ( i.e. overweight, obese, morbidly obese); BMI loss- individuals with overweight BMI (25-29.9 kg/m²) or obese BMI (>30 kg/m²) at baseline who moved to a lower BMI category at follow up ( i.e. overweight or normal); Stayed Overweight- Individuals with overweight BMI ( 25-29.9 kg/m²) at baseline and follow-up; Stayed Obese- Individuals with obese BMI ( >30 kg/m²) at baseline and follow-up; and Stayed Underweight/Other- includes individuals with underweight BMI $\left(<18.5 \mathrm{~kg} / \mathrm{m}^{2}\right)$ at base line and follow-up as well as those with weight changes not defined by the categories above.

*** $\mathrm{p}<0.001 ; * * 0.001<\mathrm{p}<0.01 ; * 0.01<\mathrm{p}<0.05$ 


\begin{tabular}{|c|c|c|c|c|c|c|}
\hline \multicolumn{7}{|c|}{$\begin{array}{c}\text { Table } 4 \\
\text { 3-Year Trend in Expenditures (Constant \$ 2005) and } \\
\text { Change in Body Mass Index Categories } \\
\text { Mean and Standard Errors } \\
\text { Medicare Current Beneficiary Survey, 2000 - } 2005 \\
\end{array}$} \\
\hline & \multicolumn{3}{|c|}{ Mean Expenditures } & \multicolumn{3}{|c|}{$\%$ Change } \\
\hline & Year 1 & Year 2 & Year 3 & Year 2-1 & Year 3-2 & Year 3-1 \\
\hline \multicolumn{7}{|l|}{ Total } \\
\hline Stayed Normal & $\begin{array}{r}8,562 \\
(257.8)\end{array}$ & $\begin{array}{r}8,892 \\
(272.9)\end{array}$ & $\begin{array}{l}10,685 \\
(336.0)\end{array}$ & $4 \%$ & $20 \%$ & $25 \%$ \\
\hline BMI loss & $\begin{array}{r}8,602 \\
(566.2)\end{array}$ & $\begin{array}{r}12,970 \\
(599.3)\end{array}$ & $\begin{array}{r}12,661 \\
(649.2)\end{array}$ & $51 \%$ & $-2 \%$ & $47 \%$ \\
\hline Stayed Overweight & $\begin{array}{r}8,033 \\
(236.0)\end{array}$ & $\begin{array}{r}8,511 \\
(227.6)\end{array}$ & $\begin{array}{l}10,522 \\
(368.4)\end{array}$ & $6 \%$ & $24 \%$ & $31 \%$ \\
\hline Stayed Obese & $\begin{array}{r}9,903 \\
(445.3)\end{array}$ & $\begin{array}{r}11,346 \\
(544.5)\end{array}$ & $\begin{array}{l}12,835 \\
(546.4)\end{array}$ & $15 \%$ & $13 \%$ & $30 \%$ \\
\hline BMI gain & $\begin{array}{c}10,907 \\
(610.7)\end{array}$ & $\begin{array}{r}9,710 \\
(618.0)\end{array}$ & $\begin{array}{r}13,693 \\
(1,410.1)\end{array}$ & $-11 \%$ & $41 \%$ & $26 \%$ \\
\hline Stayed underweight/other & 9,142 & 10,515 & 14,111 & $15 \%$ & $34 \%$ & $54 \%$ \\
\hline Inpatient & $(804.5)$ & (853.9) & $(1,181.9)$ & & & \\
\hline Stayed Normal & $\begin{array}{r}2,670 \\
(1,70.5)\end{array}$ & $\begin{array}{r}2,410 \\
(153.20\end{array}$ & $\begin{array}{r}3,263 \\
(208.8)\end{array}$ & $-10 \%$ & $35 \%$ & $22 \%$ \\
\hline BMI loss & $\begin{array}{r}2,562 \\
(357.7)\end{array}$ & $\begin{array}{r}4,800 \\
(356.0)\end{array}$ & $\begin{array}{r}3,787 \\
(297.6)\end{array}$ & $87 \%$ & $-21 \%$ & $48 \%$ \\
\hline Stayed Overweight & $\begin{array}{r}2,216 \\
(130.1)\end{array}$ & $\begin{array}{r}2,272 \\
(132.80\end{array}$ & $\begin{array}{r}2,935 \\
(174.0)\end{array}$ & $3 \%$ & $29 \%$ & $32 \%$ \\
\hline Stayed Obese & $\begin{array}{r}2,678 \\
(255.6)\end{array}$ & $\begin{array}{r}3,308 \\
(368.00\end{array}$ & $\begin{array}{r}3,876 \\
(323.0)\end{array}$ & $24 \%$ & $17 \%$ & $45 \%$ \\
\hline BMI gain & $\begin{array}{r}3,244 \\
(339.0)\end{array}$ & $\begin{array}{r}2,208 \\
(302.0)\end{array}$ & $\begin{array}{r}4,313 \\
(737.7)\end{array}$ & $-32 \%$ & $95 \%$ & $33 \%$ \\
\hline Stayed underweight/other & $\begin{array}{r}3,208 \\
(478.5)\end{array}$ & $\begin{array}{r}3,149 \\
(416.20\end{array}$ & $\begin{array}{r}4,674 \\
(685.3)\end{array}$ & $-2 \%$ & $48 \%$ & $46 \%$ \\
\hline Outpatient & & & & & & \\
\hline Stayed Normal & $\begin{array}{r}933 \\
(53.4)\end{array}$ & $\begin{array}{r}972 \\
(57.9)\end{array}$ & $\begin{array}{r}988 \\
(49.9)\end{array}$ & $4 \%$ & $2 \%$ & $6 \%$ \\
\hline BMI loss & $\begin{array}{r}888 \\
(88.2)\end{array}$ & $\begin{array}{r}1,128 \\
(102.6)\end{array}$ & $\begin{array}{r}1373 \\
(148.6)\end{array}$ & $27 \%$ & $22 \%$ & $55 \%$ \\
\hline Stayed Overweight & $\begin{array}{l}1,025 \\
(66.2)\end{array}$ & $\begin{array}{r}923 \\
(50.00\end{array}$ & $\begin{array}{r}1180 \\
(87.9)\end{array}$ & $-10 \%$ & $28 \%$ & $15 \%$ \\
\hline Stayed Obese & $\begin{array}{r}977 \\
(77.6)\end{array}$ & $\begin{array}{r}1,100 \\
(82.20\end{array}$ & $\begin{array}{r}1342 \\
(124.7)\end{array}$ & $13 \%$ & $22 \%$ & $37 \%$ \\
\hline
\end{tabular}




\begin{tabular}{|c|c|c|c|c|c|c|c|}
\hline \multicolumn{8}{|c|}{$\begin{array}{c}\text { Table } 4 \\
\text { 3-Year Trend in Expenditures (Constant \$ 2005) and } \\
\text { Change in Body Mass Index Categories } \\
\text { Mean and Standard Errors } \\
\text { Medicare Current Beneficiary Survey, 2000 - } 2005\end{array}$} \\
\hline & & \multicolumn{3}{|c|}{ Mean Expenditures } & \multicolumn{3}{|c|}{ \% Change } \\
\hline & & Year 1 & Year 2 & Year 3 & Year 2-1 & Year 3-2 & Year 3-1 \\
\hline & BMI gain & $\begin{array}{r}1,403 \\
(223.6)\end{array}$ & $\begin{array}{r}1,262 \\
(179.40\end{array}$ & $\begin{array}{r}1309 \\
(202.7)\end{array}$ & $-10 \%$ & $4 \%$ & $-7 \%$ \\
\hline & Stayed underweight/other & $\begin{array}{r}669 \\
(149.5)\end{array}$ & $\begin{array}{r}804 \\
(153.0)\end{array}$ & $\begin{array}{r}944 \\
(164.4)\end{array}$ & $20 \%$ & $17 \%$ & $41 \%$ \\
\hline \multicolumn{8}{|c|}{ Prescription Drugs } \\
\hline & Stayed Normal & $\begin{array}{l}1,386 \\
(29.3)\end{array}$ & $\begin{array}{l}1,582 \\
(37.2)\end{array}$ & $\begin{array}{l}1,533 \\
(31.5)\end{array}$ & $14 \%$ & $-3 \%$ & $11 \%$ \\
\hline & BMI loss & $\begin{array}{l}1,598 \\
(59.6)\end{array}$ & $\begin{array}{l}1,756 \\
(62.1)\end{array}$ & $\begin{array}{l}1,808 \\
(64.6)\end{array}$ & $10 \%$ & $3 \%$ & $13 \%$ \\
\hline & Stayed Overweight & $\begin{array}{l}1,531 \\
(40.4)\end{array}$ & $\begin{array}{l}1,685 \\
(43.9)\end{array}$ & $\begin{array}{l}1,767 \\
(42.1)\end{array}$ & $10 \%$ & $5 \%$ & $15 \%$ \\
\hline & Stayed Obese & $\begin{array}{l}2,092 \\
(56.6)\end{array}$ & $\begin{array}{l}2,296 \\
(63.1)\end{array}$ & $\begin{array}{l}2,352 \\
(70.1)\end{array}$ & $10 \%$ & $2 \%$ & $12 \%$ \\
\hline & BMI gain & $\begin{array}{l}1,776 \\
(79.4)\end{array}$ & $\begin{array}{l}2,076 \\
(88.3)\end{array}$ & $\begin{array}{l}2,073 \\
(75.0)\end{array}$ & $17 \%$ & $0 \%$ & $17 \%$ \\
\hline Dental & Stay underweight/other & $\begin{array}{l}1,359 \\
(82.7)\end{array}$ & $\begin{array}{r}1,580 \\
(105.3)\end{array}$ & $\begin{array}{r}1,552 \\
(104.3)\end{array}$ & $16 \%$ & $-2 \%$ & $14 \%$ \\
\hline & Stayed Normal & $\begin{array}{r}403 \\
(23.2)\end{array}$ & $\begin{array}{r}400 \\
(24.5)\end{array}$ & $\begin{array}{r}385 \\
(20.6)\end{array}$ & $-1 \%$ & $-4 \%$ & $-4 \%$ \\
\hline & BMI loss & $\begin{array}{r}300 \\
(28.1)\end{array}$ & $\begin{array}{r}341 \\
(34.1)\end{array}$ & $\begin{array}{r}270 \\
(25.1)\end{array}$ & $14 \%$ & $-21 \%$ & $-10 \%$ \\
\hline & Stayed Overweight & $\begin{array}{r}445 \\
(26.9)\end{array}$ & $\begin{array}{r}395 \\
(21.1)\end{array}$ & $\begin{array}{r}365 \\
(17.7)\end{array}$ & $-11 \%$ & $-8 \%$ & $-18 \%$ \\
\hline & Stayed Obese & $\begin{array}{r}402 \\
(33.2)\end{array}$ & $\begin{array}{r}323 \\
(25.6)\end{array}$ & $\begin{array}{r}304 \\
(28.9)\end{array}$ & $-20 \%$ & $-6 \%$ & $-24 \%$ \\
\hline & BMI gain & $\begin{array}{r}383 \\
(42.6)\end{array}$ & $\begin{array}{r}298 \\
(28.0)\end{array}$ & $\begin{array}{r}408 \\
(128.2)\end{array}$ & $-22 \%$ & $37 \%$ & $7 \%$ \\
\hline Other & Stayed underweight/other & $\begin{array}{r}256 \\
(35.9)\end{array}$ & $\begin{array}{r}257 \\
(56.6)\end{array}$ & $\begin{array}{r}142 \\
(25.5)\end{array}$ & $0 \%$ & $-45 \%$ & $-45 \%$ \\
\hline & Stayed Normal & $\begin{array}{r}3,169 \\
(110.7)\end{array}$ & $\begin{array}{r}3,529 \\
(127.0)\end{array}$ & $\begin{array}{r}4,517 \\
(159.4)\end{array}$ & $11 \%$ & $28 \%$ & $43 \%$ \\
\hline & BMI loss & $\begin{array}{r}3,253 \\
(222.6)\end{array}$ & $\begin{array}{r}4,945 \\
(325.5)\end{array}$ & $\begin{array}{r}5,422 \\
(419.0)\end{array}$ & $52 \%$ & $10 \%$ & $67 \%$ \\
\hline & Stayed Overweight & $\begin{array}{l}2,817 \\
(94.9)\end{array}$ & $\begin{array}{r}3,236 \\
(113.3)\end{array}$ & $\begin{array}{r}4,274 \\
(193.5)\end{array}$ & $15 \%$ & $32 \%$ & $52 \%$ \\
\hline
\end{tabular}




\begin{tabular}{|c|c|c|c|c|c|c|}
\hline \multicolumn{7}{|c|}{$\begin{array}{c}\text { Table } 4 \\
\text { 3-Year Trend in Expenditures (Constant \$ 2005) and } \\
\text { Change in Body Mass Index Categories } \\
\text { Mean and Standard Errors } \\
\text { Medicare Current Beneficiary Survey, 2000 - } 2005\end{array}$} \\
\hline & \multicolumn{3}{|c|}{ Mean Expenditures } & \multicolumn{3}{|c|}{ \% Change } \\
\hline & Year 1 & Year 2 & Year 3 & Year 2-1 & Year 3-2 & Year 3-1 \\
\hline Stayed Obese & $\begin{array}{r}3,753 \\
(220.8)\end{array}$ & $\begin{array}{r}4,320 \\
(273.3)\end{array}$ & $\begin{array}{r}4,961 \\
(241.4)\end{array}$ & $15 \%$ & $15 \%$ & $32 \%$ \\
\hline BMI gain & $\begin{array}{r}4,101 \\
(265.0)\end{array}$ & $\begin{array}{r}3,866 \\
(251.2)\end{array}$ & $\begin{array}{r}5,590 \\
(536.2)\end{array}$ & $-6 \%$ & $45 \%$ & $36 \%$ \\
\hline Stayed underweight/other & $\begin{array}{r}3,650 \\
(319.7)\end{array}$ & $\begin{array}{r}4,726 \\
(462.60\end{array}$ & $\begin{array}{r}6,799 \\
(644.5)\end{array}$ & $29 \%$ & $44 \%$ & $86 \%$ \\
\hline
\end{tabular}

Note: Based on community-dwelling Medicare beneficiaries over age 65, followed for three years and had no missing body mass index values and were first included in the survey between 2000 and 2003.

Body mass index change categories were defined as follows: Stayed Normal- individuals with a normal BMI (18.5$24.9 \mathrm{~kg} / \mathrm{m}^{2}$ ) at baseline and follow-up; BMI gain- individuals with normal BMI ( $18.5-24.9 \mathrm{~kg} / \mathrm{m}^{2}$ ) or overweight BMI $\left(25-29.9 \mathrm{~kg} / \mathrm{m}^{2}\right)$ at baseline who moved to a higher BMI category at follow up ( i.e. overweight, obese, morbidly obese); BMI loss- individuals with overweight BMI $\left(25-29.9 \mathrm{~kg} / \mathrm{m}^{2}\right)$ or obese BMI $\left(>30 \mathrm{~kg} / \mathrm{m}^{2}\right)$ at baseline who moved to a lower BMI category at follow up ( i.e. overweight or normal); Stayed OverweightIndividuals with overweight BMI ( $25-29.9 \mathrm{~kg} / \mathrm{m}^{2}$ ) at baseline and follow-up; Stayed Obese- Individuals with obese BMI ( $>30 \mathrm{~kg} / \mathrm{m}^{2}$ ) at baseline and follow-up; and Stayed Underweight/Other- includes individuals with underweight BMI $\left(<18.5 \mathrm{~kg} / \mathrm{m}^{2}\right)$ at base line and follow-up as well as those with weight changes not defined by the categories above.

Numbers in parentheses indicate standard errors for the estimates above. 
Figure 4. Mean Annual Total and Component Healthcare Expenditures (Constant \$ 2005) at Baseline and Follow-up Years, Medicare Current Beneficiary Survey 2000-2005

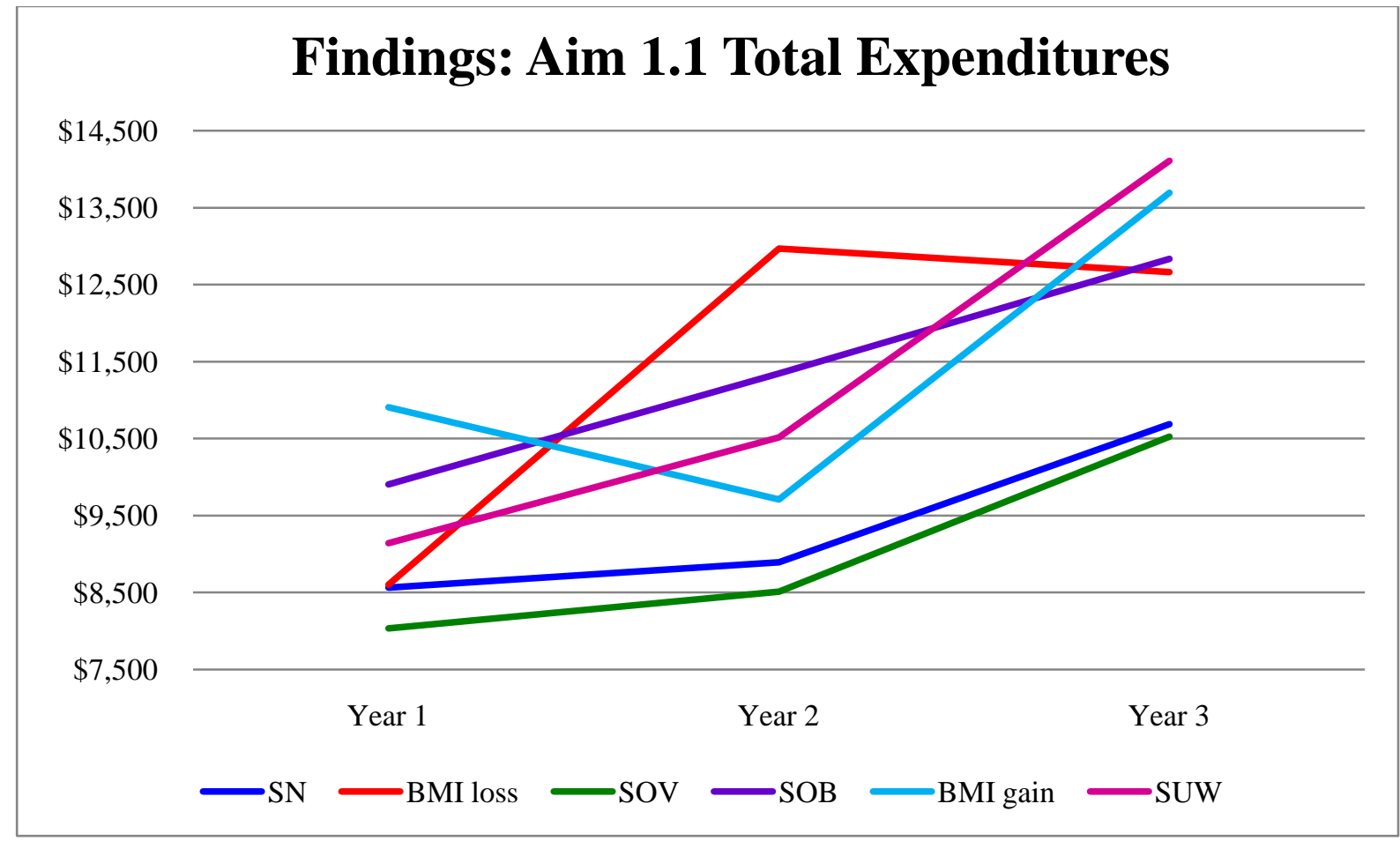

\section{Findings: Aim 1.1 Inpatient Expenditures}

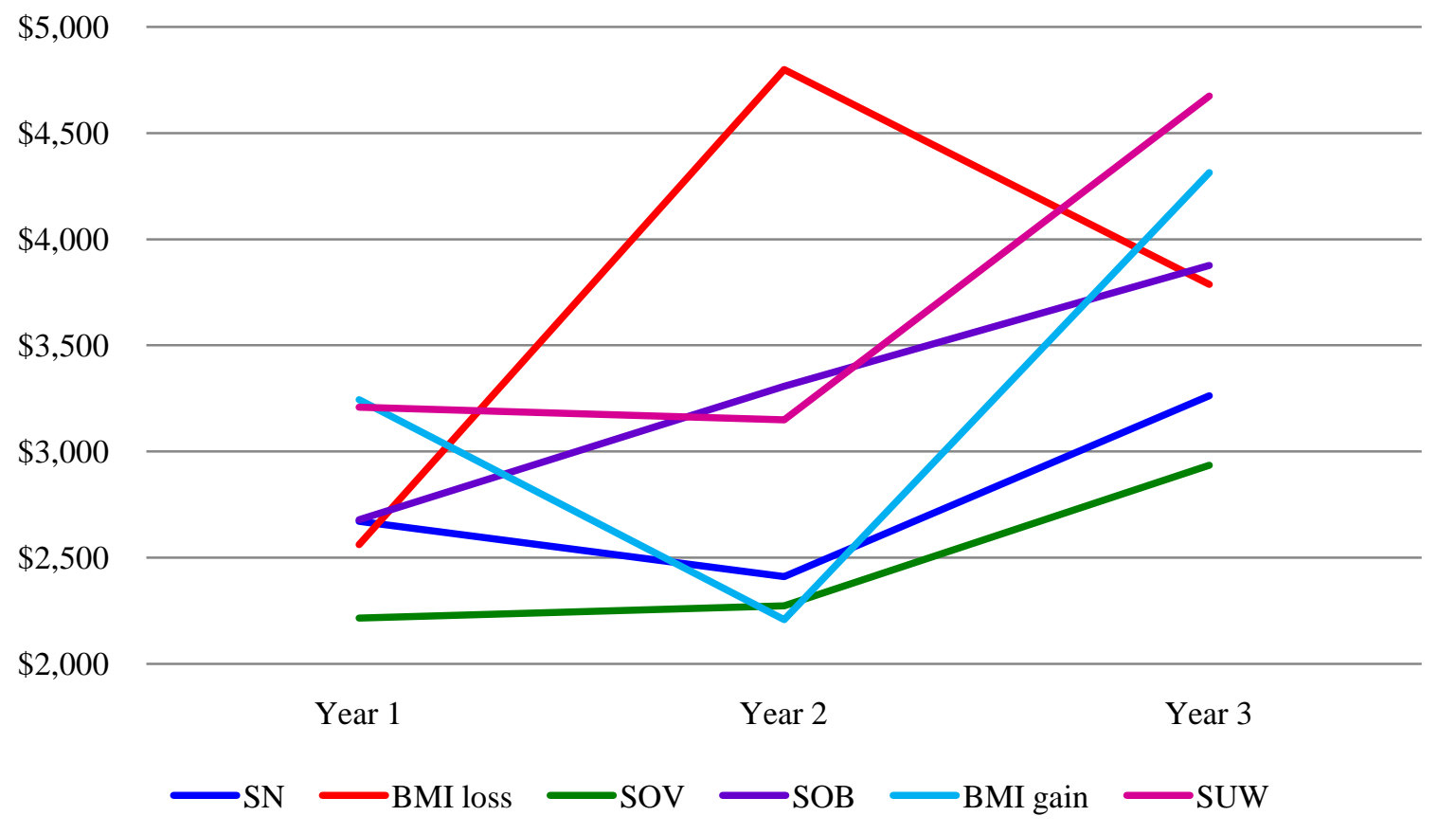



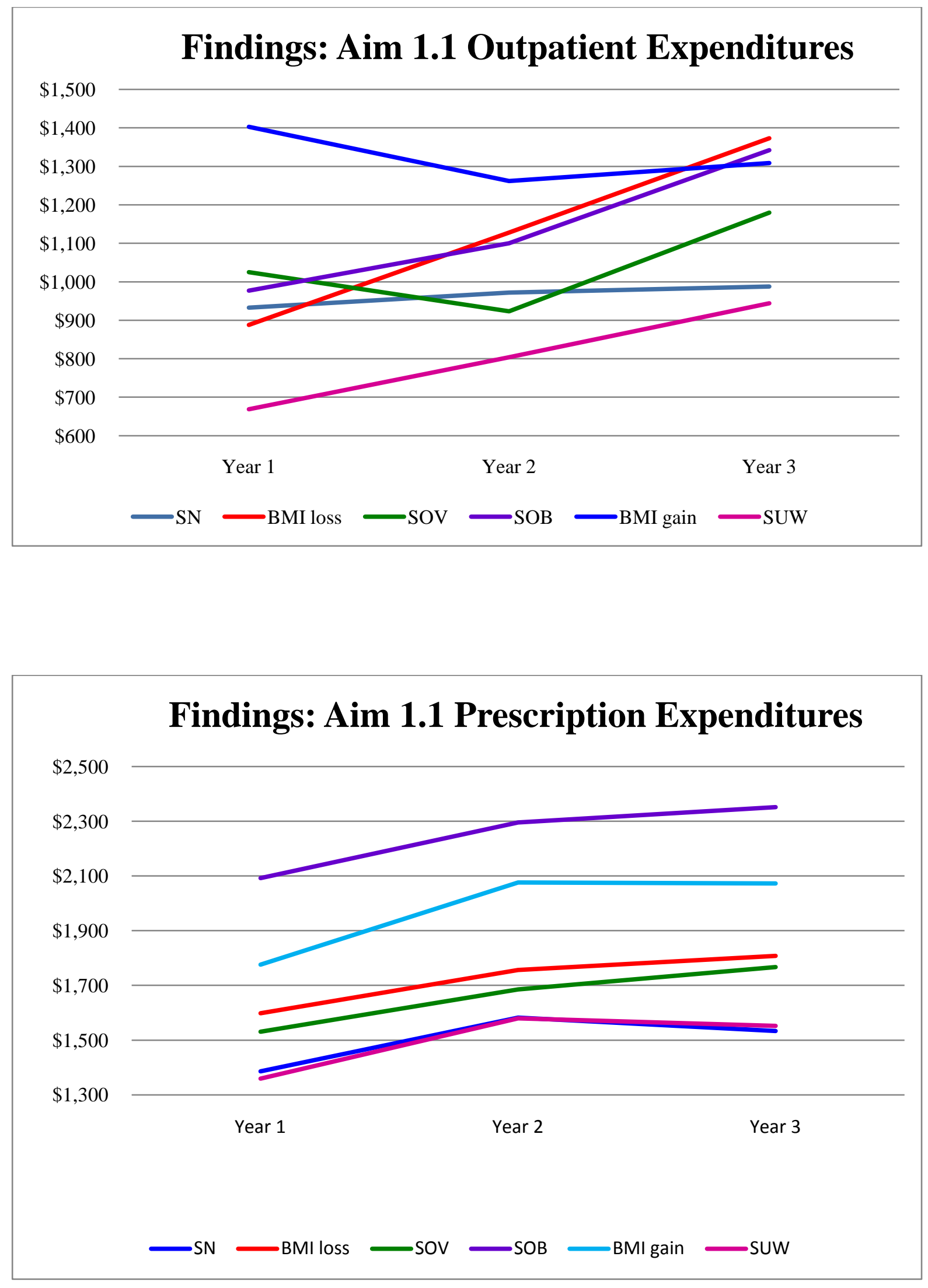


\section{Findings: Aim 1.1 Dental Expenditures}

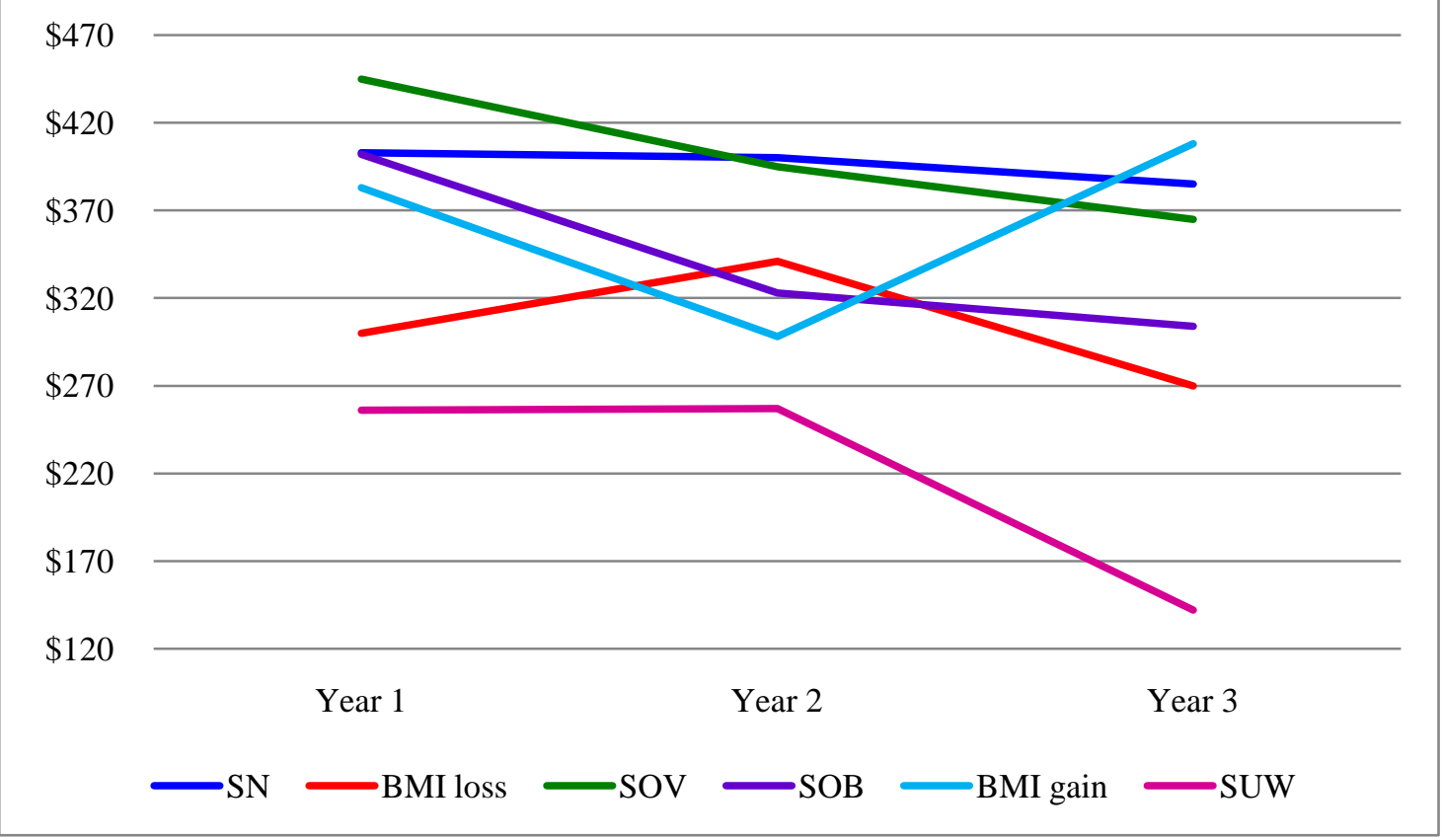

\section{Findings: Aim 1.1 Other Expenditures}

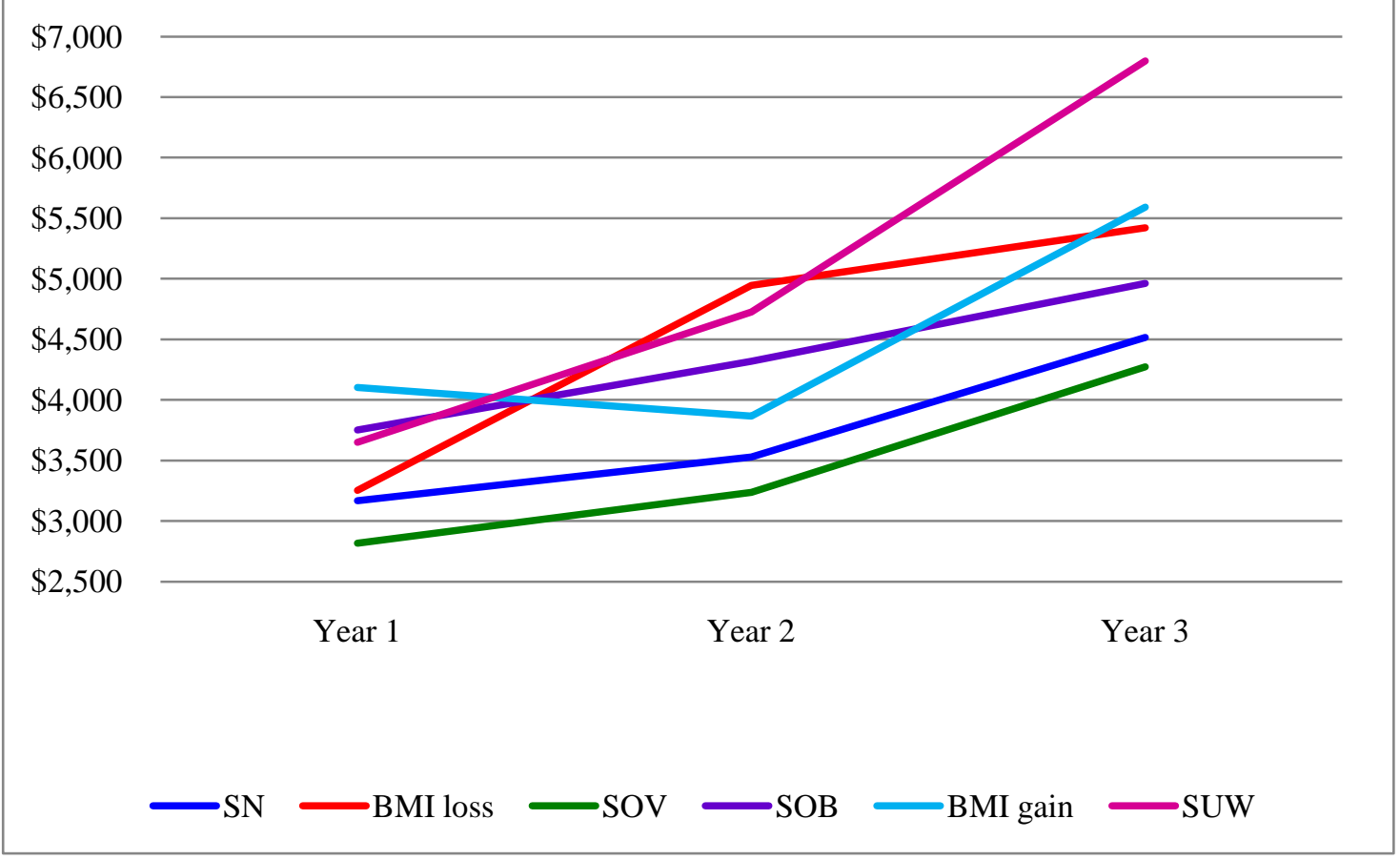




\section{FINDINGS: AIM 1.1}

\section{Aim 1.1 How do the changes in BMI categories affect the total and specific components (inpatient, outpatient, prescription, dental and other) of expenditures? \\ $\underline{\text { Total Expenditures }}$}

Description of Healthcare Expenditures (Table 4, Figure 4):

Mean total expenditures increased from year 1 to year 3. Individuals who stayed overweight had the lowest total expenditures at year $1(\$ 8,033)$, whereas the highest baseline expenditures were found among those who experienced BMI gain $(\$ 10,907)$. In year 3, the lowest total expenditures were among those who stayed overweight $(\$ 10,522)$, followed closely by those who stayed normal $(\$ 10,685)$. The highest Year 3 expenditures were among those who stayed underweight/other $(\$ 14,111)$.

Between Year 1 and 2, the highest rate of growth was seen for stayed underweight/other (54\%), followed by BMI loss (47\%). Persons with BMI gain had total expenditures that were 11\% lower in Year 2. Between Year 2 and Year 3, the highest rate of increase was among those with BMI gain (41\%). The lowest increase was among those who stayed normal (25\%).

Bivariate Association between Short-term Healthcare Expenditures and Change in BMI categories: (Table 5)

Compared to individuals maintaining normal BMI $(\$ 10,685)$, mean total expenditures were significantly higher for individuals in the BMI loss group $(\$ 12,661)$, stayed obese $(\$ 12,835)$, BMI gain $(\$ 13,693)$ and stayed underweight/other $(\$ 14,111)$ (Table 5). 


\section{Inpatient Expenditures}

Description of Healthcare Expenditures (Table 4, Figure 4):

Mean inpatient expenditures increased from Year 1 to Year 3. At baseline, individuals who stayed overweight had the lowest inpatient expenditures at baseline $(\$ 2,216)$, whereas the highest baseline expenditures were found among those who experienced BMI gain $(\$ 3,244)$. This mirrors what was observed for total expenditures. In the final year of follow-up, the lowest inpatient expenditures were among those who stayed overweight $(\$ 2,935)$, and followed by those who stayed normal $(\$ 3,263)$. The highest Year 3 expenditures were among those who stayed underweight/other $(\$ 4,674)$, followed by BMI gain $(\$ 4,313)$.

Between Year 1 and 2, the highest rate of growth was seen for BMI loss (87\%), followed by stayed obese (47\%). Inpatient expenditures decreased by 32\% for individuals with BMI gain over this time period. Between Year 2 and Year 3, the highest rate of increase was among those with BMI gain (95\%), followed by stayed underweight/other (48\%). Individuals experiencing BMI loss had a decrease of 21\% between Year 2 and Year 3.

Bivariate Association between Short-term Healthcare Expenditures and Change in BMI categories: (Table 5)

At Year 3, mean inpatient expenditures were significantly higher for stayed underweight/other (\$4674) as compared to stayed normal (\$3263). 


\section{Outpatient Expenditures}

Description of Healthcare Expenditures (Table 4, Figure 4):

Mean outpatient expenditures increased from Year 1 to Year 3. For individuals experiencing BMI gain, this was not the case, since mean outpatient expenditures were lower in Year 3 than at baseline ( $\$ 1,309$ v. $\$ 1,403)$. At baseline, individuals who stayed underweight/other had the lowest outpatient expenditures (\$669), whereas the highest baseline expenditures were found for those who experienced BMI gain $(\$ 1,403)$. In the final year of follow-up, the lowest outpatient expenditures were also among those who stayed underweight (\$944), followed closely by those who stayed normal (\$988). The highest Year 3 expenditures were among those who experienced BMI loss $(\$ 1,373)$, followed by stayed obese $(\$ 1,342)$.

Between Year 1 and 2, the highest rate of growth was seen for BMI loss (27\%), followed by stayed underweight (20\%). Inpatient expenditures decreased by $10 \%$ for both individuals who stayed overweight and those who experienced BMI gain. Between Year 2 and Year 3, the highest rate of increase was among those who stayed overweight (28\%), followed by BMI loss and stayed obese (22\%). The lowest increases over this period were seen among stayed normal (2\%) and BMI gain (4\%).

Bivariate Association between Short-term Healthcare Expenditures and Change in BMI categories: (Table 5)

Compared to stayed normal (\$988), mean follow-up outpatient changes were significantly higher for healthy loss (\$1373) and stayed obese (\$1342). When controlled for all 
independent variables, individuals with BMI loss and BMI gain had outpatient expenditures that were $27.1 \%$ and $27.6 \%$ higher than individuals who stayed normal (Table 5).

\section{Prescription Expenditures}

Description of Healthcare Expenditures (Table 4, Figure 4):

Mean prescription expenditures increased from baseline through Year 3. At baseline, individuals who stayed underweight/other or stayed normal had the lowest prescription expenditures (\$1,359 and $\$ 1,386$, respectively), whereas the highest baseline expenditures were found among those who stayed obese $(\$ 2,092)$. In the final year of follow-up, the lowest prescription expenditures were also among those who stayed normal $(\$ 1,533)$, followed by those who stayed underweight/other $(\$ 1,552)$. The highest Year 3 expenditures were among those who stayed obese (\$2,352), followed by BMI gain $(\$ 2,073)$.

Between Year 1 and 2, increases were seen for all BMI categories. Individuals with BMI gain had the largest increase for this time period (17\%), whereas prescription expenditures increased by $10 \%$ for BMI loss, stayed overweight and stayed obese. Between the second and third years, prescription expenditures increased by 5\% for individuals who stayed obese. Expenditures decreased by 3\% for stayed normal and by $2 \%$ for stayed underweight. Individuals with BMI gain had prescription expenditures that remained constant between Years 2 and 3.

Bivariate Association between Short-term Healthcare Expenditures and Change in BMI categories: (Table 5). 
At Year 3, mean prescription expenditures were significantly higher for individuals belonging to BMI loss $(\$ 1,808)$, stayed overweight $(\$ 1,767)$, stayed obese $(\$ 2,352)$ and BMI gain $(\$ 2,073)$ as compared to those who stayed normal $(\$ 1,533)$.

\section{Dental Expenditures}

Description of Healthcare Expenditures (Table 4, Figure 4):

Mean dental expenditures decreased from Year 1 to Year 3. The exception being BMI gain, for which dental expenditures increased (\$383 v. \$408). Individuals who stayed underweight/other had the lowest dental expenditures at baseline (\$256), whereas the highest baseline expenditures were found among those who stayed overweight (\$445). In the final year of follow-up, the lowest dental expenditures were among those who stayed underweight/other (\$142). The highest Year 3 expenditures were among those who experienced BMI gain (\$408).

Between Year 1 and 2, dental expenditures increased by 14\% among those with BMI loss. Individuals with BMI gain had dental expenditures that decreased by 22\% between Year 1 and Year 2. Between Years 2 and 3, dental expenditures decreased for all groups except BMI gain, which saw an increase of $7 \%$.

Bivariate Association between Short-term Healthcare Expenditures and Change in BMI categories: (Table 5)

Compared to stayed normal (\$385), mean follow-up dental expenditures were significantly lower for individuals belonging to BMI loss (\$270) and stayed underweight/other (\$142), but were higher for stayed obese (\$304). 


\section{Other Expenditures}

Description of Healthcare Expenditures (Table 4, Figure 4):

Other expenditures as listed, includes facility, home-health, institutional, medical and laboratory expenditures. Mean other expenditures increased from Year 1 to Year 3. Individuals who stayed overweight had the lowest other expenditures at baseline $(\$ 2,817)$, whereas the highest baseline expenditures were found among those who experienced BMI gain $(\$ 4,101)$. This mirrors what was observed for total expenditures. In the final year of follow-up, the lowest expenditures were among those who stayed overweight $(\$ 4,274)$, followed by those who stayed normal $(\$ 4,517)$. The highest Year 3 expenditures were among those who stayed underweight/other $(\$ 6,799)$, followed by BMI gain $(\$ 5,590)$.

Between Year 1 and 2, increases were seen for all BMI change groups except for BMI gain, for which other expenditures decreased by $6 \%$. The highest increase was seen for individuals with BMI loss who experienced an increase of 52\% over the same time period. Between Year 2 and Year 3, the largest increase in other expenditures was seen for BMI gain (45\%), followed by stayed underweight (44\%). The lowest increase between Years 2 and 3 was for BMI loss (10\%).

Bivariate Association between Short-term Healthcare Expenditures and Change in BMI categories: (Table 5)

Compared to stayed normal $(\$ 4,517)$, other expenses were significantly higher for both BMI loss $(\$ 5,422)$ and stayed underweight/other $(\$ 6,799)$. 


\begin{tabular}{|c|c|c|c|}
\hline \multicolumn{4}{|c|}{$\begin{array}{c}\text { Table } 5 \\
\text { Mean and Standard Error of Short-term Expenditures by } \\
\text { Expenditure Type and } \\
\text { Change in Body Mass Index Categories } \\
\text { (Constant Dollars -2005) } \\
\text { Medicare Current Beneficiary Survey, } \\
2000-2005 \\
\end{array}$} \\
\hline & Mean & SE & Sig \\
\hline \multicolumn{4}{|l|}{ Total } \\
\hline \multicolumn{4}{|l|}{ ALL } \\
\hline Stayed Normal & 10,685 & 336.0 & \\
\hline BMI loss & 12,661 & 649.2 & $* *$ \\
\hline Stayed Overweight & 10,522 & 368.4 & \\
\hline Stayed Obese & 12,835 & 546.4 & $* * *$ \\
\hline BMI gain & 13,693 & 1410.1 & $*$ \\
\hline Stayed underweight /other & 14,111 & 1181.9 & $* *$ \\
\hline \multicolumn{4}{|l|}{ Inpatient } \\
\hline \multicolumn{4}{|l|}{ ALL } \\
\hline Stayed Normal & 3,263 & 208.8 & \\
\hline BMI loss & 3,787 & 297.6 & \\
\hline Stayed Overweight & 2,935 & 174.0 & \\
\hline Stayed Obese & 3,876 & 323.0 & \\
\hline BMI gain & 4,313 & 737.7 & \\
\hline Stayed underweight /other & 4,674 & 685.3 & $*$ \\
\hline \multicolumn{4}{|l|}{ Outpatient } \\
\hline \multicolumn{4}{|l|}{ ALL } \\
\hline Stayed Normal & 988 & 49.9 & \\
\hline BMI loss & 1,373 & 148.6 & $*$ \\
\hline Stayed Overweight & 1,180 & 87.9 & \\
\hline Stayed Obese & 1,342 & 124.7 & $* *$ \\
\hline BMI gain & 1,309 & 202.7 & \\
\hline Stayed underweight /other & 944 & 164.4 & \\
\hline \multicolumn{4}{|l|}{ Prescription Drugs } \\
\hline \multicolumn{4}{|l|}{ ALL } \\
\hline Stayed Normal & 1,533 & 31.5 & \\
\hline BMI loss & 1,808 & 64.6 & $* * *$ \\
\hline Stayed Overweight & 1,767 & 42.1 & $* * *$ \\
\hline Stayed Obese & 2,352 & 70.1 & $* * *$ \\
\hline BMI gain & 2,073 & 75.0 & $* * *$ \\
\hline Stayed Underweight/Other & 1,552 & 104.3 & \\
\hline Continued... & & & \\
\hline
\end{tabular}




\begin{tabular}{|c|c|c|c|}
\hline \multicolumn{4}{|c|}{$\begin{array}{c}\text { Table } 5 \\
\text { Mean and Standard Error of Short-term Expendit } \\
\text { Expenditure Type and } \\
\text { Change in Body Mass Index Categories } \\
\text { (Constant Dollars -2005) } \\
\text { Medicare Current Beneficiary Survey, } \\
2000 \text { - 2005 } \\
\end{array}$} \\
\hline & Mean & SE & Sig \\
\hline \multicolumn{4}{|l|}{ Dental } \\
\hline \multicolumn{4}{|l|}{ ALL } \\
\hline Stayed Normal & 385 & 20.6 & \\
\hline BMI loss & 270 & 25.1 & $* * *$ \\
\hline Stayed Overweight & 365 & 17.7 & \\
\hline Stayed Obese & 304 & 28.9 & $*$ \\
\hline BMI gain & 408 & 128.2 & \\
\hline Stayed underweight /other & 142 & 25.5 & $* * *$ \\
\hline \multicolumn{4}{|l|}{ Other } \\
\hline \multicolumn{4}{|l|}{ ALL } \\
\hline Stayed Normal & 4,517 & 159.4 & \\
\hline BMI loss & 5,422 & 419.0 & $*$ \\
\hline Stayed Overweight & 4,274 & 193.5 & \\
\hline Stayed Obese & 4,961 & 241.4 & \\
\hline BMI gain & 5590 & 536.2 & \\
\hline Stayed underweight /other & 6,799 & 644.5 & $* * *$ \\
\hline
\end{tabular}

Note: Based on community-dwelling Medicare beneficiaries over age 65, followed for three years and had no missing body mass index values and were first included in the survey between 2000 and 2003.

Body mass index change categories were defined as follows: Stayed Normal- individuals with a normal BMI (18.5$24.9 \mathrm{~kg} / \mathrm{m}^{2}$ ) at baseline and follow-up; BMI gain- individuals with normal BMI ( $18.5-24.9 \mathrm{~kg} / \mathrm{m}^{2}$ ) or overweight BMI $\left(25-29.9 \mathrm{~kg} / \mathrm{m}^{2}\right)$ at baseline who moved to a higher BMI category at follow up ( i.e. overweight, obese, morbidly obese); BMI loss- individuals with overweight BMI $\left(25-29.9 \mathrm{~kg} / \mathrm{m}^{2}\right)$ or obese BMI $\left(>30 \mathrm{~kg} / \mathrm{m}^{2}\right)$ at baseline who moved to a lower BMI category at follow up ( i.e. overweight or normal); Stayed OverweightIndividuals with overweight BMI ( $25-29.9 \mathrm{~kg} / \mathrm{m}^{2}$ ) at baseline and follow-up; Stayed Obese- Individuals with obese BMI ( $>30 \mathrm{~kg} / \mathrm{m}^{2}$ ) at baseline and follow-up; and Stayed Underweight/Other- includes individuals with underweight BMI $\left(<18.5 \mathrm{~kg} / \mathrm{m}^{2}\right)$ at base line and follow-up as well as those with weight changes not defined by the categories above.

$* * * \mathrm{p}<0.001 ; * * 0.001 \leq \mathrm{p}<0.01 ; * 0.01 \leq \mathrm{p}<0.05$ 


\begin{tabular}{|c|c|c|c|c|c|c|c|c|c|c|c|c|c|c|c|c|c|c|}
\hline \multicolumn{19}{|c|}{$\begin{array}{c}\text { Table } 6 \\
\text { OLS Models on Log Ratio of Expenditures by Type } \\
\text { Changes in Body Mass Index Categories } \\
\text { Medicare Current Beneficiaries Survey 2000-2005 }\end{array}$} \\
\hline & \multicolumn{2}{|c|}{ Total } & \multirow[b]{2}{*}{ Sig } & \multicolumn{2}{|c|}{ Inpatient } & \multicolumn{3}{|c|}{ Outpatient } & \multicolumn{4}{|c|}{ Prescription Drugs } & \multicolumn{2}{|c|}{ Dental } & \multirow[b]{2}{*}{ Sig } & \multicolumn{3}{|c|}{ Other } \\
\hline & Beta & SE & & Beta & SE & Sig & Beta & SE & Sig & Beta & SE & Sig & Beta & SE & & Beta & SE & Sig \\
\hline Intercept & 0.189 & 0.134 & & 0.827 & 0.399 & $*$ & 0.113 & 0.286 & & 0.058 & 0.145 & & -0.198 & 0.233 & & 0.257 & 0.162 & \\
\hline \multicolumn{19}{|l|}{ BMI Changes } \\
\hline Stayed Normal & ref & & & ref & & & ref & & & ref & & & ref & & & ref & & \\
\hline BMI loss & -0.061 & 0.063 & & -0.54 & 0.178 & $* *$ & 0.152 & 0.129 & & 0.064 & 0.063 & & -0.02 & 0.104 & & 0.013 & 0.077 & \\
\hline Stayed Over & 0.025 & 0.044 & & -0.062 & 0.114 & & 0.11 & 0.083 & & -0.034 & 0.04 & & 0.062 & 0.069 & & 0.035 & 0.056 & \\
\hline Stayed Obese & 0.012 & 0.048 & & -0.232 & 0.156 & & 0.107 & 0.118 & & 0.002 & 0.05 & & 0.02 & 0.089 & & 0.084 & 0.061 & \\
\hline $\begin{array}{l}\text { BMI gain } \\
\text { Stayed Underweight/ }\end{array}$ & 0.075 & 0.056 & & 0.278 & 0.185 & & 0.202 & 0.127 & & -0.044 & 0.067 & & 0.016 & 0.106 & & 0.172 & 0.072 & $*$ \\
\hline Other & -0.024 & 0.109 & & -0.113 & 0.309 & & -0.107 & 0.221 & & -0.29 & 0.112 & * & -0.206 & 0.158 & & 0.084 & 0.136 & \\
\hline
\end{tabular}

Note: Based on community-dwelling Medicare beneficiaries over age 65, followed for three years and had no missing body mass index values and were first included in the survey between 2000 and 2003.

Body mass index change categories were defined as follows: Stayed Normal- individuals with a normal BMI (18.5-24.9 kg/m²) at baseline and follow-up; BMI gain- individuals with normal BMI ( $18.5-24.9 \mathrm{~kg} / \mathrm{m}^{2}$ ) or overweight BMI (25-29.9 kg/m²) at baseline who moved to a higher BMI category at follow up ( i.e. overweight, obese, morbidly obese); BMI loss- individuals with overweight BMI (25-29.9 kg/m²) or obese BMI (>30 kg/m²) at baseline who moved to a lower BMI category at follow up ( i.e. overweight or normal); Stayed Overweight- Individuals with overweight BMI ( $25-29.9 \mathrm{~kg} / \mathrm{m}^{2}$ ) at baseline and follow-up; Stayed Obese- Individuals with obese BMI ( $>30 \mathrm{~kg} / \mathrm{m}^{2}$ ) at baseline and follow-up; and Stayed Underweight/Other- includes individuals with underweight BMI $\left(<18.5 \mathrm{~kg} / \mathrm{m}^{2}\right)$ at base line and follow-up as well as those with weight changes not defined by the categories above.

*** $\mathrm{p}<0.001$; ** $0.001<\mathrm{p}<0.01 ; * 0.01<\mathrm{p}<0.05$ 


\begin{tabular}{|c|c|c|c|c|c|}
\hline \multicolumn{6}{|c|}{$\begin{array}{c}\text { Table 7.A } \\
\text { Ordinary Least Squares Regression on } \\
\text { Logged Expenditures (Constant 2005 \$) by Type } \\
\text { Change in Body Mass Index Categories } \\
\text { Medicare Current Beneficiary Survey 2000-2005 } \\
\end{array}$} \\
\hline & Beta & SE & P-val & Sig & $\%$ change \\
\hline \multicolumn{6}{|l|}{ Total } \\
\hline Intercept & 7.978 & 0.152 & 0.000 & $* * *$ & \\
\hline BMI loss & 0.090 & 0.063 & 0.154 & & \\
\hline Stayed overweight & -0.034 & 0.044 & 0.446 & & \\
\hline Stayed obese & -0.020 & 0.047 & 0.670 & & \\
\hline BMI gain & 0.139 & 0.067 & 0.037 & * & $14.9 \%$ \\
\hline Stayed Underweight/Other & -0.036 & 0.113 & 0.748 & & \\
\hline Stayed Normal & Ref & & & & \\
\hline \multicolumn{6}{|l|}{ Inpatient } \\
\hline Intercept & 2.254 & 0.315 & 0.000 & $* * *$ & \\
\hline BMI loss & 0.239 & 0.146 & 0.102 & & \\
\hline Stayed overweight & -0.134 & 0.091 & 0.142 & & \\
\hline Stayed obese & -0.129 & 0.120 & 0.283 & & \\
\hline BMI gain & 0.030 & 0.156 & 0.849 & & \\
\hline Stayed Underweight/Other & 0.406 & 0.233 & 0.082 & & \\
\hline Stayed Normal & Ref & & & & \\
\hline \multicolumn{6}{|l|}{ Outpatient } \\
\hline Intercept & 3.504 & 0.265 & 0.000 & $* * *$ & \\
\hline BMI loss & 0.244 & 0.107 & 0.023 & $*$ & $27.6 \%$ \\
\hline Stayed overweight & 0.131 & 0.074 & 0.079 & & \\
\hline Stayed obese & 0.137 & 0.101 & 0.176 & & \\
\hline BMI gain & 0.240 & 0.112 & 0.033 & $*$ & $27.1 \%$ \\
\hline Stayed Underweight/Other & -0.203 & 0.182 & 0.264 & & \\
\hline Stayed Normal & Ref & & & & \\
\hline \multicolumn{6}{|l|}{ Prescription Drugs } \\
\hline Intercept & 5.258 & 0.187 & 0.000 & $* * *$ & \\
\hline BMI loss & 0.154 & 0.067 & 0.022 & $*$ & $16.6 \%$ \\
\hline Stayed overweight & 0.077 & 0.056 & 0.169 & & \\
\hline Stayed obese & 0.149 & 0.062 & 0.016 & * & $16.1 \%$ \\
\hline BMI gain & 0.257 & 0.079 & 0.001 & $* *$ & $29.3 \%$ \\
\hline Stayed Underweight/Other & -0.344 & 0.145 & 0.018 & $*$ & $-29.1 \%$ \\
\hline Stayed Normal & Ref & & & & \\
\hline Continued. & & & & & \\
\hline
\end{tabular}




\begin{tabular}{|c|c|c|c|c|c|}
\hline \multicolumn{6}{|c|}{$\begin{array}{c}\text { Table 7.A } \\
\text { Ordinary Least Squares Regression on } \\
\text { Logged Expenditures (Constant 2005 \$) by Type } \\
\text { Change in Body Mass Index Categories } \\
\text { Medicare Current Beneficiary Survey 2000-2005 }\end{array}$} \\
\hline & Beta & SE & P-val & Sig & $\%$ change \\
\hline \multicolumn{6}{|l|}{ Dental } \\
\hline Intercept & 2.596 & 0.232 & 0.000 & & \\
\hline BMI loss & -0.233 & 0.106 & 0.028 & $*$ & $-20.8 \%$ \\
\hline Stayed overweight & -0.045 & 0.071 & 0.528 & & \\
\hline Stayed obese & -0.177 & 0.093 & 0.058 & & \\
\hline BMI gain & -0.242 & 0.120 & 0.044 & * & $-21.5 \%$ \\
\hline Stayed Under/Other & -0.753 & 0.168 & 0.000 & $* * *$ & $-52.9 \%$ \\
\hline Stayed Normal & Ref & & & & \\
\hline \multicolumn{6}{|l|}{ Other } \\
\hline Intercept & 7.129 & 0.180 & 0.000 & $* * *$ & \\
\hline BMI loss & 0.106 & 0.074 & 0.155 & & \\
\hline Stayed overweight & -0.119 & 0.053 & 0.024 & $*$ & $-11.2 \%$ \\
\hline Stayed obese & -0.038 & 0.057 & 0.506 & & \\
\hline BMI gain & 0.189 & 0.071 & 0.008 & $* *$ & $20.8 \%$ \\
\hline Stayed Under/Other & -0.008 & 0.123 & 0.949 & & \\
\hline Stayed Normal & Ref & & & & \\
\hline
\end{tabular}

Note: Based on community-dwelling Medicare beneficiaries over age 65, followed for three years and had no missing body mass index values and were first included in the survey between 2000 and 2003.

Body mass index change categories were defined as follows: Stayed Normal- individuals with a normal BMI (18.5$\left.24.9 \mathrm{~kg} / \mathrm{m}^{2}\right)$ at baseline and follow-up; BMI gain- individuals with normal BMI (18.5-24.9 kg/m²) or overweight BMI $\left(25-29.9 \mathrm{~kg} / \mathrm{m}^{2}\right)$ at baseline who moved to a higher BMI category at follow up ( i.e. overweight, obese, morbidly obese); BMI loss- individuals with overweight BMI $\left(25-29.9 \mathrm{~kg} / \mathrm{m}^{2}\right)$ or obese BMI $\left(>30 \mathrm{~kg} / \mathrm{m}^{2}\right)$ at baseline who moved to a lower BMI category at follow up ( i.e. overweight or normal); Stayed OverweightIndividuals with overweight BMI ( $25-29.9 \mathrm{~kg} / \mathrm{m}^{2}$ ) at baseline and follow-up; Stayed Obese- Individuals with obese BMI ( >30 kg/m²) at baseline and follow-up; and Stayed Underweight/Other- includes individuals with underweight BMI $\left(<18.5 \mathrm{~kg} / \mathrm{m}^{2}\right)$ at base line and follow-up as well as those with weight changes not defined by the categories above.

*** $\mathrm{p}<0.001 ; * * 0.001 \leq \mathrm{p}<0.01 ; * 0.01 \leq \mathrm{p}<0.05$ 


\begin{tabular}{|c|c|c|c|c|c|}
\hline \multicolumn{6}{|c|}{$\begin{array}{c}\text { Table 7.B } \\
\text { Ordinary Least Squares Regression on } \\
\text { Logged Expenditures (Constant 2005 \$) by Type } \\
\text { Change in Body Mass Index Categories Adjusted for Baseline } \\
\text { Expenditures, Medicare Current Beneficiary Survey 2000-2005 }\end{array}$} \\
\hline & Beta & SE & P-val & Sig & \% Change \\
\hline \multicolumn{6}{|l|}{ Total } \\
\hline Stayed normal & 3.998 & 0.200 & 0.000 & & \\
\hline $\begin{array}{l}\text { BMI loss } \\
\text { Stayed }\end{array}$ & 0.012 & 0.052 & 0.812 & & \\
\hline overweight & -0.004 & 0.038 & 0.925 & & \\
\hline Stayed obese & -0.003 & 0.040 & 0.932 & & \\
\hline $\begin{array}{l}\text { BMI gain } \\
\text { Stayed }\end{array}$ & 0.106 & 0.053 & 0.045 & * & $11 \%$ \\
\hline Stayed Normal & Ref & & & & \\
\hline \multicolumn{6}{|l|}{ Inpatient } \\
\hline Stayed normal & 1.993 & 0.308 & 0.000 & & \\
\hline $\begin{array}{l}\text { BMI loss } \\
\text { Stayed } \\
\text { overweight }\end{array}$ & -0.121 & 0.090 & 0.489 & & \\
\hline Stayed obese & -0.148 & 0.119 & 0.216 & & \\
\hline $\begin{array}{l}\text { BMI gain } \\
\text { Stayed }\end{array}$ & 0.075 & 0.152 & 0.621 & & \\
\hline Under/Other & 0.311 & 0.232 & 0.181 & & \\
\hline Stayed Normal & Ref & & & & \\
\hline \multicolumn{6}{|l|}{ Outpatient } \\
\hline Stayed normal & 2.274 & 0.246 & 0.000 & & \\
\hline $\begin{array}{l}\text { BMI loss } \\
\text { Stayed } \\
\text { overweight }\end{array}$ & 0.123 & 0.067 & 0.067 & $*$ & $23 \%$ \\
\hline Stayed obese & 0.126 & 0.097 & 0.194 & & \\
\hline $\begin{array}{l}\text { BMI gain } \\
\text { Stayed } \\
\text { Under/Other }\end{array}$ & 0.226 & 0.101 & $\begin{array}{l}0.026 \\
0.338\end{array}$ & $*$ & $25 \%$ \\
\hline Stayed Normal & Ref & & & & \\
\hline \multicolumn{6}{|l|}{ Prescription Drugs } \\
\hline Stayed normal & 1.474 & 0.158 & 0.000 & & \\
\hline $\begin{array}{l}\text { BMI loss } \\
\text { Stayed } \\
\text { overweight }\end{array}$ & 0.088 & 0.055 & 0.108 & & \\
\hline Stayed obese & 0.042 & 0.046 & 0.357 & & \\
\hline $\begin{array}{l}\text { BMI gain } \\
\text { Stayed }\end{array}$ & 0.038 & 0.061 & 0.535 & & \\
\hline Under/Other & -0.305 & 0.108 & 0.005 & $* *$ & $-26 \%$ \\
\hline $\begin{array}{l}\text { Stayed Normal } \\
\text { Continued... }\end{array}$ & Ref & & & & \\
\hline
\end{tabular}




\begin{tabular}{|c|c|c|c|c|c|}
\hline \multicolumn{6}{|c|}{$\begin{array}{c}\text { Table 7.B } \\
\text { Ordinary Least Squares Regression on } \\
\text { Logged Expenditures (Constant 2005 \$) by Type } \\
\text { Change in Body Mass Index Categories Adjusted for Baseline } \\
\text { Expenditures, Medicare Current Beneficiary Survey 2000-2005 } \\
\end{array}$} \\
\hline & Beta & SE & P-val & Sig & \% Change \\
\hline \multicolumn{6}{|l|}{ Dental } \\
\hline Stayed normal & 1.198 & 0.196 & 0.000 & & \\
\hline $\begin{array}{l}\text { BMI loss } \\
\text { Stayed } \\
\text { overweight }\end{array}$ & -0.127 & 0.089 & 0.153 & & \\
\hline Stayed obese & -0.078 & 0.077 & 0.312 & & \\
\hline $\begin{array}{l}\text { BMI gain } \\
\text { Stayed } \\
\text { Under/Other }\end{array}$ & -0.113 & 0.097 & 0.248 & $* * *$ & $-38 \%$ \\
\hline Stayed Normal & Ref & & & & \\
\hline \multicolumn{6}{|l|}{ Other } \\
\hline Stayed normal & 3.738 & 0.177 & 0.000 & & \\
\hline $\begin{array}{l}\text { BMI loss } \\
\text { Stayed } \\
\text { overweight }\end{array}$ & 0.060 & 0.064 & 0.349 & & \\
\hline Stayed obese & 0.022 & 0.051 & 0.667 & & \\
\hline $\begin{array}{l}\text { BMI gain } \\
\text { Stayed } \\
\text { Under/Other }\end{array}$ & 0.181 & 0.060 & $\begin{array}{l}0.003 \\
0.751\end{array}$ & $* *$ & $20 \%$ \\
\hline Stayed Normal & Ref & & & & \\
\hline
\end{tabular}

Note: Based on community-dwelling Medicare beneficiaries over age 65, followed for three years and had no missing body mass index values and were first included in the survey between 2000 and 2003.

Body mass index change categories were defined as follows: Stayed Normal- individuals with a normal BMI (18.5$24.9 \mathrm{~kg} / \mathrm{m}^{2}$ ) at baseline and follow-up; BMI gain- individuals with normal BMI ( $18.5-24.9 \mathrm{~kg} / \mathrm{m}^{2}$ ) or overweight BMI (25-29.9 $\left.\mathrm{kg} / \mathrm{m}^{2}\right)$ at baseline who moved to a higher BMI category at follow up ( i.e. overweight, obese, morbidly obese); BMI loss- individuals with overweight BMI $\left(25-29.9 \mathrm{~kg} / \mathrm{m}^{2}\right)$ or obese BMI $\left(>30 \mathrm{~kg} / \mathrm{m}^{2}\right)$ at baseline who moved to a lower BMI category at follow up ( i.e. overweight or normal); Stayed OverweightIndividuals with overweight BMI ( $25-29.9 \mathrm{~kg} / \mathrm{m}^{2}$ ) at baseline and follow-up; Stayed Obese- Individuals with obese BMI ( $>30 \mathrm{~kg} / \mathrm{m}^{2}$ ) at baseline and follow-up; and Stayed Underweight/Other- includes individuals with underweight BMI $\left(<18.5 \mathrm{~kg} / \mathrm{m}^{2}\right)$ at base line and follow-up as well as those with weight changes not defined by the categories above. ${ }^{* * *} \mathrm{p}<0.001 ; * * 0.001 \leq \mathrm{p}<0.01 ; * 0.01 \leq \mathrm{p}<0.05$ 


\section{FINDINGS: AIM 1.2}

Aim 1.2 What is the association between changes in BMI and healthcare expenditures, after controlling for individuals' demographic, socioeconomic status, physical illness and mental illness?

\section{Loq-ratio of Expenditures}

Table 6 presents the Ordinary Least Squares (OLS) model on log-ratio of expenditures controlled for all other independent variables. Recall, the log-ratio is expressed as the ratio of Year 3 expenditures to Year 2 expenditures with the log of this value; where positive values indicate increased expenditures, and negative values indicate decreased expenditures. When compared to individuals who stayed in normal BMI group, individuals who experienced BMI loss had significantly lower expenditures $(\beta=-0.54)$. When compared to individuals who stayed in normal BMI group, individuals with BMI gain had mean expenditures that were significantly higher $(\beta=0.172)$.

Table 7.A summarizes parameter estimates from the ordinary least squares (OLS) regression on short-term logged expenditures by change in BMI categories. These regressions control for gender, race/ethnicity, age, marital status, metro status, education, poverty status, supplemental health insurance, general health status, functional status, smoking, and chronic physical and mental conditions. In addition to these variables, baseline expenditures were also controlled for and results are presented in Table 7.B. Parameter estimates for these independent variables are not presented in tabular form as they are not of main interest. 


\section{Total Expenditures}

Short-term Healthcare Expenditures and Change in BMI categories: Ordinary Least Squares Regressions (Table 7.A, 7.B)

When controlled for all independent variables, individuals with BMI gain had expenditures that were $14.9 \%$ higher than individuals who stayed normal. When controlled for baseline expenditures, the results were $11 \%$ higher.

\section{Inpatient Expenditures}

Short-term Healthcare Expenditures and Change in BMI categories: Multivariate Analysis (Table 7.A, 7.B).

The OLS regression on logged expenditures did not reveal any statistically significant associations between expenditures and changes in BMI categories.

\section{Outpatient Expenditures}

Short-term Healthcare Expenditures and Change in BMI categories: OLS Regressions (Table 7.A, 7.B.)

When controlled for all independent variables, persons with BMI loss and BMI gain had outpatient expenditures that were $27.1 \%$ and $27.6 \%$ higher than persons who stayed normal.

When controlled for baseline expenditures these results were 23\% and 25\% higher, respectively. 


\section{Prescription Expenditures}

Short-term Healthcare Expenditures and Change in BMI categories: OLS Regressions (Table 7.A, 7.B).

When controlled for all independent variables, individuals with BMI loss and stayed obese had expenditures that were $16.6 \%$ and $16.1 \%$ higher than individuals who stayed normal. Individuals with BMI gain had prescription expenditures that were $29.3 \%$ higher than those who stayed normal. When looking at individuals who stayed underweight/other, Year 3 expenditures are observed to be $29.1 \%$ lower than those who stayed normal.

When controlled for baseline expenditures, only individuals who stayed underweight/other had significant results. Prescription expenditures for this group were 26\% lower than that of stayed normal.

\section{Dental Expenditures}

Short-term Healthcare Expenditures and Change in BMI categories: OLS Regressions (Table 7.A, 7.B).

When controlled for all independent variables, individuals with BMI loss had dental expenditures that were $20.8 \%$ lower than individuals who stayed normal. When controlled for baseline expenditures, only individuals who stayed underweight/other had significant results. Dental expenditures for this group were 38\% lower than that of stayed normal. 


\section{Other Expenditures}

Short-term Healthcare Expenditures and Change in BMI categories: OLS Regressions (Table 7.A, 7.B).

When controlled for all independent variables, individuals who stayed overweight had expenditures that were $11.2 \%$ lower than individuals who stayed normal. Individuals who experienced BMI gain had expenditures that were $20.8 \%$ higher than those who stayed normal.

When controlled for baseline expenditures, only individuals with BMI gain had significant results. Other expenditures for this group were $20 \%$ higher than that of stayed normal.

\section{Alternative Specifications of Changes in Healthcare Expenditures}

\section{Change in Expenditures Categories}

A multinomial logistic regression on levels of expenditure change by BMI change categories was performed. Levels of expenditure change were 1)no expenditures at Year 2 and Year 3; 2)greater than $10 \%$ decrease in expenditures from Year 2 to Year 3; 3)greater than 10\% increase in expenditures from Year 2 to Year 3; and 4)minimal variation, that represents changes in expenditures in either direction that are less than $10 \%$. For the analysis, minimal variation served as the reference group.

Individuals with BMI loss were less likely to have a decrease in prescription expenditures greater than ten percent $[\mathbf{A O R}=\mathbf{0 . 5 3}, \mathbf{9 5} \% \mathbf{C I} \mathbf{0 . 2 8 - 1 . 0 0}$ (Appendix B, Table B.2). Compared 
to stayed normal, individuals with BMI loss were 52\% more likely to have zero inpatient expenditures at Year 2 and Year3 [AOR 1.52, 95\%CI 1.22-1.91](Appendix B, Table B.3).

Compared to stayed normal, persons who experienced BMI gain were 50\% less likely to have zero outpatient expenditures at Years 2 and 3[AOR $=\mathbf{0 . 5 0 , 9 5 \% C I ~ 0 . 3 3 - 0 . 7 6 ]}$. Table B.2 also shows persons with BMI gain were less likely to have a decrease in outpatient expenditures greater than ten percent $[\mathrm{AOR}=\mathbf{0 . 4 8}, \mathbf{9 5 \%} \mathbf{C I} \mathbf{0 . 3 0 - 0 . 7 9}]$, and less likely to have increases in outpatient expenditures greater than 10\% [AOR $=\mathbf{0 . 5 5}$, 95\% CI 0.36-0.83] (Appendix B, Table B.2). 


\section{FINDINGS: AIM 1.3}

\section{Aim 1.3 How does the relationship between persistent weight gain or loss and healthcare expenditures change in the presence of mental illness (depression)?}

It was hypothesized that the effect of BMI on health expenditures would be magnified in the presence of comorbid mental illness. OLS linear regression on logged expenditures adjusted for all other independent variables was performed. When distinction for any mental illness was made, the results were no different (Table in Appendix C).

\section{Discussion Overview}

The current study set out to examine the association between changes in weight as measured by changes in BMI and short-term healthcare expenditures among Medicare beneficiaries over 65 years of age.

1) Only a small fraction of the elderly experienced changes in BMI categories: Of 10,698 individuals, 9\% experienced BMI loss (N=982) and 8.2\% experienced BMI gain $(\mathrm{N}=867)$ over the study period.

2) Subgroup differences in BMI changes were noted:

a. Females were less likely than males to experience BMI loss or BMI gain. This finding is not consistent with what has been reported elsewhere. From the Health, Aging and Body Composition (Health ABC) study, Lee et al., reported on shortterm weight changes in 522 elderly individuals ages 70-79 years. Weight gain and loss was defined as a change of greater than $5 \%$ body weight over the past year. 
Significantly more women experienced weight loss and weight gain (53\% and 66\%) ( Lee et al, 2005). In this study, however, weight loss and gain were defined using BMI, which accounts for height in addition to weight.

b. Increased age decreased the likelihood of BMI loss or BMI gain as compared to individuals 65-69 years; individuals older than 80 years were the only age group with increased risk of staying underweight/other. This is consistent with studies that have reported that average BMI declines with advanced age. (Yang et al., 2008).

c. In addition, it was observed that individuals who reported poor general health at baseline were more likely to be in stayed underweight/other BMI change categories. It is very likely that those who were in the "stayed underweight" category were mostly elderly individuals characterized by poor health and advanced age.

d. As observed in other studies, functional decline at baseline was associated with BMI changes. Jensen and Friedmann reported on the association of obesity and functional decline in a Medicare managed care population. Compared to women with weight change less than $10 \mathrm{lbs}$, those experiencing weight loss of 10 or $20 \mathrm{lbs}$ were more than twice as likely to have ADL limitations. Those experiencing weight gain of 20lbs were more than four times as likely to have ADL limitations. The results were similar for male beneficiaries (Jensen and Friedmann, 2002). 


\section{Discussion: Hypothesis 1.1}

Hypothesis 1.1 Decreases in BMI will result in reductions in short-term total and/or component health expenditures.

\section{$\underline{B M I \text { LosS }}$}

Overall, when compared to stayed normal, individuals who experienced BMI loss had relative changes in inpatient expenditures that were significantly lower than that of stayed normal. Contrary to the hypothesis that total and all components of expenditures would be lower, only the log-ratio of inpatient expenditures was lower for this group.

One may suppose that BMI loss could result from new illness, and that bouts of illness and subsequent weight loss are driving the overall effects. When looking at the initial year to year changes in expenditures, sharp increases for spending occurred for the BMI loss group compared to those who stayed normal. However, the statistical significance of this increase was not tested. For the case of inpatient expenditures, between Year 1 and 2, increases seen among those who stayed overweight (3\%), and stayed obese (24\%) were mild in comparison to BMI loss. Compared to the prior groups, BMI loss experienced relatively rapid increases over the same time period (87\%). It would seem then that illness could have caused this sharp rise in inpatient expenditures over the first 2 years. It should be noted, however, that between Year 2 and Year 3, persons experiencing BMI loss were the only group with decreasing inpatient expenditures. If these persons did in fact experience illness, it was short lived, as represented by the decrease in inpatient expenditures through the last year of follow-up. It is likely that individuals who experienced BMI loss, were themselves healthy individuals and would therefore incur less inpatient expenditures. More persons with BMI loss were of good health with no functional 
limitations (Table 2). Additionally more persons in this group were free of chronic physical and mental diseases, with the exception of arthritis and hypertension, which are common in the elderly. Previous studies have shown the benefit of weight loss in improving chronic diseases such as diabetes and hypertension (Ballantyne et al., 2006; Palomar et al., 2005; Knowler et al., 2002). It is possible that over the short-term, benefits of weight reduction resulted in avoidance of hospitalizations associated with comorbid diseases. Future studies are needed to confirm or disprove this study's findings that BMI loss resulted in lower relative inpatient expenditures. Work should be done to uncover the mechanism by which these results may occur.

\section{Discussion: Hypothesis 1.2}

\section{Aim 1.2 Increases in BMI will result in increases in total and/or component healthcare expenditures.}

\section{$\underline{\text { BMI qain }}$}

Overall, when compared to individuals who stayed normal, those who experienced BMI gain had relative changes in other expenditures that were significantly higher than that of stayed normal. Relative increases in the log-ratio across multiple expenditure types was expected. However, this was the case only for other expenditures.

Following the change in BMI, other expenditures increased the most for those experiencing BMI gain (45\%). Recall, that “other” expenditures included those for facility, home health, institutional, medical and laboratory. Both overweight and obesity are associated with increased healthcare expenditures (Sullivan et al., 2008; Thorpe KE, 2006; Wee et al., 2005; yang and Hall, 2008). The short-term effect of weight gain on health expenditures has been demonstrated in persons with diabetes. Yu et al., modeled changes in total and diabetes-related 
health expenditures one year after weight gain/loss in a group of 458 diabetic patients. Weight gain/loss was defined as a minimum of one pound change over a six month period between 1997 and 2005. Mean total healthcare costs were higher for weight gainers $(\mathrm{N}=224)$ as compared to non-weight gainers $(\$ 7,260$ v. $\$ 5,541)$. Models showed that a $1 \%$ increase in weight would result in an increase in total health costs of 3.1\% (Yu et al., 2007).

Additionally, persons who experienced BMI gain were less likely to have zero outpatient expenditures at Year 2 and Year3 [AOR $=\mathbf{0 . 5 0 , 9 5 \% C I ~ 0 . 3 3 - 0 . 7 6 ] ~ ( T a b l e ~ B 4 ) . ~ I n d i v i d u a l s ~ w i t h ~}$ BMI gain were less likely to have a decrease in outpatient expenditures greater than $10 \%[$ AOR $=\mathbf{0 . 4 8}, \mathbf{9 5} \% \mathbf{C I} \mathbf{0 . 3 0 - 0 . 7 9 ]}$, and less likely to have increases in outpatient expenditures greater than $10 \%[\mathbf{A O R}=\mathbf{0 . 5 5}, \mathbf{9 5} \% \mathbf{C I} \mathbf{0 . 3 6 - 0 . 8 3}$. These findings seem to point to inconsistency in utilization of outpatient healthcare. When looking at the year to year changes in expenditures presented in Table 4, mean expenses for all expenditure types excepting prescriptions, decreased in Year 2, but increased sharply in Year 3.

Whether BMI gain is preceded by inconsistent healthcare utilization or both cooccur is unknown. In this sample of Medicare beneficiaries, those with BMI gain have presented inconsistencies in healthcare expenditures across multiple service types. Researchers should seek to understand whether these findings are artifacts of behaviors at the patient or physicianlevel. For example, there are reports that associate underutilization of weight-loss services with patient level factors such as health seeking behaviors and fear of stigmatization (Brown et al., 2006; Visram et al., 2009) Literature has also shown that physician practices such as referral patterns and counseling can affect the use of weight-loss services (Orleans et al., 1985; McAver et al, 1999). Future research is needed to establish and understand the determinants of this phenomenon. 


\section{Discussion: Hypothesis 1.3}

\section{Aim 1.3 The effect of BMI on health expenditures will be magnified in the presence of comorbid mental illness.}

Results from the OLS linear regression on logged expenditures adjusted for all other independent variables are presented in Appendix C. In this regression, comorbid mental illness is measured by the presence of any mental illness and depression. As suggested by the table, the relationship between BMI changes and expenditures remained similar.

It has been shown previously that healthcare expenditures increase in the presence of comorid mental illness. In one cross sectional study, the Medical Expenditure Panel Survey was used to analyze data on 2,825 obese adults. The average total expenditures for obese adults with physical and mental illness were higher than for those with physical illness only ( $\$ 7,429 \mathrm{v}$. $\$ 6,759$ ). Mean pharmacy expenditures were $\$ 2,431$ and $\$ 1,806$, respectively. After controlling for all independent variables, total, inpatient, outpatient, emergency room, pharmacy, and other expenditures were higher for obese adults with both mental and physical illness compared to obese adults with physical illness alone (Shen et al., 2007).

The findings of Aim 1.3 are surprising since evidence exists that links symptomatic depression with the worsening of comorbid conditions (Carnethon et al., 2007; Ciechanowski et al., 2007; Mancuso et al., 2000; Remington et al., 2001; and Rou et al., 2003). One study followed patients with heart failure over a period of 4-6 weeks to evaluate the relationship between baseline depressive symptoms and symptoms of heart failure at follow-up. Symptomatic depression was measured using the Medical Outcomes Study-Depression questionnaire. The Kansas City Cardiomyopathy Questionnaire (KCCQ) was used to measure symptoms of heart failure, in which increasing scores indicate improved functional status and 
quality of life. At baseline, persons presenting with depressive symptoms had lower symptoms of heart failure. However, at follow-up, symptomatic depression was a significant predictor of symptoms of heart failure. The KCCQ heart failure score showed an average decrease of 7.1 (where a 5 point change is clinically relevant) for persons with depressive symptoms (Rumsfeld et al., 2003).

Mental illness in this study was measured by self-report as well as by Medicare diagnostic codes. No distinction was made by symptomatic/non-symptomatic mental illness. Along the same lines, duration and severity of mental illness was not measured. It may be that both the presence of and duration of symptomatic mental illness serves to mediate the effect of mental illness on changing health expenditures. Further research into the time-dependent effects of mental illness on physical diseases will help make this relationship clear. 


\section{CHAPTER 5}

\section{CONCLUSIONS/IMPLICATIONS}

\section{Summary}

Obesity has become an epidemic affecting all ages including the elderly, and is associated with increased morbidity, mortality and healthcare expenditures. Previous studies have focused primarily on the effects of weight loss on healthcare expenditures. The current study explored how changes in BMI affect a variety of healthcare expenditures within a Medicare population and additionally how comorbid mental illness impacts this relationship.

Findings from the current study reveal that weight gain (i.e. BMI increase) increases total and outpatient expenditures including the medical provider component measured by other expenditures. These findings parallel those found by studies reviewed in the introduction section that higher BMI values (i.e. overweight and obesity) are consistently associated with increased expenditures.

Study findings indicate that BMI loss is associated with decreased inpatient expenditures after BMI changes were measured as compared to those who stayed in normal BMI group. Inpatient expenditures account for a major proportion of total healthcare expenditures. A review article on understanding the drivers behind inpatient cost growth indicated that in 2001, out of \$1.4 trillion spent on healthcare, 37.5\% (\$451.2 billion) were spent on inpatient care. In addition, during that year, $51 \%$ of the growth in total spending was due to inpatient services (Goetghebeur et al., 2003). Therefore, it is encouraging that weight loss at any level (i.e. moving from obesity to overweight or overweight to normal) may reduce expenditures. This finding has implications for weight loss programs, policy makers and payers. 
Expenditures did not change for individuals who stayed in the same BMI categories over a two year period. In light of the possible negative effects of weight changes on healthcare expenditures and the positive association between increasing BMI values and health expenditures in the elderly, having a stable BMI is necessary to reduce expenditure burden on the individuals and the payers.

Despite the possible short-term benefits of weight loss, several studies have reported the hazards of "weight cycling". Weight cycling is a term that describes fluctuations in body weight characterized by weight loss and then gain, or weight gain, and then loss. Although, in this study, BMI fluctuations were not measured, the phenomenon is worth discussing. Whereas, weight cycling can occur over a short or longer period of time, it has been associated with increased allcause and cardiovascular-related mortality (Hamm et al., 1989; Lissner et al., 1989; Lissner et al., 1991;Blair et al., 1991). Additionally, although findings presented here associate changes in healthcare expenditures with recent changes in BMI (for persons aged 65 and older), there is evidence that links healthcare expenditures in older age with previous BMI during adulthood (Daviglus et al., 2010).

Collectively, all the findings in the current study point to the need for preventing overweight or obesity rather than treating these conditions and their negative effects. In this context, weight management and wellness programs that include nutrition and physical activity need to be an integral part of healthcare management of all individuals including the elderly.

The current study focused on total expenditures that included the out-of-pocket spending by the beneficiaries/families. Nearly one fifth of the total healthcare spending is borne by the beneficiaries/families (Crystal et al., 2000) representing a substantial burden on the family. 
Future research needs to explore whether out-of-pocket spending burden is increased in those with BMI gain or BMI loss. Such studies may illustrate the direct financial burden on the beneficiaries/families due to fluctuations in weight.

Those with comorbid mental illness were more likely to be in the BMI gain category compared to those without metnal illness. In addition, comorbid mental illness (depression and history of mental illness) did not change the relationship between BMI and changes in expenditures in the population studied. Prior research suggests that in the context obesity, mental illness increased healthcare expenditures (Shen et al., 2008). Taken together these findings imply that the sub-population of elderly with mental illness need to be closely monitored for unhealthy weight gain.

Prior to 2004, obesity was not considered by Medicare as a disease (Kaiser Family Foundation, 2004). Obesity treatments were only covered for beneficiaries with obesity related conditions such as diabetes. Under new Medicare policy, obesity is considered a disease. It is my hope that Medicare will make it a priority to prevent this disease by proactively promoting weight maintenance, and identifying individuals who can benefit from additional interventions.

\section{Future Research}

Future research is needed to identify intentional versus unintentional weight loss among Medicare enrollees. Patterns of service utilization among persons with weight loss or gain also deserves a closer look. The link between obesity and mental illness remains unclear. Research in this area is ongoing, and with time a better understanding of the causal pathways of the relationship will be realized. 


\section{Strengths}

The following strengths of this study should be noted: 1)The combination of both survey and claims data in which repeated interviews minimize recall bias; 2) the compilation of a comprehensive list of variables from a large, representative sample of US persons 65 and older; 3) Healthcare expenditures were covered not only Medicare but also other payers; and 4) The longitudinal design allowed for tracking of expenditures after BMI changes.

\section{$\underline{\text { Limitations }}$}

\section{BMI Measurement in the Elderly}

Termed sarcopenia, the decreased of muscle mass with increasing adiposity has been shown to occur in aging populations (Baumgarter et al., 1995; Forbes GB., 1999; Goodpaster et al., 2001; Hughes et al., 2002). Additionally, with the potential for vertebral fractures and loss of height in older persons, the use of the conventional BMI measurement has been questioned. One longitudinal study on aging reported that from age 30 to 70 years, men and women lose an average of 3 and $5 \mathrm{~cm}$ in height, respectively. By age 80 , loses were $5 \mathrm{~cm}$ for men and $8 \mathrm{~cm}$ for women (Sorkin et al.,1999). The study also estimated that by age 70, BMI would be artificially raised by $0.7 \mathrm{~kg} / \mathrm{m}^{2}$ in men and $1.6 \mathrm{~kg} / \mathrm{m}^{2}$ in women. At 80 years of age this increase would by 1.4 and $2.6 \mathrm{~kg} / \mathrm{m}^{2}$ respectively. Age adjusted measures of body mass have been suggested. Andres et al., proposed age-adjusted weight standards by which ideal weight could be derived (Andres et al., 1985). Despite these findings, both the World Health Organization and National Heart, Lung, Blood Institute regard BMI as the index of choice to define weight categories in all adults (NHLBI, 2000; WHO, 1997). 
Intentional loss and unintentional loss is not known. Unintentional loss may indicate poor health in these individuals. However, multiple domains of poor health such as presence of chronic conditions, functional status and perceived health status were controlled for in the analyses.

\section{Clinical Relevance of BMI changes}

Weight categories have been defined by the following BMI ranges:

- Underweight: $<18.5 \mathrm{~kg} / \mathrm{m} 2$

- Healthy weight: 18.5 to $24.9 \mathrm{~kg} / \mathrm{m} 2$

- Overweight: 25.0 to $29.9 \mathrm{~kg} / \mathrm{m} 2$

- Obese: $\geq 30$ kg/m2 (Class I 30-34.9 kg/m2; Class II 35-39.9 kg/m2; Class III $\geq 40$ kg/m2)

The following six BMI categories were used in this study: 1) Stayed normal (BMI 18.524.9); 2) BMI loss (decrease in BMI in individuals with baseline BMI greater than or equal to 25); 3) Stayed overweight (BMI between 25 and 29.9 at baseline and follow-up year); 4) Stayed obese (BMI greater than or equal to 30 in baseline and follow-up year); 5)BMI gain (increase in BMI category in individuals with baseline BMI between 18.5 and 24.9); and 6) Stayed underweight/other ( persons with BMI $<18.5$ or other weight change not defined by the previous groups). Theoretically, these categories are easily defined and hold intuitive meaning. However, their clinical relevance may be questioned. For example, does weight loss represented by a change in BMI from 35 to $27 \mathrm{~kg} / \mathrm{m}^{2}$, have the same clinical relevance as a change from 30 to 29

$\mathrm{kg} / \mathrm{m}^{2}$ ? Since the only thresholds for clinical meaning are the weight categories themselves, this 
then becomes a limitation. Therefore, in the previous example, both BMI changes would be categorized as BMI loss.

\section{Length of observation}

The use of three years of observations allowed only for examination of short-term associations between weight loss and expenditures. 


\section{BIBLIOGRAPHY}

Andersen, R. Revisiting the Behavioral Model and Access to Medical Care: Does it Matter? Journal of Health and Social Behavior 199536 (1): 1-10.

Andres R, Elahi D, Tobin JD, Muller DC, Brant L. Impact of age on weight goals. Ann Intern Med. 1985 Dec;103(6 ( Pt 2)):1030-3.

AOA. Administration on Aging. US Department of Health and Human Services. A Profile of Older Americans: 2009.

http://www.aoa.gov/AoARoot/Aging_Statistics/Profile/2009/docs/2009profile_508.pdf Accessed July 10, 2010.

Argen G, Narbro K, Jonsson E, Naslund I, Sjostrom L and Peltonen M. Cost of In-patient care over 7 years among surgically and conventionally treated obese patients. Obes Res 2002 10(12) 1276-1283.

Argen G, Narbro K, Naslund I, Sjostrom L and Peltonen M. Long-term effets of weight loss on pharmaceutical costs in obese subjects. A report from the SOS intervention study. Int $\mathrm{j} \mathrm{Ob}$ 2006(26) 184-192.

Arterburn DE, Crane PK, Sullivan SD The coming epidemic of obesity in elderly Americans. J Am Geriatr Soc. 2004 Nov;52(11):1907-12.

Arterburn DE, Maciejewski ML, Tsevat J. Impact of morbid obesity on medical expenditures in adults. Int J Obes (Lond). 2005 Mar;29(3):334-9.

Associated Press “Alabama Workers Pay for Extra Pounds” Aug. 21, 2008 Available at MSNBC.com http://www.msnbc.msn.com/id/26337794/ Accessed July 1, 2010.

Associated Press “Companies penalizing workers with high health risks” Sept. 9, 2009. Avaailable at USAtoday.com http://www.usatoday.com/money/industries/health/2007-09-09risk-penalties_N.htm Accessed July 1,2010.

Ballantyne GH, Farkas D, Laker S, Wasielewski A. Short-term changes in insulin resistance following weight loss surgery for morbid obesity: laparoscopic adjustable gastric banding versus laparoscopic Roux-en-Y gastric bypass. Obes Surg. 2006 Sep;16(9):1189-97.

Baumgartner RN, Stauber PM, McHugh D, Koehler KM, Garry PJ. Cross-sectional age differences in body composition in persons 60+ years of age. J Gerontol 1995; 50: M307-M316.

Bechtold M, Palmer J, Valtos J, Iasiello C, Sowers J. Metabolic syndrome in the elderly. Curr Diab Rep. 2006 Feb;6(1):64-71. 
Bell JF, Zimmerman FJ, Arterburn DE, Maciejewski ML. Health-care expenditures of overweight and obese males and females in the medical expenditures panel survey by age cohort. Obesity (Silver Spring). 2010 May 13.

Blair SN, Shaten J, Brownell K, Collins G, Lissner L. Body weight change, allcause mortality, and cause-specific mortality in the Multiple Risk Factor Intervention Trial. Ann Intern Med. 1993;119(7 pt 2):749-757.

BLS. Measuring price change for medical care in CPI. Bureau of Labor Statistics., http://www.bls.gov/cpi/cpifact4.htm Accessed July 9, 2010.

Burt CW, McCaig LF, Retchsteiner EA. Centers for Disease Control and Prevention. Ambulatory Medical Care estimates for 2007 http://www.cdc.gov/nchs/data/ad/ad388.pdf. Accessed July 12, 2010.

Brown I, Thompson J, Tod A, Jones G.Primary care support for tackling obesity: a qualitative study of the perceptions of obese patients. Br J Gen Pract. 2006 Sep;56(530):666-72.

Carnethon MR, Biggs ML, Barzilay JI, Smith NL, Vaccarino V, Bertoni AG, Arnold A, Siscovick D.Longitudinal association between depressive symptoms and incident type 2 diabetes mellitus in older adults: the cardiovascular health study. Arch Intern Med. 2007 Apr 23;167(8):802-7.

CDC. Centers for Disease Control and Prevention, 2009 "Prevalence of overweight, obesity and extreme obesity among adults: United States, trends 1960-62 through 2005-2006” http://www.cdc.gov/nchs/data/hestat/overweight/overweight_adult.htm\#table2 Accessed June 15, 2010.

CDC. Centers for Disease Control and Prevention.2010 Physical activity for everyone.How much physical activity do older adults need? http://www.cdc.gov /physicalactivity /everyone /guidelines /olderadults.html.Accessed July 19, 2010.

CDC .Centers for Disease Control and Prevention, "About BMI fir Adults". http://www.cdc.gov/healthyweight/assessing/bmi/adult_bmi/index.html Accessed July 9, 2010.

Charlson M, Charlson RE, Briggs W, Hollenberg J Can disease management target patients most likely to generate high costs? The impact of comorbidity. J Gen Intern Med. 2007 Apr;22(4):464-9.

Ciechanowski PS, Katon WJ, Russo JE, Hirsch IB.The relationship of depressive symptoms to symptom reporting, self-care and glucose control in diabetes. Gen Hosp Psychiatry. 2003 JulAug;25(4):246-52.

Colagiuri S, Lee CM, Colagiuri R, Magliano D, Shaw JE, Zimmet PZ, Caterson IDThe cost of overweight and obesity in Australia. Med J Aust. 2010 Mar 1;192(5):260-4 
Collins RW, Anderson JW. Medication cost savings associated with weight loss for obese noninsulin-dependent diabetic men and women. Prev Med. 1995 Jul;24(4):369-74.

Crystal S, Johnson RW, Harman J, Sambamoorthi U, Kumar ROut-of-pocket health care costs among older Americans. J Gerontol B Psychol Sci Soc Sci. 2000 Jan;55(1):S51-62.

Crystal S, Sambamoorthi U, Walkup JT, Akincigil A. Diagnosis and treatment of depression in the elderly Medicare population: predictors, disparities, and trends. J Am Geriatr Soc. 2003 Dec;51(12):1718-28.

Daviglus ML, Liu K, Yan LL, Pirzada A, Manheim L, Manning W, Garside DB, Wang R, Dyer AR, Greenland P, Stamler JRelation of body mass index in young adulthood and middle age to Medicare expenditures in older age. JAMA. 2004 Dec 8;292(22):2743-9.

DHHS. Department of Health and Human Services. 2008 physical activityguidelines for Americans. http://www.health.gov/paguidelines/guidelines. Accessed July 192010.

Elsawy B, Higgins KE. Physical activity guidelines for older adults. Am Fam Physician. 2010 Jan 1;81(1):55-9.

Ferraro KF, Su YP, Gretebeck RJ, Black DR, Badylak SF. Body mass index and disability in adulthood: a 20-year panel study.Am J Public Health. 2002 May;92(5):834-40.

Finkelstein, EA, Fiebelkorn, IC, Wang, G. National medical spending attributable to overweight and obesity: How much, and who's paying? Health Affairs 2003;W3;219-226.

Finkelstein EA, Linnan LA, Tate DF, Leese PJA longitudinal study on the relationship between weight loss, medical expenditures, and absenteeism among overweight employees in the WAY to Health study. J Occup Environ Med. 2009 Dec;51(12):1367-73.

Finkelstein EA, Trogdon JG, Cohen JW, Dietz W. Annual medical spending attributable to obesity: payer-and service-specific estimates. Health Aff (Millwood). 2009 Sep-Oct;28(5):w82231.

Flegal KM, Carroll MD, Ogden CL, Curtin LR. Prevalence and trends in obesity among US adults, 1999-2008. JAMA. 2010 Jan 20;303(3):235-41. Epub 2010 Jan 13.

Forbes GB. Longitudinal changes in adult fat-free mass: influence of body weight. Am J Clin Nutr. 1999 Dec;70(6):1025-31.

Gami AS, Caples SM, Somers VK. Obesity and obstructive sleep apnea. Endocrinol Metabol Clin North Am 2003;32(4):455-62.

Goetghebeur MM, Forrest S, Hay JW. Understanding the underlying drivers of inpatient cost growth: a literature review. Am J Manag Care. 2003 Jun;9 Spec No 1:SP3-12. 
Goodpaster BH, Carlson CL, Visser M, Kelley DE, Scherzinger A, Harris TB, Stamm E, Newman AB. Attenuation of skeletal muscle and strength in the elderly: The Health ABC Study. J Appl Physiol. 2001 Jun;90(6):2157-65.

Grayson K. Vincent GK and Velkoff VA The Next Four DecadesThe Older Population in the United States:2010 to 2050 US Census Bureau. Washington , DC: US Government Printing Office; May 2010 accessed at http://www.aoa.gov/AoARoot/Aging_Statistics/future_growth/DOCS/p25-1138.pdf

Green V. The domino effect: obesity, type 2 diabetes and cardiovascular disease. Br J Community Nurs. 2005 Aug;10(8):358-61.

Habbu A, Lakkis NM, Dokainish H The obesity paradox: fact or fiction? Am J Cardiol. 2006 Oct 1;98(7):944-8. Epub 2006 Aug 7

Hamm P, Shekelle RB, Stamler J. Large fluctuations in body weight during youngadulthood and twenty-five-year risk of coronary death in men. Am J Epidemiol.1989;129:312-318.

Hart DJ, Spector TD. The relationship of obesity, fat distribution and osteoarthritis in women in the general population: the Chingford Study. J Rheumatol. 1993 Feb;20(2):331-5.

Haslam D. Understanding obesity in the older person: prevalence and risk factors. $\mathrm{Br} \mathrm{J}$ Community Nurs. 2008 Mar;13(3):115-6, 118, 120-2.

Helmer D, Banerjea R, Sambamoorthi U. Longitudinal changes in obesity and expenditures. Annual Meeting of the AcademyHealth, June 2007.

Hibbert-Jones E, Regan G, Bramwell J.What do we know about... diabetes and obesity in adults and children? J Fam Healthcare. 2004;14(4):95-8.

Houston DK, Nicklas BJ, Zizza CA Weighty concerns: the growing prevalence of obesity among older adults. J Am Diet Assoc. 2009 Nov;109(11):1886-95.

Hoover DR, Crystal S, Kumar R, Sambamoorthi U, Cantor JC. Medical expenditures during the last year of life: findings from the 1992-1996 Medicare current beneficiary survey. Health Serv Res.2002 Dec;37(6):1625-42.

Hubbard RE, Lang IA, Llewellyn DJ, Rockwood K. Frailty, body mass index, and abdominal obesity in older people. J Gerontol A Biol Sci Med Sci. 2010 Apr;65(4):377-81. Epub 2009 Nov 25. 
Hughes VA, Frontera WR, Roubenoff R, Evans WJ, Singh MA. Longitudinal changes in body composition in older men and women: role of body weight change and physical activity. Am J Clin Nutr. 2002 Aug;76(2):473-81.

Jaen CR, Stange KC, Nutting PA. Competing demands of primary care: a model for the delivery ofclinical preventive services. J Fam Pract 1994;38(2):166-71.

Janssen I, Katzmarzyk PT, Ross R Body mass index, waist circumference, and health risk: evidence in support of current National Institutes of Health guidelines. Arch Intern Med. 2002 Oct 14;162(18):2074-9.

Janssen I, Lam M, Katzmarzyk PT.Influence of overweight and obesity on physician costs in adolescents and adults in Ontario, Canada.Obes Rev. 2009 Jan;10(1):51-7. Epub 2008 Jul 18.

Jensen GL, Friedmann JM.Obesity is associated with functional decline in community-dwelling rural older persons. J Am Geriatr Soc. 2002 May;50(5):918-23.

Jon R. Gabel, Heidi Whitmore, Jeremy Pickreign, Christine C. Ferguson, Anjali Jain, Shova KC and Hilary Scherer Obesity And The Workplace: Current Programs And Attitudes Among Employers And Employees Health Affairs, 28, no. 1 (2009): 46-56

Kaiser Family Foundation. Medicare Removes Barriers to Obesity Treatment Coverage. http://www.kaisernetwork.org/daily_reports/rep_index.cfm?hint=3\&DR_ID=24756 Accessed July 15, 2010.

Klinkman MS. Competing demands in psychosocial care. A model for the identification and treatment of depressive disorders in primary care. Gen Hosp Psychiatry 1997;19(2):98-111.

Knowler WC, Barrett-Connor E, FowlerSE, et al. Reduction in the incidence of type 2diabetes with lifestyle intervention or metformin. N Engl J Med 2002;346:393-403.

Lawati N, Patel S, Ayas N. Epidemiology, risk factors and consequences of obstructive sleep apnea and short sleep duration. Prog Cardiovasc Dis 2009;51:285-93.

Lechleitner M. Obesity and the metabolic syndrome in the elderly--a mini-review. Gerontology. 2008;54(5):253-9.

Lee JS, Kritchevsky SB, Harris TB, Tylavsky F, Rubin SM, Newman ABShort-term weight changes in community-dwelling older adults: the Health, Aging, and Body Composition Weight Change Substudy. Am J Clin Nutr. 2005 Sep;82(3):644-50.

Lissner L, Bengtsson C, Lapidus L, Larsson B, Bengtsson B, Brownell K. Bodyweight variability and mortality in the Gothenburg prospective studies of menand women. In: Bjorntorp P, Rossner S, eds. Obesity in Europe. London, England:John Libbey; 1989:55-60. 
Lissner L, Odell PM, D’Agostino EB, et al. Variability of body weight and healthoutcomes in the Framingham population. N Engl J Med. 1991;324:1839-1844.

Llaneza P, Iñarrea J, Gonzalez C, Alonso A, Arnott I, Ferrer-Barriendos J. Differences in health related quality of life in a sample of Spanish menopausal women with and without obesity. Maturitas. 2007 Dec 20;58(4):387-94.

Lorenzen, G., “Log-ratios and the logarithmic mean”, Stat. Papers 30 (1989) 61-75

Luppino FS, de Wit LM, Bouvy PF, Stijnen T, Cuijpers P, Penninx BW, Zitman FG. Overweight, obesity, and depression: a systematic review and meta-analysis of longitudinal studies. Arch Gen Psychiatry. 2010 Mar;67(3):220-9.

Mancuso CA, Peterson MG, Charlson MEEffects of depressive symptoms on health-related quality of life in asthma patients. J Gen Intern Med. 2000 May;15(5):301-10.

McAuley P, Myers J, Abella J, Froelicher V Body mass, fitness and survival in veteran patients: another obesity paradox? Am J Med. 2007 Jun;120(6):518-24.

McAvoy BR, Kaner EF, Lock CA, Heather N, Gilvarry E.Our Healthier Nation: are general practitioners willing and able to deliver? A survey of attitudes to and involvement in health promotion and lifestyle counselling. Br J Gen Pract. 1999 Mar;49(440):187-90.

Monk JS, MD; Nagib ND; Stehr W, MD. Pharmaceutical Savings after Gastric Bypass Surgery Obesity Surgery,2004 14, 13-15

Moyers SB. Medications as adjunct therapy for weight loss: approved and off-label agents in use. J Am Diet Assoc. 2005 Jun;105(6):948-59.

National Heart, Lung, and Blood Pressure (NHLB) National Institutes of Health (NIH); North American Association for the Study of Obesity (NAASO. The practical guide: identification, evaluation, and treatment of overweight and obesity in adults, NIH Publication No 00-4084 National Institutes of Health: Rockville, MD; 2000. http://www.nhlbi.nih.gov/guidelines/obesity/prctgd_c.pdf Accessed July11,2010

Nguyen NT, Magno CP, Lane KT, Hinojosa MW, Lane JS. Association of hypertension, diabetes, dyslipidemia, and metabolic syndrome with obesity: findings from the National Health and Nutrition Examination Survey, 1999 to 2004. J Am Coll Surg. 2008 Dec;207(6):928-34.

Nutting PA, Rost K, Smith J, Werner JJ, Elliot C. Competing demands from physical problems: effect on initiating and completing depression care over 6 months. Arch Fam Med 2000;9(10):1059-64.

Oreopoulos A, Kalantar-Zadeh K, Sharma AM, Fonarow GC The obesity paradox in the elderly: potential mechanisms and clinical implications. Clin Geriatr Med. 2009 Nov;25(4):643-59, viii. 
Orleans CT, George LK, Houpt JL, Brodie KH.Health promotion in primary care: a survey of U.S. family practitioners Prev Med. 1985 Sep;14(5):636-47.

Oster G, Thompson D, Edelsberg J, Bird AP, Colditz GA. Lifetime health and economic benefits of weight loss among obese persons. Am J Public Health. 1999 Oct;89(10):1536-42.

Palomar R, Fernández-Fresnedo G, Domínguez-Diez A, López-Deogracias M, Olmedo F, Martín de Francisco AL, Sanz de Castro S, Casado Martín F, Gómez-Fleitas M, Arias M, FernándezEscalante CEffects of weight loss after biliopancreatic diversion on metabolism and cardiovascular profile. Obes Surg. 2005 Jun-Jul;15(6):794-8.

Patterson r, Frank L., Kristal A, White E. A comprehensive examination of health conditions associated with obesity in older adults. Am J Prev Med 2004; 27:385-90.

Peytremann-Bridevaux I, Santos-Eggimann B. Health correlates of overweight and obesity in adults aged 50 years and over: results from the Survey of Health, Ageing and Retirement in Europe (SHARE). Obesity and health in Europeans aged $>$ or $=50$ years. Swiss Med Wkly. 2008 May 3;138(17-18):261-6.

Piette JD, Richardson C, Valenstein M. Addressing the needs of patients with multiple chronic illnesses: the case of diabetes and depression. Am J Manag Care 2004;10(2 Pt 2):152-62.

Rimington LD, Davies DH, Lowe D, Pearson MGRelationship between anxiety, depression, and morbidity in adult asthma patients. Thorax. 2001 Apr;56(4):266-71.

Rexrode KM, Hennekens CH, Willett WC. Colditz GA, Stampfer MJ, Rich-Edwards JW, et al. A prospective study of ody mass index, weight change and risk of stroke in women., JAMA 1997; 277(19): 1539-45.

Rost K, Nutting P, Smith J, Coyne JC, Cooper-Patrick L, Rubenstein L.The role of competing demands in the treatment provided primary care patients with major depression. Arch Fam Med. 2000 Feb;9(2):150-4.

Rumsfeld JS, Havranek E, Masoudi FA, Peterson ED, Jones P, Tooley JF, Krumholz HM, Spertus JA; Cardiovascular Outcomes Research Consortium.. Depressive symptoms are the strongest predictors of short-term declines in health status in patients with heart failure. J Am Coll Cardiol. 2003 Nov 19;42(10):1811-7.

Ruo B, Rumsfeld JS, Hlatky MA, Liu H, Browner WS, Whooley MA.Depressive symptoms and health-related quality of life: the Heart and Soul Study. JAMA. 2003 Jul 9;290(2):215-21.

Sambamoorthi U, Akincigil A, Wei W, Crystal S. National trends in out-of-pocket prescription drug spending among elderly Medicare beneficiaries. Expert Rev Pharmacoecon Outcomes Res. 2005 Jun;5(3):297-315.PMID: 19807600 
Shen C, Sambamoorthi U, Rust G.Co-occurring mental illness and health care utilization and expenditures in adults with obesity and chronic physical illness. Dis Manag. 2008 Jun;11(3):15360.

Sommers AR. Obesity Among Older Americans. Februaury 8, 2008. Congressional Research Service Report to Congress Order no RL34358. http://aging.senate.gov/crs/aging3.pdf Accessed June 30, 2010

Sorkin JD, Muller DC, Andres R. Longitudinal change in height of men and women: implications for interpretation of the body mass index: the Baltimore Longitudinal Study of Aging. Am J Epidemiol. 1999 Nov 1;150(9):969-77.

Stuart B, Lloyd J, Zhao L, Kamal-Bahl S. Obesity, disease burden, and prescription spending by community-dwelling Medicare beneficiaries. Curr Med Res Opin. 2008 Aug;24(8):2377-87.

Sullivan PW, Ghushchyan V, Ben-Joseph RH. The effect of obesity and cardiometabolic risk factors on expenditures and productivity in the United States. Obesity (Silver Spring). 2008 Sep;16(9):2155-62.

Thorpe KE.Factors accounting for the rise in health-care spending in the United States: the role of rising disease prevalence and treatment intensity.Public Health. 2006 Nov;120(11):1002-7.

Trasande L, Chatterjee S. The impact of obesity on health service utilization and costs in childhood. Obesity (Silver Spring). 2009 Sep;17(9):1749-54. Epub 2009 Mar 19.

Trogdon J, Finkelstein EA, Reyes M, Dietz WH. A return-on-investment simulation model of workplace obesity interventions. J Occup Environ Med. 2009 Jul;51(7):751-8.

Tsai AW, CushmanM, Rosamond WD, Heckbert SR, Polak JF, Folsom AR. Cardiovascular risk factors and venous thromboembolism incidence: the longitudinal investigation of thromboembolism etiology. Arch Int Med 2002; 162(10):1182-9.

Tsai AG, Wadden TA.Treatment of obesity in primary care practice in the United States: a systematic review. J Gen Intern Med. 2009 Sep;24(9):1073-9.

Visram S, Crosland A, Cording H.Triggers for weight gain and loss among participants in a primary care-based intervention. Br J Community Nurs. 2009 Nov;14(11):495-501.

Vogeli C, Shields AE, Lee TA, Gibson TB, Marder WD, Weiss KB, Blumenthal D Multiple chronic conditions: prevalence, health consequences, and implications for quality, care management, and costs. J Gen Intern Med. 2007 Dec;22 Suppl 3:391-5.

Wee CC, Phillips RS, Legedza AT, Davis RB, Soukup JR, Colditz GA, Hamel MB.Healthcare expenditures associated with overweight and obesity among US adults: importance of age and race. Am J Public Health. 2005 Jan;95(1):159-65. 
WHO. Preventing and managing the global epidemic of obesity: Report of the World Health Organization Consultation of Obesity. WHO:Geneva, June 1997.

Willett WC, Dietz WH Colditz GA., Guidelines for healthy weight. N Engl J Med 199;341(6)427-34.

Wilson PW, D’Agostino RB, Sullivan L, Parise H, Kannel WB. Overweight and obesity as determinants of cardiovascular risk: the Framingham experience. Arch Intern Med 2002; 162(16): 1867-72.

Yang Z, Hall AG.The financial burden of overweight and obesity among elderly Americans: the dynamics of weight, longevity, and healthcare cost. Health Serv Res. 2008 Jun;43(3):849-68.

Yu AP, Wu EQ, Birnbaum HG, Emani S, Fay M, Pohl G, Wintle M, Yang E, Oglesby A. Shortterm economic impact of body weight change among patients with type 2 diabetes treated with antidiabetic agents: analysis using claims, laboratory, and medical record data. Curr Med Res Opin. 2007 Sep;23(9):2157-69. 


\section{APPENDIX A \\ Cohort Sample Sizes by Round and Observation Year of Survey \\ Medicare Current Beneficiary Survey 2000-2005}

\begin{tabular}{|c|c|c|c|c|c|c|c|c|c|}
\hline \multicolumn{10}{|c|}{$\begin{array}{c}\text { Table A.1 Panel Sample Sizes by Round and Observation Year of Survey } \\
\text { Medicare Current Beneficiary Survey 2000-2005 }\end{array}$} \\
\hline Round & $\begin{array}{r}\text { Year } \\
2000\end{array}$ & 2001 & 2002 & 2003 & 2004 & 2005 & 2006 & 2007 & 2008 \\
\hline 19 & 3774 & & & & & & & & \\
\hline 22 & 3984 & 3616 & & & & & & & \\
\hline 25 & 4547 & 4042 & 3663 & & & & & & \\
\hline 28 & 311 & 4471 & 4003 & 3615 & & & & & \\
\hline 31 & 399 & 367 & 4308 & 3812 & 3402 & & & & \\
\hline 34 & & 368 & 337 & 4337 & 3815 & 3452 & & & \\
\hline 37 & & & 386 & 348 & 4166 & 3693 & & & \\
\hline 40 & & & & 374 & 349 & 4192 & & & \\
\hline 43 & & & & & 347 & 323 & & & \\
\hline 46 & & & & & & 369 & & & \\
\hline 49 & & & & & & & & & \\
\hline 52 & & & & & & & & & \\
\hline
\end{tabular}

Sample sizes in red font represent newly enrolled beneficiaries who were included in interviews even if they became Medicare eligible after the start date for a new round and have missing or incomplete survey information 


\section{APPENDIX B \\ Sensitivity Analyses of Change in Body Mass Index Categories and Expenditures Alternative Specifications of the Dependent Variable (Expenditures)}

\begin{tabular}{|c|c|c|c|c|c|c|c|c|c|c|}
\hline \multicolumn{11}{|c|}{$\begin{array}{c}\text { Table B1 } \\
\begin{array}{c}\text { Description by Percent Change in Expenditures Categories } \\
\text { Medicare Current Beneficiaries Survey 2000-2005 }\end{array} \\
\end{array}$} \\
\hline & \multicolumn{2}{|c|}{ \$0 Both } & \multicolumn{2}{|c|}{$>10 \%$ Decrease } & \multicolumn{2}{|c|}{ Minimal Variation } & \multicolumn{2}{|c|}{$>10 \%$ Increase } & \multirow{3}{*}{ Chi-sq } & \multirow{3}{*}{ sig } \\
\hline & $\mathbf{N}$ & $\%$ & $\mathbf{N}$ & $\%$ & $\mathbf{N}$ & $\%$ & $\mathbf{N}$ & $\%$ & & \\
\hline & 14,056 & $22 \%$ & 21,293 & $34 \%$ & 3,905 & $6 \%$ & 24,288 & $38 \%$ & & \\
\hline \multicolumn{11}{|l|}{ Total } \\
\hline Stayed Normal & 26 & 0.8 & 1443 & 41.2 & 321 & 9.4 & 1675 & 48.6 & 12.91 & \\
\hline BMI loss & 4 & 0.3 & 444 & 45.3 & 78 & 8.4 & 456 & 46.0 & & \\
\hline Stayed Overweight & 17 & 0.7 & 1386 & 42.2 & 279 & 8.0 & 1648 & 49.0 & & \\
\hline Stayed Obese & 9 & 0.7 & 684 & 41.0 & 161 & 9.5 & 842 & 48.8 & & \\
\hline BMI gain & 5 & 0.7 & 341 & 40.7 & 78 & 9.8 & 443 & 48.8 & & \\
\hline Stayed Over/Other & 1 & 0.2 & 143 & 39.3 & 29 & 8.2 & 185 & 52.2 & & \\
\hline \multicolumn{11}{|l|}{ Inpatient } \\
\hline Stayed Normal & 2335 & 69.8 & 468 & 12.4 & 32 & 0.8 & 630 & 17.0 & 62.53 & $* * *$ \\
\hline BMI loss & 579 & 61.0 & 213 & 20.4 & 7 & 1.1 & 183 & 17.5 & & \\
\hline Stayed Overweight & 2284 & 70.3 & 460 & 13.1 & 24 & 0.7 & 562 & 15.9 & & \\
\hline Stayed Obese & 1092 & 66.2 & 267 & 15.4 & 13 & 0.7 & 324 & 17.8 & & \\
\hline BMI gain & 575 & 69.1 & 103 & 11.1 & 3 & 0.6 & 186 & 19.2 & & \\
\hline Stayed Over/Other & 198 & 57.7 & 66 & 17.5 & 2 & 0.5 & 92 & 24.2 & & \\
\hline \multicolumn{11}{|l|}{ Outpatient } \\
\hline Stayed Normal & 516 & 15.4 & 1445 & 41.0 & 86 & 2.4 & 1418 & 41.2 & 29.13 & $*$ \\
\hline BMI loss & 130 & 14.3 & 387 & 39.0 & 31 & 3.1 & 434 & 43.6 & & \\
\hline Stayed Overweight & 471 & 15.1 & 1270 & 38.5 & 128 & 3.7 & 1461 & 42.7 & & \\
\hline Stayed Obese & 199 & 12.3 & 713 & 42.0 & 65 & 3.7 & 719 & 42.0 & & \\
\hline BMI gain & 105 & 12.7 & 340 & 39.9 & 35 & 4.1 & 387 & 43.3 & & \\
\hline Stayed Over/Other & 57 & 16.5 & 154 & 41.7 & 7 & 1.8 & 140 & 39.9 & & \\
\hline \multicolumn{11}{|l|}{ Prescription Drugs } \\
\hline Stayed Normal & 168 & 5.0 & 1370 & 38.9 & 441 & 12.3 & 1486 & 43.7 & 36.37 & $* *$ \\
\hline BMI loss & 22 & 2.3 & 375 & 36.7 & 137 & 14.4 & 448 & 46.6 & & \\
\hline Stayed Overweight & 143 & 4.7 & 1234 & 36.6 & 466 & 14.2 & 1487 & 44.5 & & \\
\hline Stayed Obese & 45 & 2.9 & 681 & 40.6 & 251 & 14.3 & 719 & 42.3 & & \\
\hline BMI gain & 25 & 3.2 & 322 & 37.2 & 126 & 15.0 & 394 & 44.7 & & \\
\hline Stayed Over/Other & 20 & 5.5 & 152 & 40.6 & 47 & 12.7 & 139 & 41.2 & & \\
\hline \multicolumn{11}{|l|}{ Dental } \\
\hline Stayed Normal & 1513 & 41.6 & 973 & 28.6 & 132 & 4.1 & 847 & 25.7 & 81.24 & $* * *$ \\
\hline BMI loss & 493 & 49.1 & 265 & 26.9 & 28 & 3.1 & 196 & 20.8 & & \\
\hline Stayed Overweight & 1421 & 41.2 & 944 & 28.7 & 94 & 2.7 & 871 & 27.3 & & \\
\hline Stayed Obese & 828 & 47.5 & 432 & 25.9 & 55 & 3.2 & 381 & 23.3 & & \\
\hline
\end{tabular}




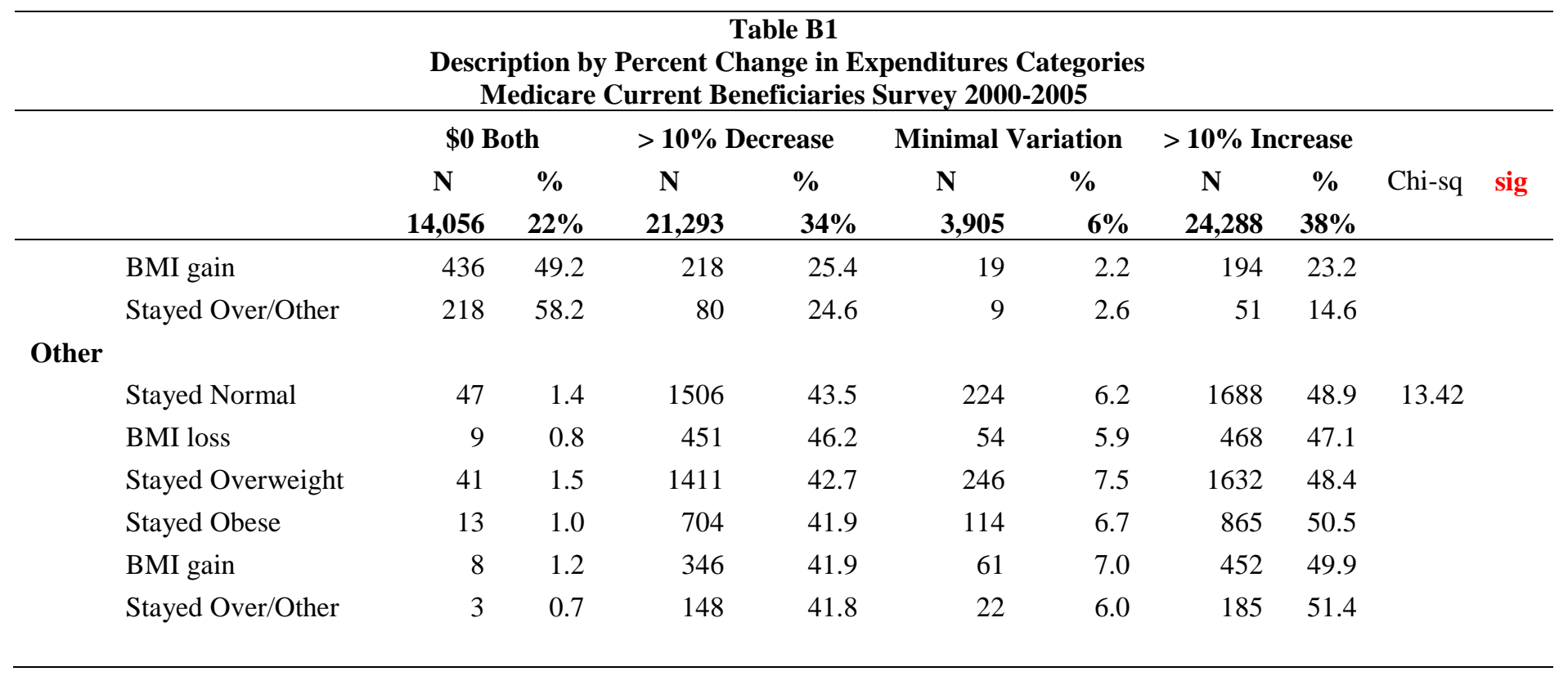

Note: Based on community-dwelling Medicare beneficiaries over age 65, followed for three years and had no missing body mass index values and were first included in the survey between 2000 and 2003.

Body mass index change categories were defined as follows: Stayed Normal- individuals with a normal BMI (18.5$24.9 \mathrm{~kg} / \mathrm{m}^{2}$ ) at baseline and follow-up; BMI gain- individuals with normal BMI ( $18.5-24.9 \mathrm{~kg} / \mathrm{m}^{2}$ ) or overweight BMI (25-29.9 $\left.\mathrm{kg} / \mathrm{m}^{2}\right)$ at baseline who moved to a higher BMI category at follow up ( i.e. overweight, obese, morbidly obese); BMI loss- individuals with overweight BMI $\left(25-29.9 \mathrm{~kg} / \mathrm{m}^{2}\right)$ or obese BMI $\left(>30 \mathrm{~kg} / \mathrm{m}^{2}\right)$ at baseline who moved to a lower BMI category at follow up ( i.e. overweight or normal); Stayed OverweightIndividuals with overweight BMI ( $25-29.9 \mathrm{~kg} / \mathrm{m}^{2}$ ) at baseline and follow-up; Stayed Obese- Individuals with obese BMI ( $>30 \mathrm{~kg} / \mathrm{m}^{2}$ ) at baseline and follow-up; and Stayed Underweight/Other- includes individuals with underweight BMI $\left(<18.5 \mathrm{~kg} / \mathrm{m}^{2}\right)$ at base line and follow-up as well as those with weight changes not defined by the categories above.

*** $\mathrm{p}<0.001 ; * * 0.001<\mathrm{p}<0.01 ; * 0.01<\mathrm{p}<0.05$ 


\begin{tabular}{|c|c|c|c|c|c|c|c|c|c|}
\hline \multicolumn{10}{|c|}{$\begin{array}{c}\text { Table B2 } \\
\begin{array}{c}\text { Multinomial Logistic Regression on Percent Change in Expenditures Categories } \\
\text { by Body Mass Index Change Categories }\end{array} \\
\begin{array}{c}\text { Reference Group for Dependent Variable: Minimal Variations in Expenditures } \\
\text { Medicare Current Beneficiaries Survey 2000-2005 }\end{array}\end{array}$} \\
\hline & \multicolumn{3}{|c|}{ \$0 Both Years } & \multicolumn{3}{|c|}{$>10 \%$ Decrease } & \multicolumn{3}{|c|}{$>10 \%$ Increase } \\
\hline & AOR & $95 \%$ CI & Sig & AOR & $95 \%$ CI & Sig & AOR & $95 \% \mathrm{CI}$ & Sig \\
\hline \multicolumn{10}{|l|}{ Outpatient } \\
\hline Healthy Loss & 0.68 & {$[0.44,1.06]$} & & 0.73 & {$[0.44,1.21]$} & & 0.76 & {$[0.47,1.23]$} & \\
\hline Stayed Over & 0.57 & {$[0.40,0.80]$} & $* *$ & 0.60 & {$[0.42,0.87]$} & $* *$ & 0.62 & {$[0.44,0.88]$} & $* *$ \\
\hline Stayed Obese & 0.63 & {$[0.44,0.89]$} & $* *$ & 0.65 & {$[0.43,0.96]$} & $*$ & 0.63 & {$[0.45,0.88]$} & $* *$ \\
\hline $\begin{array}{l}\text { Unhealthy Gain } \\
\text { Stayed } \\
\text { under/Other }\end{array}$ & 0.50 & {$[0.33,0.76]$} & $* *$ & 0.48 & {$[0.30,0.79]$} & $* *$ & 0.55 & {$[0.36,0.83]$} & $* *$ \\
\hline \multicolumn{10}{|l|}{ Prescription } \\
\hline Healthy Loss & 0.83 & {$[0.65,1.05]$} & & 0.53 & {$[0.28,1.00]$} & * & 0.96 & {$[0.75,1.23]$} & \\
\hline Stayed Over & 0.84 & {$[0.72,0.99]$} & $*$ & 1.00 & {$[0.73,1.37]$} & & 0.88 & {$[0.75,1.04]$} & \\
\hline Stayed Obese & 0.96 & {$[0.79,1.18]$} & & 1.12 & {$[0.72,1.75]$} & & 0.90 & {$[0.74,1.11]$} & \\
\hline $\begin{array}{l}\text { Unhealthy Gain } \\
\text { Stayed }\end{array}$ & 0.84 & {$[0.65,1.08]$} & & 0.70 & {$[0.41,1.19]$} & & 0.90 & {$[0.71,1.15]$} & \\
\hline
\end{tabular}

\section{Table B3}

Multinomial Logistic Regression on Percent Change in Inpatient Expenditures Categories by Body Mass Index Change Categories

Reference Group for Dependent Variable: $10 \%$ Increase

Medicare Current Beneficiaries Survey 2000-2005

\begin{tabular}{lcccccc}
\hline & \multicolumn{3}{c}{ \$0 Both Years } & \multicolumn{3}{c}{ Less Than 10\% Increase } \\
& AOR & $\mathbf{9 5 \%} \mathbf{~ C I}$ & Sig & AOR & $\mathbf{9 5 \%}$ CI & Sig \\
Inpatient & & & & & & \\
$\quad$ Healthy Loss & 1.52 & {$[1.22,1.91]$} & $* * *$ & 0.90 & {$[0.74,1.09]$} & \\
$\quad$ Stayed Over & 1.08 & {$[0.90,1.29]$} & & 1.06 & {$[0.92,1.22]$} & \\
Stayed Obese & 1.14 & {$[0.91,1.44]$} & & 1.06 & {$[0.89,1.26]$} & \\
$\quad$ Unhealthy Gain & 0.80 & {$[0.60,1.06]$} & & 0.98 & {$[0.79,1.21]$} \\
$\quad$ Stayed under/Other & 1.09 & {$[0.74,1.60]$} & & 0.75 & {$[0.57,1.00]$} \\
& & & & & & \\
\hline
\end{tabular}




\begin{tabular}{|c|c|c|c|c|c|c|}
\hline \multicolumn{7}{|c|}{$\begin{array}{c}\text { Table B4 } \\
\begin{array}{c}\text { Multinomial Logistic Regression on Percent Change in Total Expenditures Categories } \\
\text { by Body Mass Index Change Categories }\end{array} \\
\begin{array}{c}\text { Reference Group for Dependent Variable: Minimal Variation in Expenditures } \\
\text { Medicare Current Beneficiaries Survey 2000-2005 }\end{array}\end{array}$} \\
\hline & & 10 \% Declin & & & \% Increase & \\
\hline & AOR & $95 \%$ CI & Sig & AOR & $95 \%$ CI & Sig \\
\hline \multicolumn{7}{|l|}{ Total } \\
\hline Healthy Loss & 1.05 & {$[0.81,1.37]$} & & 1.21 & {$[0.96,1.54]$} & \\
\hline Stayed Over & 1.12 & {$[0.92,1.38]$} & & 1.13 & {$[0.93,1.37]$} & \\
\hline Stayed Obese & 0.94 & {$[0.75,1.18]$} & & 0.92 & {$[0.73,1.14]$} & \\
\hline Unhealthy Gain & 0.94 & {$[0.70,1.26]$} & & 0.92 & {$[0.68,1.23]$} & \\
\hline Stayed under/Other & 1.26 & {$[0.82,1.94]$} & & 1.15 & {$[0.76,1.75]$} & \\
\hline
\end{tabular}

Note: Based on community-dwelling Medicare beneficiaries over age 65, followed for three years and had no missing body mass index values and were first included in the survey between 2000 and 2003.

Body mass index change categories were defined as follows: Stayed Normal- individuals with a normal BMI (18.5$24.9 \mathrm{~kg} / \mathrm{m}^{2}$ ) at baseline and follow-up; BMI gain- individuals with normal BMI ( $18.5-24.9 \mathrm{~kg} / \mathrm{m}^{2}$ ) or overweight BMI $\left(25-29.9 \mathrm{~kg} / \mathrm{m}^{2}\right)$ at baseline who moved to a higher BMI category at follow up ( i.e. overweight, obese, morbidly obese); BMI loss- individuals with overweight BMI (25-29.9 $\left.\mathrm{kg} / \mathrm{m}^{2}\right)$ or obese BMI $\left(>30 \mathrm{~kg} / \mathrm{m}^{2}\right)$ at baseline who moved to a lower BMI category at follow up ( i.e. overweight or normal); Stayed OverweightIndividuals with overweight BMI ( $25-29.9 \mathrm{~kg} / \mathrm{m}^{2}$ ) at baseline and follow-up; Stayed Obese- Individuals with obese BMI ( $>30 \mathrm{~kg} / \mathrm{m}^{2}$ ) at baseline and follow-up; and Stayed Underweight/Other- includes individuals with underweight BMI $\left(<18.5 \mathrm{~kg} / \mathrm{m}^{2}\right)$ at base line and follow-up as well as those with weight changes not defined by the categories above.

$* * * \mathrm{p}<0.001 ; * * \quad 0.001 \leq \mathrm{p}<0.01 ; * 0.01 \leq \mathrm{p}<0.05$ 


\section{Appendix C \\ Mental Illness and Change in Body Mass Index Categories and Short-term Expenditures Ordinary Least Squares regression on Logged Expenditures (Constant \$ 2005)}

\begin{tabular}{|c|c|c|c|c|c|c|}
\hline \multicolumn{7}{|c|}{$\begin{array}{r}\text { Table C1 } \\
\text { Ordinary Least Squares Regression on } \\
\text { With and Without Menta } \\
\text { Change in Body Mass Index } \\
\text { Medicare Current Beneficiary Su }\end{array}$} \\
\hline+2 & \multicolumn{2}{|c|}{$\begin{array}{c}\begin{array}{c}\text { With } \\
\text { Mental Illness }\end{array} \\
\frac{\text { as Control }}{\text { Variables }}\end{array}$} & \multirow[b]{2}{*}{ Sig } & \multicolumn{3}{|c|}{$\underset{\text { As }}{\frac{\text { Without }}{\text { Mental Illness }}}$} \\
\hline & & & & Beta & SE & Sig \\
\hline \multicolumn{7}{|l|}{ Total } \\
\hline Stayed normal & 7.978 & 0.152 & ref & 7.990 & 0.151 & Ref \\
\hline BMI loss & 0.090 & 0.063 & & 0.088 & 0.063 & \\
\hline Stayed overweight & -0.034 & 0.044 & & -0.035 & 0.044 & \\
\hline Stayed obese & -0.020 & 0.047 & & -0.021 & 0.047 & \\
\hline BMI gain & 0.139 & 0.067 & $*$ & 0.146 & 0.067 & $*$ \\
\hline Stayed Under/Other & -0.036 & 0.113 & & -0.034 & 0.114 & \\
\hline \multicolumn{7}{|l|}{ Inpatient } \\
\hline Stayed normal & 2.254 & 0.315 & ref & 2.269 & 0.314 & Ref \\
\hline BMI loss & 0.239 & 0.146 & & 0.238 & 0.146 & \\
\hline Stayed overweight & -0.134 & 0.091 & & -0.136 & 0.091 & \\
\hline Stayed obese & -0.129 & 0.120 & & -0.131 & 0.121 & \\
\hline BMI gain & 0.030 & 0.156 & & 0.040 & 0.156 & \\
\hline Stayed Under/Other & 0.406 & 0.233 & & 0.410 & 0.234 & \\
\hline \multicolumn{7}{|l|}{ Outpatient } \\
\hline Stayed normal & 3.504 & 0.265 & ref & 3.520 & 0.265 & Ref \\
\hline BMI loss & 0.244 & 0.107 & $*$ & 0.243 & 0.107 & $*$ \\
\hline Stayed overweight & 0.131 & 0.074 & & 0.129 & 0.074 & \\
\hline Stayed obese & 0.137 & 0.101 & & 0.136 & 0.102 & \\
\hline BMI gain & 0.240 & 0.112 & $*$ & 0.249 & 0.112 & $*$ \\
\hline Stayed Under/Other & -0.203 & 0.182 & & -0.201 & 0.183 & \\
\hline \multicolumn{7}{|l|}{ Prescription Drugs } \\
\hline Stayed normal & 5.258 & 0.187 & ref & 5.275 & 0.186 & ref \\
\hline BMI loss & 0.154 & 0.067 & $*$ & 0.152 & 0.067 & $*$ \\
\hline Stayed overweight & 0.077 & 0.056 & & 0.077 & 0.056 & \\
\hline Stayed obese & 0.149 & 0.062 & $*$ & 0.151 & 0.062 & $*$ \\
\hline BMI gain & 0.257 & 0.079 & $* *$ & 0.265 & 0.079 & $* * *$ \\
\hline Stayed Under/Other & -0.344 & 0.145 & $*$ & -0.345 & 0.146 & $*$ \\
\hline
\end{tabular}




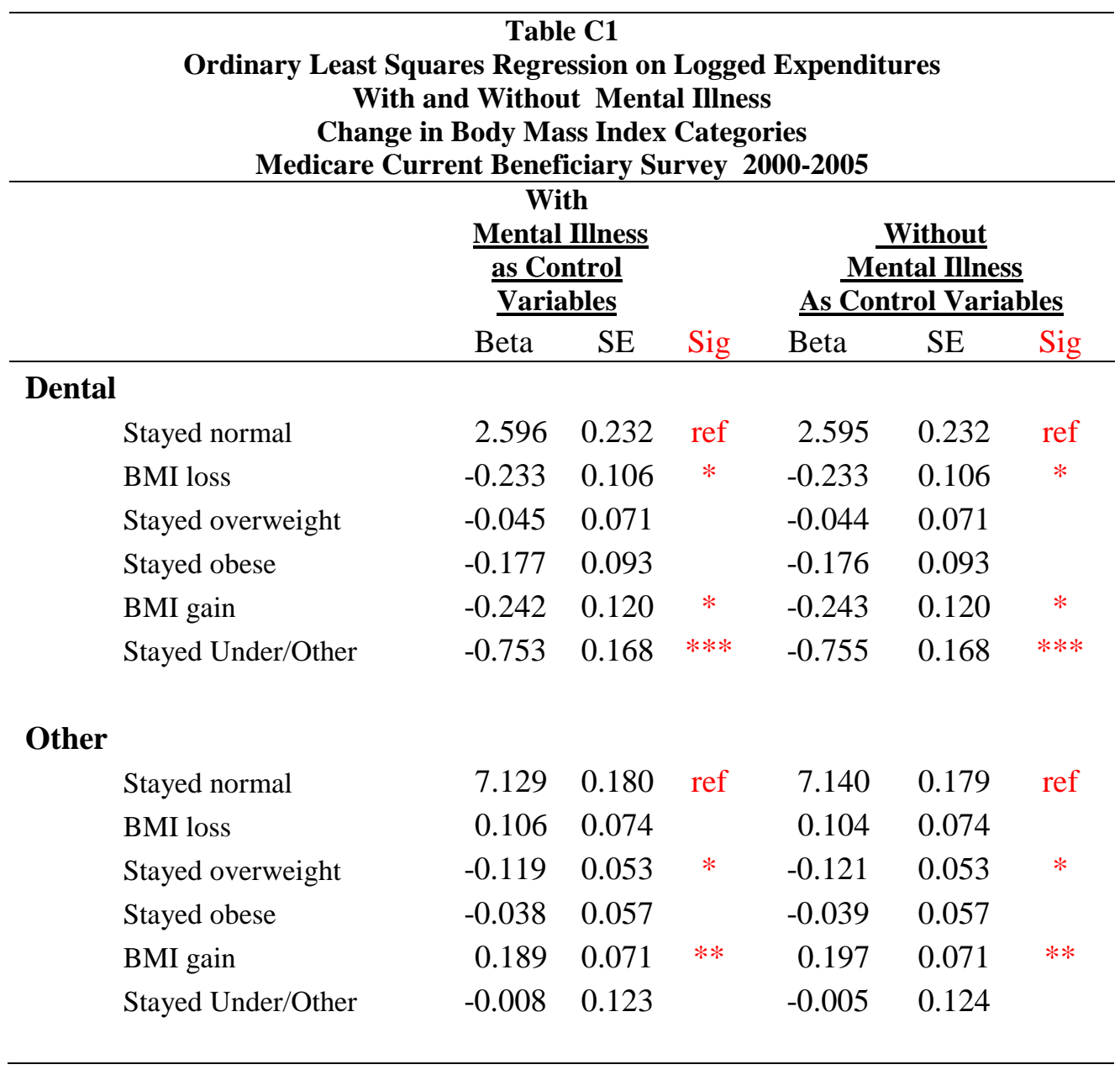

Note: Based on community-dwelling Medicare beneficiaries over age 65, followed for three years and had no missing body mass index values and were first included in the survey between 2000 and 2003.

Body mass index change categories were defined as follows: Stayed Normal- individuals with a normal BMI (18.5$24.9 \mathrm{~kg} / \mathrm{m}^{2}$ ) at baseline and follow-up; BMI gain- individuals with normal BMI ( $18.5-24.9 \mathrm{~kg} / \mathrm{m}^{2}$ ) or overweight BMI $\left(25-29.9 \mathrm{~kg} / \mathrm{m}^{2}\right)$ at baseline who moved to a higher BMI category at follow up ( i.e. overweight, obese, morbidly obese); BMI loss- individuals with overweight BMI $\left(25-29.9 \mathrm{~kg} / \mathrm{m}^{2}\right)$ or obese BMI $\left(>30 \mathrm{~kg} / \mathrm{m}^{2}\right)$ at baseline who moved to a lower BMI category at follow up ( i.e. overweight or normal); Stayed OverweightIndividuals with overweight BMI ( $25-29.9 \mathrm{~kg} / \mathrm{m}^{2}$ ) at baseline and follow-up; Stayed Obese- Individuals with obese BMI ( >30 kg/m²) at baseline and follow-up; and Stayed Underweight/Other- includes individuals with underweight BMI $\left(<18.5 \mathrm{~kg} / \mathrm{m}^{2}\right)$ at base line and follow-up as well as those with weight changes not defined by the categories above. ${ }^{* * *} \mathrm{p}<0.001 ; * * 0.001<\mathrm{p}<0.01 ; * 0.01<\mathrm{p}<0.05$ 